\title{
Rescue ventilation using expiratory ventilation assistance : innovating while clutching at straws
}

Citation for published version (APA):

Hamaekers, A. E. W. (2015). Rescue ventilation using expiratory ventilation assistance : innovating while clutching at straws. [Doctoral Thesis, Maastricht University]. Maastricht University. https://doi.org/10.26481/dis.20151211ah

Document status and date:

Published: 01/01/2015

DOI:

10.26481/dis.20151211ah

Document Version:

Publisher's PDF, also known as Version of record

\section{Please check the document version of this publication:}

- A submitted manuscript is the version of the article upon submission and before peer-review. There can be important differences between the submitted version and the official published version of record.

People interested in the research are advised to contact the author for the final version of the publication, or visit the DOI to the publisher's website.

- The final author version and the galley proof are versions of the publication after peer review.

- The final published version features the final layout of the paper including the volume, issue and page numbers.

Link to publication

\footnotetext{
General rights rights.

- You may freely distribute the URL identifying the publication in the public portal. please follow below link for the End User Agreement:

www.umlib.nl/taverne-license

Take down policy

If you believe that this document breaches copyright please contact us at:

repository@maastrichtuniversity.nl

providing details and we will investigate your claim.
}

Copyright and moral rights for the publications made accessible in the public portal are retained by the authors and/or other copyright owners and it is a condition of accessing publications that users recognise and abide by the legal requirements associated with these

- Users may download and print one copy of any publication from the public portal for the purpose of private study or research.

- You may not further distribute the material or use it for any profit-making activity or commercial gain

If the publication is distributed under the terms of Article $25 \mathrm{fa}$ of the Dutch Copyright Act, indicated by the "Taverne" license above, 


\title{
Rescue ventilation using Expiratory Ventilation Assistance Innovating while clutching at straws
}

\author{
PROEFSCHRIFT
}

ter verkrijging van de graad van doctor aan de Universiteit Maastricht, op gezag van de rector Magnificus prof. dr. L.G. Soete volgens het besluit van het College van Decanen, in het openbaar te verdedigen op vrijdag 11 december 2015 om 14.00.

door Ankie Elisabeth Wilhelmus Hamaekers 


\section{Promotores:}

Prof. dr. W.F. Buhre

Prof. dr. M. van Kleef

\section{Beoordelingscommissie:}

Prof. dr B. Kremer (voorzitter)

Prof. MD. C.A. Hagberg, The University of Texas Medical School, Houston, TX, USA

Prof. dr. F.W. Prinzen

Prof. dr. P.M. Roekaerts

Prof. Dr. Med. A. Timmerman, DRK Kliniken Berlin Teaching Hospital Charite University of Berlin, Germany 


\section{Rescue ventilation using Expiratory Ventilation Assistance}

Innovating while clutching at straws

Ankie E.W. Hamaekers 
The studies described in this thesis are carried out at the department of Anaesthesia and Pain Therapy at the Maastricht University Medical Centre ${ }^{+}$. The studies were financially supported by European funding, OP-Zuid [31R104].

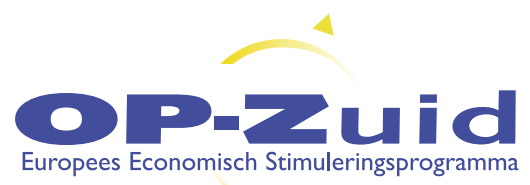

Copyright $\odot 2015$ AEW Hamaekers, Maastricht, The Netherlands ISBN: 978-90-9029-341-7

\section{Cover and lay-out:}

Karen Knols, Studio Lampro, www.lampro.nl

All rights reserved: No part of this publication may be reproduced or transmitted in any form without permission of the author, or when appropriate, the publishers of the papers. 
Aan Anne \& Thijs Aan mijn ouders 

Acknowledgements

Traveller, your footprints

Are the road and nothing more;

Traveller, there is no road,

The road is made by walking.

By walking the road is made

And when you look back

You'll see the path

Never to be trodden again.

Traveller there is no road -

Only wakes upon the sea.

Fragment from "Proverbios y cantares" in Campos de Castilla. 1912, Antonio Machado

This $\mathrm{PhD}$ project was a fascinating journey with several unexpected turns, a lot of fun, many challenges, numerous opportunities to learn something new, some difficult decisions to make and a lot of delay, but moreover it was a journey with valuable encounters with wise, creative, passionate, inspiring and beautiful people. I would like to thank everybody that I met on this journey and who walked along for some time, whether it was just for a brief moment or from beginning to end. You all supported, advised, motivated, educated, guided or inspired me while I was creating my own path.

Thank you!! 
viii 


\section{Contents}

\section{Prologue}

An anaesthetist's nightmare

\section{Chapter 1}

A General introduction

Adapted from:

Equipment and strategies for emergency tracheal access in the adult patient

Anaesthesia 2011, 66 Suppl 2:65-80

B Aims of this thesis

\section{Chapter 2}

Potential hazard unrevealed

The importance of flow and pressure release in emergency jet ventilation devices Paediatric Anaesthesia 2009, 19 (5): 452-7

\section{Chapter 3}

Important safety feature of a high-pressure ventilation device

A bench study of two self-assembled jet devices and the Oxygen Flow Modulator in a simulated upper airway obstruction

Anaesthesia 2009, 64(12): 1353-8

\section{Chapter 4}

The introduction of the concept of Expiratory Ventilation Assistance

Achieving an adequate minute volume through a $2 \mathrm{~mm}$ transtracheal catheter in a simulated upper airway obstruction using a modified industrial ejector

Br J Anaesth 2010, 104(3): 382-6 


\section{Chapter 5}

Optimizing Expiratory Ventilation Assistance

Ventilation through a small-bore catheter: optimizing expiratory ventilation assistance

Br J Anaesth 2011, 106:403-409

\section{Chapter 6}

The effect of expiratory ventilation assistance on re-oxygenation and ventilation

Emergency ventilation through a small-bore transtracheal cannula in severe

hypoxic pigs using expiratory ventilation assistance (EVA)

Anesth Analg 2015, 120 (4): 890-4

\section{Chapter 7}

Implementation of EVA in a commercially available product

Ventrain: an emergency ventilation ejector

Br J Anaesth 2012, 108(6): 1017-21

\section{Chapter 8}

General discussion

\section{Epilogue}

The use of expiratory ventilation assistance in clinical practice

Ventrain ${ }^{\circledast}$ for ventilation of the lungs

Br J Anaesth 2012, 109(5): 833-4

\section{Appendices}

Summary . . . . . . . . . . . . . . . . . . . . . . . . . 123

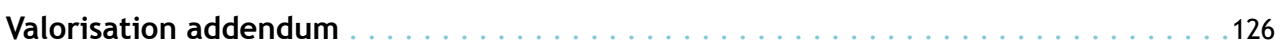

Curriculum vitae . . . . . . . . . . . . . . . . . . . . . . . 128

Publications . . . . . . . . . . . . . . . . . . . . . . . . 129

Abstracts $\&$ book chapters . . . . . . . . . . . . . . . . . . . . . 130 


\section{Prologue}

An anaesthetist's nightmare 



\section{Case Report}

\section{3:00 am Monday August 9th 2010}

A 55 year-old male was admitted to the emergency room with severe respiratory distress and a loud inspiratory stridor. He had been diagnosed with an untreatable oropharynx carcinoma a couple of days earlier. Although the airway was already clearly compromised at that time, the patient refused a tracheostomy and decided he only wanted palliative care at home. He was discharged from the hospital on Friday afternoon. Sunday evening he became progressively dyspnoeic and returned to the hospital. After obtaining informed consent from the patient the ENT surgeon decided to perform an emergency tracheostomy.

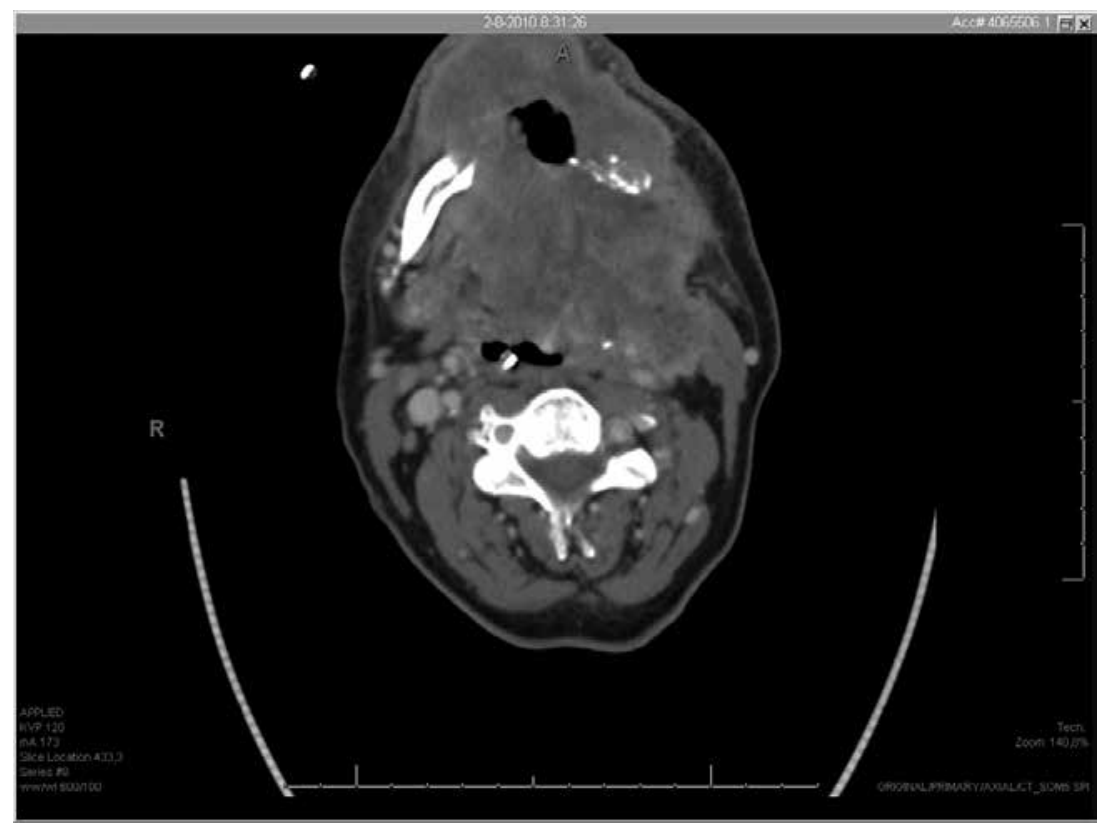

Figure 1 A prior CT scan showed a large tumour extending on the left side from the oropharynx, invading the mandible all the way down to the thyroid cartilage. 
The patient arrived at the $O R$ in an upright position with his head flexed to his chest. He could not extend his neck or obtain a supine position as this would make the airway to obstruct. He had a severe inspiratory stridor, was tachypnoeic and used his accessory breathing muscles. While breathing through a non-rebreathing-mask the pulse-oximetry reading was $92 \%$. The patient was anxious and his blood pressure and heart rate were elevated. The external anatomy of the airway was distorted due to the tumour that ulcerated through the skin. The mouth opening was limited to $1.5 \mathrm{~cm}$.

As a team, consisting of the ENT surgeon, ENT and anaesthetic resident, anaesthetic nurse, scrub nurses and anaesthesist, we devised a clear airway strategy. According to the ENT surgeon an awake tracheostomy was not possible as the neck couldn't be flexed and the anatomy was distorted. Our first choice was an awake flexible intubation. Plan $B$ was a needle cricothyroidotomy with jet ventilation and subsequently a surgical tracheostomy.

After the application of local anaesthetic the airway obstructed and the patient desaturated quickly. Even by applying CPAP it wasn't possible to open up the airway. As the patient was chocking we induced anaesthesia, paralysed him and placed the patient in supine position. As expected mask ventilation was impossible. His mouth opening was too small to place a supraglottic airway or attempt direct laryngoscopy so as planned we immediately inserted a needle cricothyroidotomy cannula (Ravussin catheter). A manual jet ventilator was connected and oxygen was insufflated. Saturation improved quickly. However, the egress of air through the upper airway was severely compromised even with jaw trust and chin lift applied. The chest failed to fall after insufflation of oxygen and blood pressure decreased. The jet ventilator was repeatedly disconnected from the Ravussin catheter to allow egress of air through the catheter and to avoid barotrauma and limit hemodynamic instability. Within a couple of minutes the ENT surgeon had performed successfully an emergency tracheostomy. The patient woke up without neurologic sequelae and left the hospital after a few days.

The inability to maintain oxygenation by non-invasive means is one of the most pressing emergencies in anaesthesia and emergency care. To prevent hypoxic brain damage and death in a 'cannot intubate, cannot oxygenate' situation, emergency percutaneous airway access must be performed immediately. Even though this emergency is rare, 


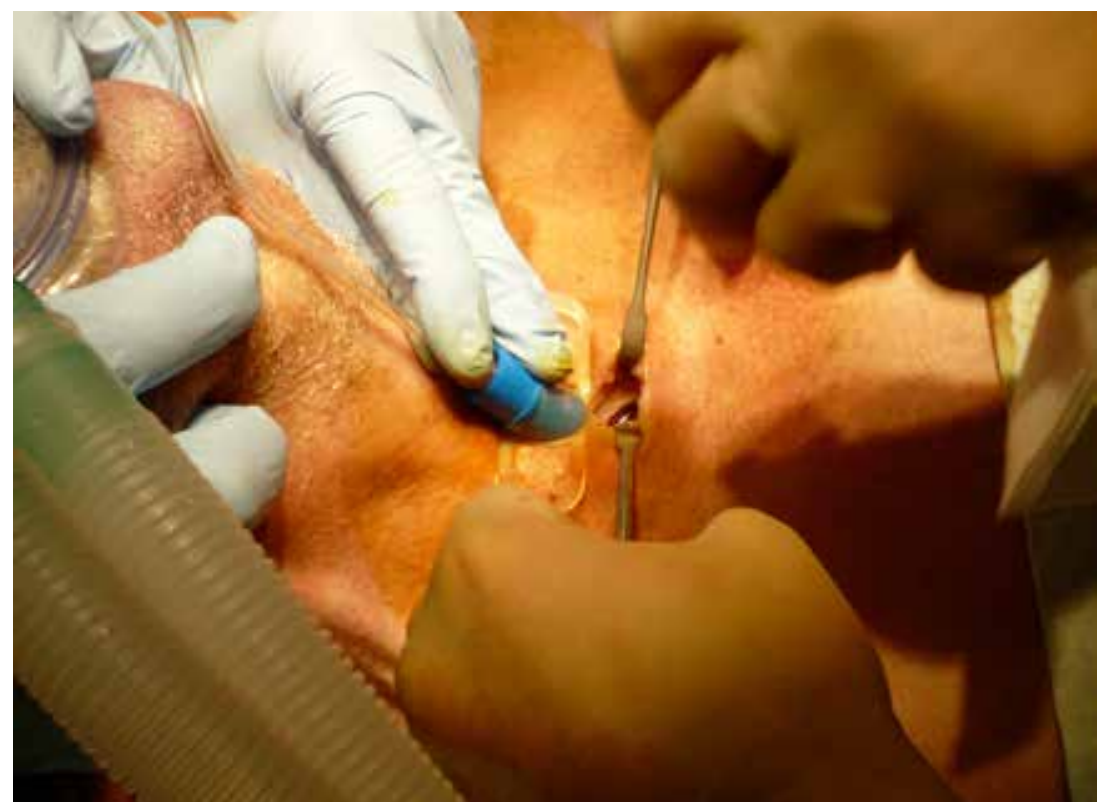

Figure 2 After successful re-oxygenation through the needle cricothyroidotomy an emergency tracheostomy was performed.

every anaesthetist should be capable of performing an emergency percutaneous airway as the situation may arise unexpectedly. Various techniques have been described for emergency oxygenation and several commercial emergency cricothyroidotomy sets are available. However, all available techniques have their limitations.

In the above case a narrow-bore catheter was successfully inserted in the airway and oxygen could be insufflated into the lungs. Unfortunately a new problem arose as it was impossible to provide an adequate outflow of the gas, which resulted in air trapping and haemodynamic instability. Although a narrow-bore cricothyroidotomy catheter is easy to insert, reoxygenation and ventilation through a narrow-bore catheter poses new challenges. The ideal rescue technique for a 'cannot intubate, cannot oxygenate' situation seems not yet to exist. 



\section{Chapter}

A General introduction

Part of this introduction has been published in:

Equipment and strategies for emergency tracheal access in the adult patient

Ankie Hamaekers \& John Henderson

Anaesthesia 2011, 66 Suppl 2:65-80 


\section{Summary}

The inability to maintain oxygenation by non-invasive means is one of the most pressing emergencies in anaesthesia and emergency care. To prevent hypoxic brain damage and death in a 'cannot intubate, cannot oxygenate' situation, emergency percutaneous airway access must be performed immediately. Even though this emergency is rare, every anaesthetist should be capable of performing an emergency percutaneous airway as the situation may arise unexpectedly. Clear knowledge of the anatomy and the insertion technique, and repeated skill training are essential to ensure completion of this procedure rapidly and successfully. Various techniques have been described for emergency oxygenation and several commercial emergency cricothyroidotomy sets are available. There is, however, no consensus on the best technique or device. As each has its limitations, it is recommended that all anaesthetists are skilled in more than one technique of emergency percutaneous airway. Avoiding delay in initiating rescue techniques is at least as important as device choice in determining outcome. 
The 'cannot intubate, cannot oxygenate' (CICO) scenario describes the clinical situation where attempted tracheal intubation has failed and oxygenation cannot be maintained by non-invasive means. If not corrected rapidly $\mathrm{CICO}$ will inevitably lead to brain hypoxia and death. As emphasised in the Difficult Airway Society guidelines a percutaneous airway must be established without delay [1].

\section{Incidence and causation of $\mathrm{CICO}$}

The incidence of $\mathrm{CICO}$ in general anaesthetic practice is low. Kheterpal et al. reported only 4 cases of impossible mask ventilation and intubation in 53,041 anaesthetics in a tertiary university hospital, only in one of which an EPA was performed [2]. The 4th National Audit Project of the Royal College of Anaesthetists and Difficult Airway Society (NAP4) reported a calculated incidence of 1 in 50,000 general anaesthetics [3]. The incidence of EPA is strongly influenced by clinical setting and case-mix. In the emergency department incidences of $0.3 \%$ [4] and $0.8 \%$ [5] and in the pre-hospital setting as high as $11 \%$ [6] have been reported.

Risk factors for $\mathrm{CICO}$ include known risk factors for difficult mask ventilation [7] and difficult direct laryngoscopy [8]. Patients difficult to mask ventilate are more likely to be difficult or impossible to intubate compared to patients with easy mask ventilation [9]. Furthermore, multiple attempts at tracheal intubation can cause airway oedema and may change a 'cannot intubate, can oxygenate' situation into a CICO situation [10-12]. Cricoid pressure, especially when performed poorly, can hinder laryngoscopy [13] and may itself cause airway obstruction and hence CICO [14-16]. Laryngospasm in the non-paralysed patient can be an important factor in failure of mask ventilation. Use of narcotic an- aesthesia without paralysis may cause ventilation difficulty with the likely mechanism being vocal cord closure $[17,18]$.

Diagnosed and undiagnosed laryngeal disease is a more frequent contributor to $\mathrm{CICO}$ than generally realised [19, 20]. Of the 58 cases of EPA in 133 anaesthetic patients reported to the NAP4 43 (74\%) were head/neck cases [12], suggesting a significantly increased risk in this patient population.

\section{Management of $\mathrm{CICO}$}

\section{Anticipation of risk and preparing an optimum strategy to prevent $\mathrm{CICO}$}

Reducing the risk of $\mathrm{CICO}$ starts with assessment of the airway and use of awake flexible intubation in patients in whom difficulty with mask ventilation, direct laryngoscopy or cricothyroidotomy is anticipated. A clear airway strategy including back-up plans in case of failure, and availability of an anaesthetist skilled in alternative techniques of laryngoscopy (e.g. flexible laryngoscopy with or without a conduit and straight blade or rigid indirect laryngoscopy) may all reduce the risk of $\mathrm{CICO}$ [21]. Effective pre-oxygenation increases the time available to secure the airway before profound hypoxia occurs [22, 23]. Strictly limiting the number of intubation attempts makes better use of the available time and decreases the likelihood of airway trauma $[10,11]$.

\section{Initial, non-invasive techniques for managing $\mathrm{CICO}$}

Standard airway clearing manoeuvres (head extension, jaw thrust, two-person mask ventilation, an oropharyngeal air- 
way and a gently inserted nasopharyngeal airway) are the first steps in management of the obstructed airway [1]. Early insertion of a supraglottic airway device (SAD), as long as mouth opening is sufficient, is now standard practice. The SAD chosen should be familiar and easy to insert, but should also be reliable at achieving ventilation and ideally offer some protection against aspiration. While SADs have been effective in many cases of difficult or impossible mask ventilation [24] success is not guaranteed [24-27]. Cricoid pressure, if applied, should be reduced or withdrawn completely [28]. The Larson manoeuvre [29] (strong medial digital pressure between the angle of the mandible and the mastoid process) should be tried and is easily added to conventional jaw thrust. In the NAP4 report the probable value of neuromuscular blockade when $\mathrm{CICO}$ arises in a patient who is not paralysed has been emphasised [12]. If all these fail and the airway is still obstructed, the option of waking the patient should be strongly considered at this point.

\section{Decision to proceed to emergency percutaneous airway (EPA)}

Immediate EPA is indicated when maximal efforts at non-invasive techniques fail to relieve severe hypoxaemia [1]. It is not possible to define the oxygen saturation at which cricothyroidotomy should be performed. However, it should certainly have been started (rather than just considered) by the time bradycardia supervenes. In a life-threatening airway emergency there are no contra-indications to EPA. However, the presence of a large laryngeal tumour, neck pathology, obesity or coagulopathy will make the procedure more hazardous.

\section{Cricothyroid membrane anatomy and advantages over other sites}

Percutaneous (or transcutaneous) access to the trachea can be achieved by tracheostomy through the upper tracheal cartilages or by cricothyroidotomy. Tracheostomy involves incision through the skin and subcutaneous tissues, separation of the strap muscles, division of the isthmus of the thyroid gland, control of haemorrhage and incision through two tracheal cartilages. Access to the trachea can be difficult because of its depth in the neck and the vascularity of the thyroid gland. Good lighting, competent assistance and a range of surgical instruments are needed. Although elective tracheostomy has a high success rate and a low risk of complications, emergency tracheostomy is associated with a higher complication rate [30].

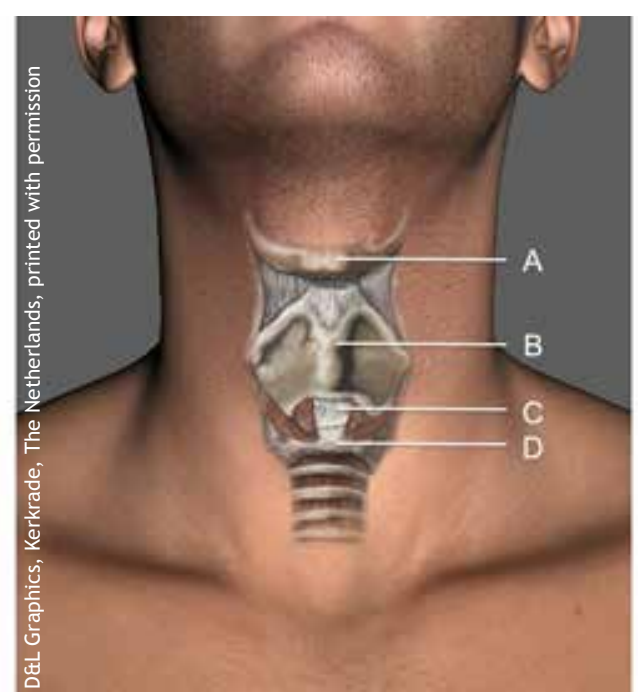

Figure 1 Relevant anatomical structures for cricothyroidotomy: A: hyoid bone, B: thyroid cartilage, C: cricothyroid membrane, and D: cricoid cartilage. 
Cricothyroidotomy achieves percutaneous tracheal access through the cricothyroid membrane: a dense fibro-elastic membrane between the thyroid and cricoid cartilages with an average height of $10 \mathrm{~mm}$ and a width of $11 \mathrm{~mm}$ [31] (Figure 1). Transverse incision in the lower half of the cricothyroid membrane is recommended to avoid damaging the cricothyroid arteries and the vocal cords. The circumferential cricoid cartilage is partially resistant to compression [32] and its posterior lamina lies behind the cricothyroid membrane providing some protection against posterior wall and oesophagus injury during cricothyroidotomy. Failure to identify the cricothyroid membrane occurs frequently [33] and is the principal cause of failed cricothyroidotomy. We recommend its position should be confirmed before induction of anaesthesia in all patients using palpation of the hyoid bone and the thyroid and cricoid cartilages. The hyoid can be located by balloting the bone laterally between the thumb and index finger. The thyroid cartilage's superior notch is then identified in males as the greatest laryngeal prominence. In females the greatest prominence is usually the cricoid cartilage, which is best identified by moving the palpating finger upward from the sternal notch. Identification of the thyroid and cricoid cartilages leads to the cricothyroid membrane over which there is a slight depression. Cricothyroidotomy is the preferred route for EPA on account of the shorter duration required for its completion and its greater safety [34, 35].

\section{Overview of types of cricothyroidotomy}

Cricothyroidotomy can be performed by puncture or surgical incision of the cricothyroid membrane. Puncture may be achieved using a narrow-bore (usually an internal diameter
(ID) of $\leq 2 \mathrm{~mm}$ ) cannula-over-needle, a wide-bore (usually ID $\geq 4 \mathrm{~mm}$ ) cannula-over-trocar or a wire-guided (Seldinger) technique, with dilation after cricothyroid membrane puncture. All techniques will be discussed briefly.

\section{Narrow-bore cricothyroidotomy}

Surveys have shown that for most anaesthetists the firstchoice device for EPA is a narrow-bore cannula [36, 37], which was also used in the case described in the prologue. Insertion of a narrow-bore cannula is suggested to be simple, relatively safe and only minimally traumatic [38].

Although often it is suggested that in an emergency situation any type of available narrow-bore cannula is suitable, it is strongly recommended to use a kink-resistant cannula such as the Ravussin cannula (VBM Medizintechnik GmbH, Sulz, Germany) or the emergency transtracheal airway catheter (Cook Medical, Bloomington, IN, USA) (Figure 2). An intravenous catheter is widely available, but is not designed for percutaneous emergency ventilation. Several case reports have described problems with kinking or catheter dislodgement.

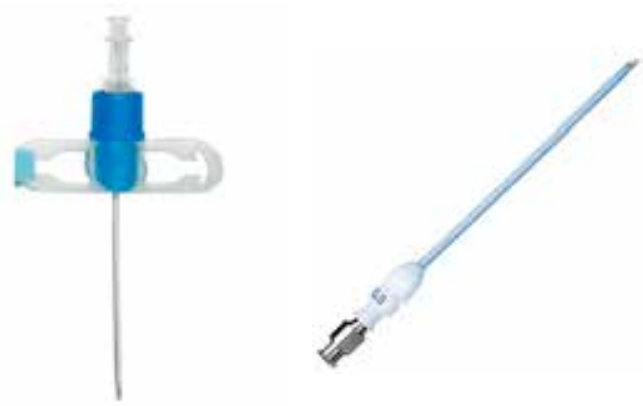

Figure 2 The Ravussin airway catheter (VBM Medizintechnik GmbH, Sulz, Germany) and emergency transtracheal airway catheter (ETAC, Cook Medical, Bloomington, IN, USA) are designed for needle cricothyroidotomy. 
Once inserted a high-pressure ventilator is necessary to achieve normal tidal volumes via the narrow-bore cannula [39-41]. In 1967 Sanders introduced a hand-triggered oxygen injector using hospital oxygen pipeline pressure (4 bar) for ventilation through a narrow-bore cannula placed down the side arm of a rigid bronchoscope [42]. The modern oxygen injector, Manujet (VBM Medizintechnik GmbH, Sulz, Germany; Figure 3), allows adjustment of the driving pressure between 0.5 and 4 bar and is designed for emergency use. In a sheep model of $\mathrm{CICO}$ rescue with a narrow-bore cricothyroidotomy and manual injector was as efficient as with a surgical wide-bore cricothyroidotomy [43]. Various simple, self-assembled devices, consisting of a three-way stopcock or hole in the oxygen tubing, have also been proposed for emergency ventilation through a narrow-bore cannula [4446]. Connected to an appropriate high-pressure oxygen source (e.g. a wall flow meter or oxygen cylinder set at 15 l. $\min ^{-1}$ or higher), such self-assembled devices create an adequate inspiratory flow [47] and are capable of maintaining adequate oxygenation in a $36 \mathrm{~kg}$ pig model [45]. Many self-assembled devices, however, have been advocated without validation of their ability to achieve sufficient ven-

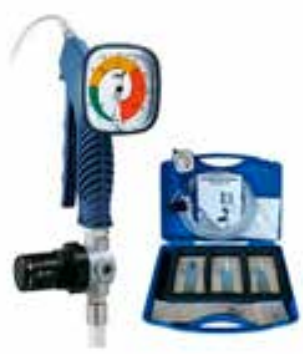

Figure 3 The Manujet (VBM Medizintechnik GmbH, Sulz, Germany; http://www.vbm-medical.de/cms/files/p329_2.0_05.08_gb.pdf) is a hand-triggered oxygen injector. tilation to restore oxygenation in the hypoxaemic patient. Such techniques are dangerous as they may be ineffective [48]. In addition, self-assembled devices are 'off-licence' use of equipment and might carry inherent risks. The Oxygen Flow Modulator (OFM; Cook Medical, Bloomington, IN, USA; Figure 4) is a single-use emergency device for use with a narrow-bore cannula. Connected to a flow meter set at 15 $1 \cdot \mathrm{min}^{-1}$ the OFM was as effective as the Manujet (at $1.5 \mathrm{bar}$ ) in restoring oxygenation in a $30 \mathrm{~kg}$ hypoxic pig model [49].

It is mandatory to maintain a patent upper airway for the egress of gas when ventilating through a narrow-bore cannula. Obstruction of the outflow tract or insufficient expiratory time results in air trapping [50] with subsequent barotrauma and haemodynamic instability. In a CICO situation partial obstruction of the upper airway, resulting from oedema, laryngospasm or distorted anatomy occurs frequently, so chest movements should be observed carefully and subsequent inspirations should not be initiated before complete fall of the chest wall. If the upper airway is completely obstructed and cannot be relieved from above (e.g. airway clearing manoeuvres, SAD) the injector must be detached from the cannula to allow egress of gas via the

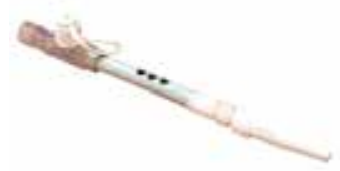

Figure 4 The Oxygen flow Modulator (OFM; Cook Medical, Bloomington, IN, USA;

http://www.cookmedical.com/cc/content/mmedia/C-EMB1004. pdf) is single use emergency ventilation device. 
cannula. Unfortunately, even with manually compression of the chest to augment the exhalation the passive outflow through a narrow-bore cannula is very slow. Eger and Dunlap have suggested that expiration could be facilitated by applying suction in order to increase the achievable minute volume through a narrow-bore cannula and lower the risk of air trapping [51, 52]. However, none of the proposed techniques are available in clinical practice.
The success rate of emergency narrow-bore cannula cricothyroidotomy in clinical practice varies widely (from 37 to $79 \%$ ) [12, 38]. Additionally, numerous case reports have described failures, severe complications and deaths as a consequence of the emergency use of high-pressure ventilation [53-56]. It is not clear whether the reason for these complications was poor insertion technique, use of inappropriate equipment, lack of training and practice or an inherently

\section{NARROW-BORE CANNULA CRICOTHYROIDOTOMY AND HIGH PRESSURE VENTILATION}

1 position the patient (head and neck extended) and identify the landmarks

2 immobilise the cricoid cartilage between the thumb and middle finger of the non-dominant hand

3 puncture the cricothyroid membrane in the midline with a kink-resistant narrow-bore cannula attached to a 5 or $10 \mathrm{ml}$ syringe

4 confirm needle placement in the trachea by aspiration of air; if time permits partial filling the syringe with saline makes the end-point of tracheal entry much easier to identify.

5 hold the needle in one hand and use the other to advance the cannula in a 450 caudad direction over the needle; remove needle only when cannula is fully inserted

6 aspirate air or saline through cannula to confirm correct placement; capnography may also be used to confirm tracheal entry

7 delegate one person to hold the cannula in position

8 connect high-pressure ventilation device and insufflate oxygen for 1 second; start at a driving pressure of 1 bar

9 watch (and palpate) chest rise and fall

10 do not insufflate until chest has fallen: adjust frequency to ensure there is sufficient time for expiration, in order to prevent air trapping

11 if there is inadequate egress of gas through the upper airway (as seen by chest wall not falling) place oral airway or supraglottic airway, perform jaw thrust if necessary. Consider administering neuromuscular blocking agent if not already done, manually compress chest to augment exhalation

12 discuss plan: wake the patient, intubate or convert to cuffed tracheostomy or cricothyroidotomy

Table 1 A step by step checklist for performing a narrow-bore cannula cricothyroidotomy and using high-pressure ventilation 
greater risk involved in use of manual high-pressure ventilation. Experience with high-pressure ventilation and meticulous technique should reduce the risk of complications. The steps included in the technique are shown in Table 1 . In case of an obstructed upper airway rescue ventilation through a narrow-bore cannula is inefficient and dangerous and should not be used.

\section{Wide-bore cannula-over-trocar cricothyroidotomy} Insertion of a wide-bore cannula/tube (ID of $\geq 4 \mathrm{~mm}$ ) offers advantages regarding ventilation. Adequate minute volume can be achieved using a conventional low-pressure breathing system with expiration via the cannula. However, reliable ventilation can only be guaranteed with a cuffed tube as use of an uncuffed tube may lead to gas leakage to the upper airway [57, 58]. The Quicktrach II (VBM; Medizintechnik GmbH,

Sulz, Germany; Figure 5) and Portex $®$ cricothyroidotomy kit (PCK; Smiths Medical Ltd, Hythe, UK; Figure 6) have cuffed cannulae and are designed and marketed for emergency cricothyroidotomy. When wide-bore cannula-over trocar devices are used there is a risk of compression of the airway as considerable force is sometimes required to push the device through the cricothyroid membrane with the consequence that the trocar enters the trachea with a high velocity and lack of control, increasing the risk of damage of perforation of the posterior tracheal wall [59]. An initial scalpel incision to reduce the force required [60] and insertion of the Quicktrach in a caudal direction minimises risks. The Quicktrach includes a red detachable stopper designed to limit initial insertion depth and thereby prevent posterior airway trauma. This mechanism does limit the utility in obese patients (patients with a thick neck) as the cannula might fail to reach the trachea: such failure was reported in NAP4 [3]. The PCK incorporates a Veres needle and signalling system

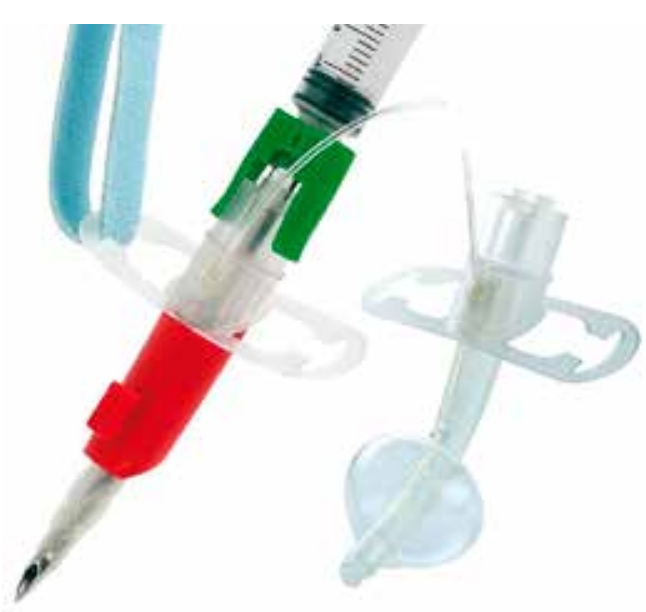

Figure 5 Quicktrach II (VBM; Medizintechnik GmbH, Sulz, Germany) http://www.hospitecnica.com.mx/productos/VBM/cricotomia.pdf

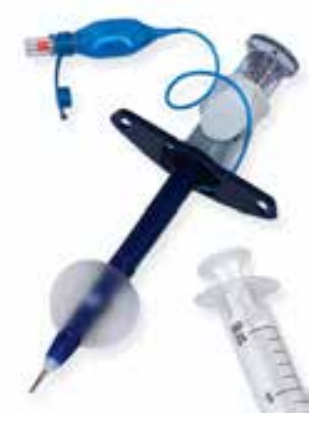

Figure 6 Portex cricothyroidotomy kit (PCK; Smiths Medical Ltd, Hythe, UK) http://www.smiths-medical.com/catalog/cricothyroidotomy-kits/

that indicates tracheal entry and any subsequent contact with the posterior tracheal wall. Although designed to limit posterior wall damage a $70 \%$ incidence of such damage was reported in a pig larynx model [61]. 


\section{Seldinger cricothyroidotomy}

A guide wire is placed in the trachea through a narrow-bore needle and the tract is then dilated for the passage of a larger cannula (Figure 4), a sequence familiar to anaesthetists. The separation of the puncture and dilatation steps minimizes the risk of trauma [62]. Although several anaesthetists have attempted to use the Portex® Mini-Trach II device (Smiths Medical; http://www.smiths-medical.com/ catalog/cricothyrotomy-kits/), which is widely available, during $\mathrm{CICO}$, this is not recommended by the manufacturer. It was designed for sputum aspiration, is uncuffed and several failures to restore oxygenation have been reported [63, 64]. The Melker emergency cricothyroidotomy set (Cook Medical; http://www.cookmedical.com/cc/content/
mmedia/C-EMB1004.pdf) is Seldinger-based and sizes 3.0 to $6.0 \mathrm{~mm} \mathrm{ID}$ are available. Only the $5.0 \mathrm{~mm}$ ID cannula has a cuff. In general, anaesthetists prefer the wire-guided cricothyroidotomy technique above the surgical and wide-bore cannula-over-trocar techniques [61]. In a manikin study the Seldinger technique was considered more intuitive and $75 \%$ of anaesthetists felt confident with the Melker wire-guided technique [65]. While good results have been achieved with the Seldinger technique in human cadavers and manikin studies by those well trained, inexperienced operators have low success rates and a long performance time [66]. The most frequent technical problems are kinking of the guide wire [65] and attempts to place the cannula without using the dilator $[67,68]$. Guide wire kinking prevents passage of
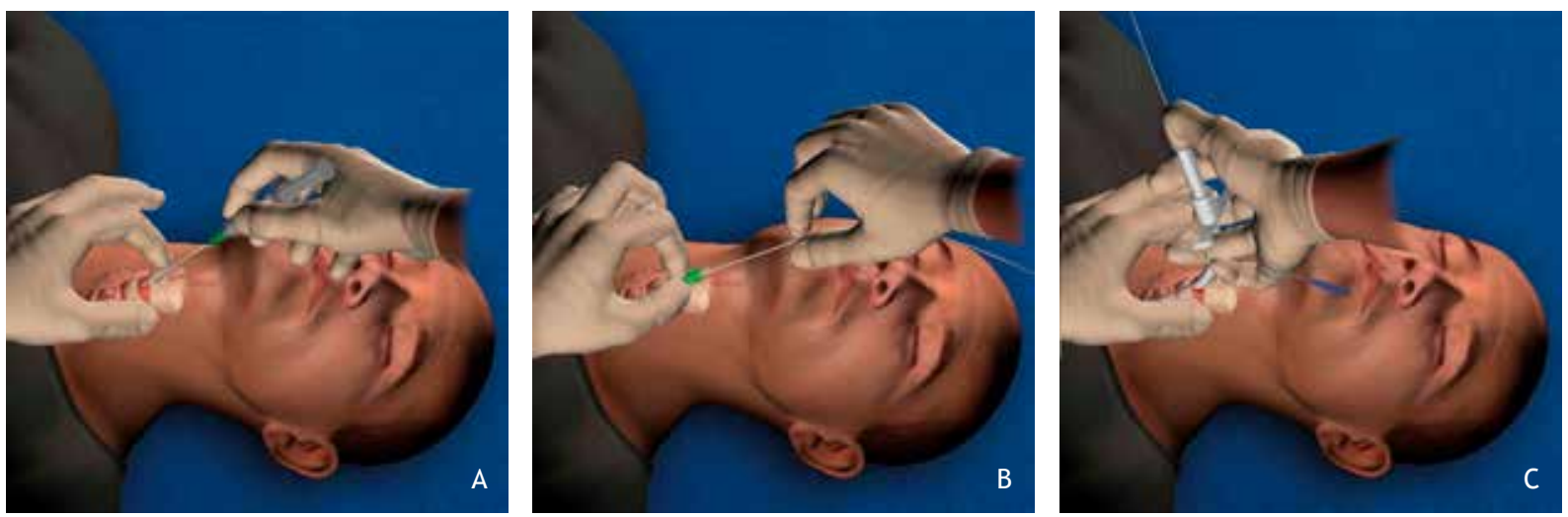

Figure 7 Illustrated procedure for Seldinger cricothyroidotomy:

position the patient (head and neck extended) and identify the landmarks

2 immobilise the cricoid cartilage between the thumb and middle finger of the non-dominant hand and puncture the cricothyroid membrane in the midline with the puncture needle attached to a 5 or $10 \mathrm{ml}$ syringe while aspirating (figure 7A)

3 confirm needle placement in the trachea by aspiration of air, disconnect the syringe and insert guide wire through the needle in a caudad direction; to confirm the wire is not kinked check it can be withdrawn and advanced $1-2 \mathrm{~cm}$ without resistance (figure 7B)

4 incise the skin and membrane close to the guide wire and remove the needle

5 insert the dilator and cannula over the guide wire into the trachea in the same direction as the needle was inserted; a single advancement is ideal and lessens the risk of kinking the wire (figure $7 \mathrm{C}$ )

6 remove the guide wire and dilator, leaving the cannula in place

7 inflate the cuff, ventilate the patient, check correct placement (capnography and auscultation) and secure the cannula 
a dilator and increases risk of misplacement by creation of a false passage. If identified it is safer to convert immediately to a surgical cricothyroidotomy.

\section{Surgical cricothyroidotomy}

Although many anaesthetists are reluctant to use this technique the skills are basic and all should be capable of this procedure. In the rapid four step cricothyroidotomy technique the steps are palpation, horizontal incision through both skin and cricothyroid membrane, insertion of a tracheal hook while the blade is within the larynx, retraction of the cricoid cartilage anteriorly and caudally with the hook, and passage of the tube (Figure 4) [69]. A no. 20 blade is used to minimise extension required for passage of a $6 \mathrm{~mm}$ ID tube and the risk of damage to the posterior wall of the larynx. Holding a blade between thumb and index finger to limit insertion depth also reduces this risk. Many techniques use an initial vertical midline skin incision: although the standard rapid four step technique does not, this is an essential first step in patients (e.g. obesity) in whom cricothyroid membrane identification is difficult. In many techniques the incision is kept maximally patent during tube insertion by a dilator, speculum or tracheal hook. If there is difficulty advancing the tube through the incision, the incision should be extended with a blunt rather than sharp instrument (surgical forceps, an appropriate dilator or a digit) and initial passage of an introducer (e.g. bougie or exchange catheter) should be used to facilitate tube placement [70]. Whatever procedure is used, gentle technique should minimise the risk of complications. Where a tracheostomy tube is immediately available, a tracheal tube should be inserted until its cuff is just beyond the incision to minimise the risk of endobronchi-
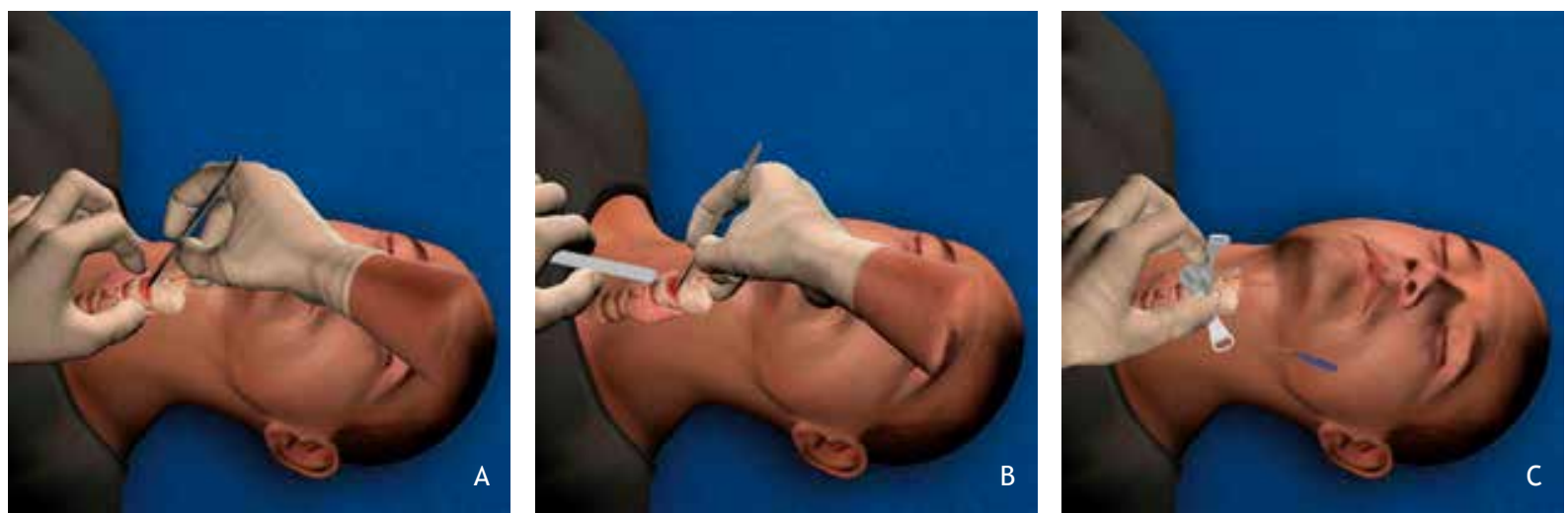

Figure 8 Illustrated procedure for surgical cricothyroidotomy (rapid four step cricothyroidotomy):

1 position the patient (head and neck extended) and identify the landmarks

2 immobilise the trachea with non-dominant hand and make a horizontal $25 \mathrm{~mm}$ stab incision through the skin and cricothyroid membrane with a no. 20 scalpel blade; keep the scalpel blade in place (figure 8A)

3 place the tracheal hook in the incision before removing the blade and apply caudal and ventral traction on the cricoid cartilage (figure 8B)

4 remove scalpel blade and insert 6.0 ID tracheal tube gently (figure $8 \mathrm{C}$ )

5 inflate the cuff, ventilate the patient, check correct placement (capnography and auscultation) and secure the tube 
al intubation. Although some bleeding is normal, life-threatening haemorrhage is exceptionally rare and can normally be controlled by pressure after passage of the tube.

\section{Complications of EPA}

Reported complication rates of cricothyroidotomy vary from 0 to $52 \%$, depending on the technique, the experience level of the operator, the patient population and the clinical situation [30, 34, 71-73]. The main complication is initial misplacement, (e.g. paratracheal, superior or inferior to the cricothyroid membrane or through the posterior tracheal wall) and is the principal cause of failure. This underlines the importance of taking care to identify the cricothyroid membrane. Inferior placement through the crico-tracheal space increases the risk of airway injury [32] and bleeding, but can still result in effective re-oxygenation.

Some complications are technique-related. Narrow-bore cannula techniques are associated with ventilation-related complications such as barotrauma [38, 39], (e.g. subcutaneous emphysema, pneumothorax, pneumomediastinum and circulatory arrest due to impaired venous return), and cannula obstruction due to kinking. Kinking of the guide wire is a common problem peculiar to the Seldinger technique and increases the risk of tube misplacement [65, 74]. The surgical method is associated with complications of tube insertion (e.g. bleeding, laryngeal fracture). Damage to the larynx is normally a consequence of excessive pressure during device insertion and is reduced by use of small tubes and gentle technique [59]. Long-term complications are subglottic stenosis, scarring and voice changes [34].

\section{Which cricothyroidotomy technique should we use?}

The ideal EPA technique is readily available, can be completed rapidly, has few steps and is easy to master and retain, has a high success and low complication rate, allows adequate ventilation independent of upper airway resistance and provides protection against aspiration [75]. While recent technical developments likely make EPA simpler, faster and more precise, delayed decision-making in $\mathrm{CICO}$ is often a reason for bad outcome. Retrospective studies of pre-hospital airway management show that most patients were already in cardiac arrest prior to EPA [76, 77]. In two thirds of the claims included in a closed claims analysis where an airway emergency occurred, EPA was performed too late to prevent poor outcome [11]. A reluctance to perform EPA (ie, human factors reasons) is likely the commonest cause of delay $[78,79]$. The ideal EPA technique, therefore, should also be familiar to the anaesthetist.

Recently, NAP4 reported a success rate of only $37 \%$ for narrow-bore cannula-over-needle cricothyroidotomy, 57\% for wide-bore cannula techniques and $100 \%$ for surgical cricothyroidotomy [12]. In a recent meta-analysis the pooled success rates of pre-hospital puncture cricothyroidotomy (27 patients included) and surgical cricothyroidotomy (485 patients included) were $66 \%$ and $91 \%$, respectively [80] and retrospective cohorts from emergency departments confirmed the high success rate of surgical cricothyroidotomy $[6,81]$. While it is tempting to conclude from these data that surgical cricothyroidotomy should be our preferred technique, we need to realise that although these studies provide valuable data they cannot be used to directly compare the effectiveness and safety of different EPA techniques. Randomised control trials (RCTs) are normally required to 
find the best management. For obvious reasons, which have been recently discussed by Cook and Bogod [82], no RCT exists or is likely to be completed in the CICO setting. Although several RCTs have been performed on manikins, isolated pig larynxes, animals or human cadavers, these studies vary in anatomic validity, outcome measures used and in the qualifications, prior experience and training of those performing EPA (Tables 2-4). Consequently, conflicting results have been published. For example, in a pig trachea model paramedics were faster and more successful with the surgical technique than the Seldinger technique [83]. Other studies in larynx models or manikins also reported greater speed with the surgical technique $[61,67,84]$. However, in three out of four human cadaver studies the performance time of the Seldinger technique was as fast $[74,85]$ or faster [86] as the surgical technique. Reported success rates of the different techniques vary widely and range for surgical cricothyroidotomy from $55 \%$ to $100 \%$, for wide-bore cannula-over-trocar from 30 to $100 \%$ and for Seldinger technique from $60 \%$ to $100 \%$ [32, 60-62, 65-67, 74, 83-94]. The differences in success rates may reflect varying definition of success (e.g. only one attempt allowed, or a certain time limit) and operator experience, but the study model likely has also an important influence on the outcome [95]. Due to lack of fidelity the results obtained from plastic models are likely biased towards wide-bore cannula-over-trocar and surgical techniques [96]. Overall the strength of current evidence does not justify recommending one technique over others.

It is however clear from NAP4 that we need to improve our clinical practice. The success rate of cricothyroidotomies performed by anaesthetists was only $39 \%$. So, in $61 \%$ of the cases our final back-up plan fails. In the NAP4 report there are several recommendation on how to improve the logistics, having all equipment available, training and decision-making. There might also be room for technical improvement as we have the dilemma that anaesthetists generally feel more comfortable inserting a narrow-bore cannula (needle cricothyroidotomy) compared to a largebore cannula [99], but a safe and efficient ventilation technique for rescue ventilation through a narrow-bore cannula is still lacking [100]. 


\section{References}

1. Henderson JJ, Popat MT, Latto IP, Pearce AC. Difficult Airway Society guidelines for management of the unanticipated difficult intubation. Anaesthesia 2004; 59: 675-94.

2. Kheterpal S, Martin L, Shanks AM, Tremper KK. Prediction and outcomes of impossible mask ventilation: a review of 50,000 anesthetics. Anesthesiology 2009; 110: 891-7.

3. Cook T, Woodall N, Frerk C. Major complications of airway management in the UK: results of the 4th National Audit Project of the Royal College of Anaesthetists and the Difficult Airway Society. Part 1: Anaesthesia. British Journal of Anaesthesia 2011; 106:617-31.

4. Stephens CT, Kahntroff S, Dutton RP. The success of emergency endotracheal intubation in trauma patients: a 10year experience at a major adult trauma referral center. Anesthesia and Analgesia 2009; 109: 866-72.

5. Walls RM, Brown CA, Bair AE, Pallin DJ. Emergency airway management: a multi-center report of 8937 emergency department intubations. ePub ahead of print. The Journal of Emergency Medicine 2010 nov 8; doi:10.1016/j. jemermed.2010.02.024

6. Bair AE, Panacek EA, Wisner DH, Bales R, Sakles JC. Cricothyrotomy: a 5-year experience at one institution. The Journal of Emergency Medicine 2003; 24: 151-56.

7. Kheterpal S, Han R, Tremper KK, et al. Incidence and predictors of difficult and impossible mask ventilation. Anesthesiology 2006; 105: 885-91.

8. el-Ganzouri AR, McCarthy RJ, Tuman KJ, Tanck EN, Ivankovich AD. Preoperative airway assessment: predictive value of a multivariate risk index. Anesthesia and Analgesia 1996; 82: 1197-204.

9. Langeron $\mathrm{O}$, Masso $\mathrm{E}$, Huraux $\mathrm{C}$, et al. Prediction of difficult mask ventilation. Anesthesiology 2000; 92: 1229-36.

10. Benumof JL. Management of the difficult adult airway; with special emphasis on awake tracheal intubation. Anesthesiology 1991; 75:1087-110.
11. Peterson GN, Domino KB, Caplan RA, Posner KL, Lee LA, Cheney FW. Management of the difficult airway: a closed claims analysis. Anesthesiology 2005; 103: 33-9.

12. Frerk C, Cook T. Management of the 'can't intubate can't ventilate' situation and the emergency surgical airway. In: Fourth National Audit Project of the Royal College of Anaesthetists and the Difficult Airway Society. Major complications of airway management in the United Kingdom. Report and findings. Editors Cook TM, Woodall N, Frerk C.March 2011. ISBN 978-1-9000936-03-3 Royal College of Anaesthetists. London (http://www.rcoa.ac.uk/index.asp?PagelD $=1089$ )

13. Levitan RM, Kinkle WC, Levin WJ, Everett WW. Laryngeal view during laryngoscopy: a randomized trial comparing cricoid pressure, backward-upward-rightward pressure, and bimanual laryngoscopy. Annals of emergency medicine 2006; 47: 548-55.

14. Shorten GD, Alfille PH, Gliklich RE. Airway obstruction following application of cricoid pressure. Journal of Clinical Anesthesia 1991; 3: 403-5.

15. Allman KG. The effect of cricoid pressure application on airway patency. Journal of Clinical Anesthesia 1995; 7: 197-9.

16. Hartsilver EL, Vanner RG. Airway obstruction with cricoid pressure. Anaesthesia 2000; 55: 208-11.

17. Arandia HY, Patil VU. Glottic closure following large doses of fentanyl. Anesthesiology 1987; 66: 574-5.

18. Abrams JT, Horrow JC, Bennett JA, Van Riper DF, Storella RJ. Upper airway closure: a primary source of difficult ventilation with sufentanil induction of anesthesia. Anesthesia and Analgesia 1996; 83: 629-32.

19. Jones DH, Cohle SD. Unanticipated difficult airway secondary to lingual tonsillar hyperplasia. Anesthesia and Analgesia 1993; 77: 1285-8. 
20. Ovassapian A, Glassenberg R, Randel GI, Klock A, Mesnick PS, Klafta JM. The unexpected difficult airway and lingual tonsil hyperplasia: a case series and a review of the literature. Anesthesiology 2002; 97: 124-32.

21. Henderson J. Airway management in the adult. In: Miller, RD ed. Miller's Anesthesia, 7th edn. Philadelphia, PA: Churchill Livingstone/Elsevier, 2009: 1573 - 610.

22. Farmery AD. Simularing hypoxia and managing the airway. [This issue of Suppl]

23. Pandit JJ, Duncan T, Robbins PA Total oxygen uptake with two maximal breathing techniques and the tidal volume breathing technique: a physiologic study of preoxygenation. Anaesthesiology 2003; 99: 841-6.

24. Parmet JL, Colonna-Romano P, Horrow JC, Miller F, Gonzales $\mathrm{J}$, Rosenberg $\mathrm{H}$. The laryngeal mask airway reliably provides rescue ventilation in cases of unanticipated difficult tracheal intubation along with difficult mask ventilation. Anesthesia and Analgesia 1998; 87: 661-5.

25. Fundingsland BW, Benumof JL. Difficulty using a laryngeal mask airway in a patient with lingual tonsil hyperplasia. Anesthesiology 1996; 84: 1265-6.

26. Bromiley M. The case of Elaine Bromiley. http://wwwchfgorg/wp-content/uploads/ElaineBromileyAnonymousReportpdf $(21 / 4 / 2011)$

27. Metzner J, Posner KL, Lam MS, Domino KB. Closed claims' analysis. Best Practice \& Research Clinical Anaesthesiology 2011; 25: 263-76.

28. Vanner RG, Asai T. Safe use of cricoid pressure. Anaesthesia 1999; 54: 1-3.

29. Larson CP, Jr. Laryngospasm: the best treatment. Anesthesiology 1998; 89: 1293-4.

30. McClelland RM. Complications of tracheostomy. British Medical Journal 1965; 2: 567-9.

31. Dover K, Howdieshell TR, Colborn GL. The dimensions and vascular anatomy of the cricothyroid membrane: relevance to emergent surgical airway access. Clinical Anatomy 1996; 9: 291-5.
32. Salah N, El Saigh I, Hayes N, McCaul C. Airway injury during emergency transcutaneous airway access: a comparison at crico-thyroid and tracheal sites. Anesthesia and Analgesia 2009; 109: 1901-7.

33. Elliott DS, Baker PA, Scott MR, Birch CW, Thompson JM. Accuracy of surface landmark identification for cannula cricothyroidotomy. Anaesthesia 2010; 65: 889-94.

34. Sise MJ, Shackford SR, Cruickshank JC, Murphy G, Fridlund $\mathrm{PH}$. Cricothyroidotomy for long-term tracheal access. A prospective analysis of morbidity and mortality in 76 patients. Annals of Surgery 1984; 200: 13-7.

35. Mace SE. Cricothyrotomy. The Journal of Emergency Medicine 1988; 6: 309-19.

36. Wong DT, Lai K, Chung FF, Ho RY. Cannot intubate-cannot ventilate and difficult intubation strategies: results of a Canadian national survey. Anesthesia and Analgesia 2005; 100: $1439-46$.

37. Ezri T, Szmuk P, Warters RD, Katz J, Hagberg CA. Difficult airway management practice patterns among anesthesiologists practicing in the United States: have we made any progress? Journal of Clinical Anesthesia 2003; 15: 418-22.

38. Patel RG. Percutaneous transtracheal jet ventilation: a safe, quick, and temporary way to provide oxygenation and ventilation when conventional methods are unsuccessful. Chest 1999; 116: 1689-94.

39. Benumof JL, Scheller MS. The importance of transtracheal jet ventilation in the management of the difficult airway. Anesthesiology 1989; 71: 769-78.

40. Cook TM, Nolan JP, Cranshaw J, Magee P. Needle cricothyroidotomy. Anaesthesia 2007; 62: 289-90

41. Flint NJ, Russell WC, Thompson JP. Comparison of different methods of ventilation via cannula cricothyroidotomy in a trachea-lung model. British Journal of Anaesthesia 2009; 103: 891-5.

42. Sanders RD: Two ventilating attachments for bronchoscopes. Delaware Medical Journal 1967; 39: 170-5. 
43. Manoach S, Corinaldi C, Paladino L, et al. Percutaneous transcricoid jet ventilation compared with surgical cricothyroidotomy in a sheep airway salvage model. Resuscitation 2004; 62: 79-87.

44. Gal T. Airway management. In: Miller RD, ed. Miller's Anesthesia, 6th edn. Philadelphia, PA: Elsevier, 2005: 1637-39.

45. Schaefer R, Hueter L, Preussler NP, Schreiber T, Schwarzkopf K. Percutaneous transtracheal emergency ventilation with a self-made device in an animal model. Paediatric Anaesthesia 2007; 17: 972-6.

46. Mace SE. Needle cricothyrotomy. Emergency Medicine Clinics of North America 2008; 26: 1085-101.

47. Bould MD, Bearfield P. Techniques for emergency ventilation through a needle cricothyroidotomy. Anaesthesia 2008; 63: 535-9.

48. Tighe SQ, Staber M, Hardman JG, Henderson JJ. Emergency airway access equipment. Anaesthesia 2004; 59: 505-6.

49. Yildiz Y, Preussler NP, Schreiber T, et al. Percutaneous transtracheal emergency ventilation during respiratory arrest: comparison of the oxygen flow modulator with a hand-triggered emergency jet injector in an animal model. The American Journal of Emergency Medicine 2006; 24: 455-9.

50. Craven RM, Vanner RG. Ventilation of a model lung using various cricothyrotomy devices. Anaesthesia 2004; 59: 595-9.

51. Eger El, Hamilton WK. Positive-negative pressure ventilation with a modified Ayre's T-piece. Anesthesiology 1958; 19: 611-8.

52. Dunlap LB, Oregon E. A modified, simple device for the emergency administration of percutaneous transtracheal ventilation. Journal of the American College of Emergency Physicians 1978; 7: 42-6.

53. Kiyama S, Koyama K, Takahashi J, Fukushima K. Tension pneumothorax resulting in cardiac arrest during emergency tracheotomy under transtracheal jet ventilation. Journal of Anesthesia 1991; 5: 427-30.
54. Metz S, Parmet JL, Levitt JD. Failed emergency transtracheal ventilation through a 14-gauge intravenous catheter. Journal of Clinical Anesthesia 1996; 8: 58-62.

55. Nunn C, Uffman J, Bhananker SM. Bilateral tension pneumothorax following jet ventilation via an airway exchange catheter. Journal of Anesthesia 2007; 21: 76-9.

56. Cook TM, Bigwood B, Cranshaw J. A complication of transtracheal jet ventilation and use of the Aintree intubation catheter during airway resuscitation. Anaesthesia 2006; 61: $692-7$

57. Sulaiman L, Tighe SQ, Nelson RA. Surgical vs wire-guided cricothyroidotomy: a randomised crossover study of cuffed and uncuffed tracheal tube insertion. Anaesthesia 2006; 61: 565-70.

58. Wong DT, Kumar A, Prabhu A. The laryngeal mask airway prevents supraglottic leak during ventilation through an uncuffed cricothyroidotomy. Canadian Journal of Anaesthesia 2007; 54: 151-4.

59. Abbrecht PH, Kyle RR, Reams WH, Brunette J. Insertion forces and risk of complications during crico-thyroid cannulation. The Journal of Emergency Medicine 1992; 10: 417-26.

60. Fikkers BG, van Vugt $S$, van der Hoeven JG, van den Hoogen FJ, Marres HA. Emergency cricothyrotomy: a randomised crossover trial comparing the wire-guided and catheter-over-needle techniques. Anaesthesia 2004; 59: 1008-11.

61. Murphy C, Rooney SJ, Maharaj CH, Laffey JG, Harte BH. Comparison of three cuffed emergency percutaneous cricothyroidotomy devices to conventional surgical cricothyroidotomy in a porcine model. British Journal of Anaesthesia 2011; 106: 57-64.

62. Metterlein T, Frommer M, Ginzkey C, et al. A randomized trial comparing two cuffed emergency cricothyrotomy devices using a wire-guided and a catheter-over-needle technique. "ePub ahead of print" The Journal of Emergency Medicine 2010 June 3; doi:1016/j.jemermed.2010.04.008 
63. Department of Health. Report on Confidential enquiries into Maternal Deaths in the United Kingdom 1991 - 1993. London: Her Majesty's Stationery Office; 1996.

64. Clancy MJ. A study of the performance of cricothyroidotomy on cadavers using the Minitrach II. Archives of Emergency Medicine 1989; 6: 143-5.

65. Assmann NM, Wong DT, Morales E. A comparison of a new indicator-guided with a conventional wire-guided percutaneous cricothyroidotomy device in mannequins. Anesthesia and Analgesia 2007; 105: 148-54.

66. Schober P, Hegemann MC, Schwarte LA, Loer SA, Noetges P. Emergency cricothyrotomy-a comparative study of different techniques in human cadavers. Resuscitation 2009; 80: 204-9.

67. Dimitriadis JC, Paoloni R. Emergency cricothyroidotomy: a randomised crossover study of four methods. Anaesthesia 2008; 63: 1204-8.

68. Bruppacher HR, Naik VN, Bould MD, Friedman Z. Design flaw of Melker kit may compromise patient safety. Anaesthesia 2009; 64: 1147.

69. Brofeldt BT, Panacek EA, Richards JR. An easy cricothyrotomy approach: the rapid four-step technique. Academic. Emergency.Medicine 1996; 3: 1060-3.

70. Morris A, Lockey D, Coats T. Fat necks: modification of a standard surgical airway protocol in the pre-hospital environmental. Resuscitation 1997; 35: 253-4.

71. Morain WD. Cricothyroidotomy in head and neck surgery. Plastic and Reconstructive Surgery 1980; 65: 424-8.

72. Kuriloff DB, Setzen M, Portnoy W, Gadaleta D. Laryngotracheal injury following cricothyroidotomy. The Laryngoscope 1989; 99: 125-30.

73. Schroeder AA. Cricothyroidotomy: when, why, and why not? American Journal of Otolaryngology 2000; 21: 195201.

74. Eisenburger P, Laczika K, List M, et al. Comparison of conventional surgical versus Seldinger technique emergency cricothyrotomy performed by inexperienced clinicians. Anesthesiology 2000; 92: 687-90.
75. Smith CE, Dejoy SJ. New equipment and techniques for airway management in trauma. Current Opinion in Anaesthesiology 2001; 14: 197-209.

76. Spaite DW, Joseph M. Pre-hospital cricothyrotomy: an investigation of indications, technique, complications, and patient outcome. Annals of Emergency Medicine 1990; 19: 279-85.

77. Boyle MF, Hatton D, Sheets C. Surgical cricothyrotomy performed by air ambulance flight nurses: a 5-year experience. The Journal of Emergency Medicine 1993; 11: 41-5

78. Frerk C, Frampton C. Cricothyroidotomy; time for change. Anaesthesia 2006; 61: 921-3.

79. Greenland KB, Acott C, Segal R, Goulding G, Riley RH, Merry AF. Emergency surgical airway in life-threatening acute airway emernegncies - why are we so reluctant to do it? Anaesthesia and Intensive Care 2011; 39: 578-84

80. Hubble MW, Wilfong DA, Brown LH, Hertelendy A, Benner RW. A meta-analysis of pre-hospital airway control techniques part II: alternative airway devices and cricothyrotomy success rates. Pre-hospital Emergency Care 2010; 14: 515-30.

81. Gillespie MB, Eisele DW. Outcomes of emergency surgical airway procedures in a hospital-wide setting. The Laryngoscope 1999; 109: 1766-9.

82. Cook T, Bogod D. Evidence-based medicine and airway management: are they compatible? In: Fourth National Audit Project of the Royal College of Anaesthetists and the Difficult Airway Society. Major complications of airway management in the United Kingdom. Report and findings. Editors Cook TM, Woodall N, Frerk C.March 2011. ISBN 9781-9000936-03-3 Royal College of Anaesthetists. London (http: / / www.rcoa.ac.uk/index.asp?PagelD=1089)

83. Keane MF, Brinsfield KH, Dyer KS, Roy S, White D. A laboratory comparison of emergency percutaneous and surgical cricothyrotomy by pre-hospital personnel. Pre-hospital Emergency Care 2004; 8: 424-6.

84. Salah N, Mhuircheartaigh RN, Hayes N, McCaul C. A comparison of four techniques of emergency transcricoid oxygenation in a manikin. Anesthesia and Analgesia 2010; 110: 1083-5. 
85. Chan TC, Vilke GM, Bramwell KJ, Davis DP, Hamilton RS, Rosen $\mathrm{P}$. Comparison of wire-guided cricothyrotomy versus standard surgical cricothyrotomy technique. The Journal of Emergency Medicine 1999; 17: 957-62.

86. Schaumann N, Lorenz V, Schellongowski P, et al. Evaluation of Seldinger technique emergency cricothyroidotomy versus standard surgical cricothyroidotomy in 200 cadavers. Anesthesiology 2005; 102: 7-11.

87. Davis DP, Bramwell KJ, Vilke GM, Cardall TY, Yoshida E, Rosen P. Cricothyrotomy technique: standard versus the Rapid Four-Step Technique. The Journal of Emergency Medicine 1999; 17: 17-21.

88. Davis DP, Bramwell KJ, Hamilton RS, Chan TC, Vilke GM. Safety and efficacy of the Rapid Four-Step Technique for cricothyrotomy using a Bair Claw. The Journal of Emergency Medicine 2000; 19: 125-9.

89. Hill C, Reardon R, Joing S, Falvey D, Miner J. Cricothyrotomy technique using gum elastic bougie is faster than standard technique: a study of emergency medicine residents and medical students in an animal lab. Academic Emergency Medicine 2010; 17: 666-9.

90. Holmes JF, Panacek EA, Sakles JC, Brofeldt BT. Comparison of 2 cricothyrotomy techniques: standard method versus rapid 4-step technique. Annals of Emergency Medicine 1998; 32: 442-6.

91. Johnson DR, Dunlap A, McFeeley P, Gaffney J, Busick B. Cricothyrotomy performed by prehospital personnel: a comparison of two techniques in a human cadaver model. The American Journal of Emergency Medicine 1993; 11: 207-9.
92. Mariappa V, Stachowski E, Balik M, Clark P, Nayyar V. Cricothyroidotomy: comparison of three different techniques on a porcine airway. Anaesthesia and Intensive Care 2009; 37: 961-7.

93. Benkhadra $M$, Lenfant $F$, Nemetz $W$, Anderhuber $F$, Feigl $G$, Fasel J. A comparison of two emergency cricothyroidotomy kits in human cadavers. Anesthesia and Analgesia 2008; 106: 182-5.

94. Vadodaria BS, Gandhi SD, McIndoe AK. Comparison of four different emergency airway access equipment sets on a human patient simulator. Anaesthesia 2004; 59: 73-9.

95. Hodgson R. A response to 'Emergency cricothyrotomy: a randomised crossover trial comparing the wire-guided and catheter-over-needle techniques'. Anaesthesia 2005; 60: 105.

96. Lacquiere A, Heard AM. Emergency cricothyroidotomy: training is paramount and oxygenation is the aim. Anaesthesia 2009; 64: 447-8.

97. Smith CE, Dejoy SJ. New equipment and techniques for airway management in trauma. Current Opinion in Anaesthesiology 2001; 14: 197-209.

98. Boyle MF, Hatton D, Sheets C. Surgical cricothyrotomy performed by air ambulance flight nurses: a 5 -year experience. The Journal of Emergency Medicine 1993; 11: 41-5.

99. Green L. Can't intubate, can't ventilate! A survey of knowledge and skills in a large teaching hospital. European Journal of Anaesthesiology 2009; 26: 480-3.

100. Scrase I, Woollard M. Needle vs surgical cricothyroidotomy: a short cut to effective ventilation. Anaesthesia 2006; 61: $962-74$. 


\begin{tabular}{|c|c|c|c|}
\hline $\begin{array}{l}\text { AUTHORS } \\
\text { [REF] }\end{array}$ & TECHNIQUES STUDIED & $\begin{array}{l}\text { NUMBER OF } \\
\text { CADAVERS }\end{array}$ & OPERATOR \\
\hline Benkhadra et al. [93] & $\begin{array}{l}\text { - Melker } \\
\text { O Portex }\end{array}$ & $\mathrm{n}=40$ & Anaesthetists $(n=2)$ \\
\hline Chan et al. [85] & $\begin{array}{ll}\text { - } & \text { Melker } \\
\text { ○ } & \text { surgical }\end{array}$ & $n=15$ & EM attendings / residents $(n=15)$ \\
\hline
\end{tabular}

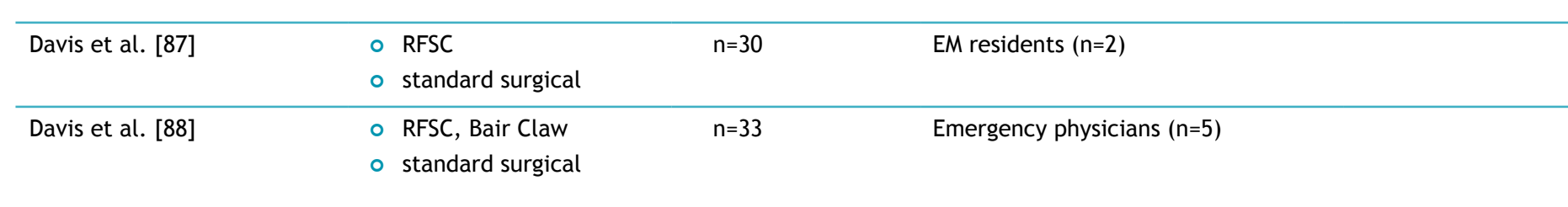

\begin{tabular}{|c|c|c|c|}
\hline Eisenburger et al. [74] & $\begin{array}{ll}\circ & \text { Melker } \\
\circ & \text { surgical }\end{array}$ & $n=40$ & ICU physicians $(n=20)$ \\
\hline
\end{tabular}

\begin{tabular}{|c|c|c|c|}
\hline Holmes et al. [90] & - RFSC & $n=64$ & $E M$ interns, residents, students $(n=32)$ \\
\hline
\end{tabular}

\begin{tabular}{lll}
\hline Johnson et al. [91] & $\circ$ Pertrach & $n=44 \quad$ students $(n=44)$ \\
& $\circ$ surgical &
\end{tabular}

\begin{tabular}{lll}
\hline Schaumann et al. [86] & $\circ$ Arndt & $\mathrm{n}=200 \quad$ emergency physicians $(\mathrm{n}=20)$ \\
& $\circ$ surgical &
\end{tabular}

Schober et al. [66]

- Crico-scissor $\quad \mathrm{n}=63$
- Melker
- Quicktrach
- surgical

students $(n=63)$ 


\section{OUTCOME MEASURES}

insertion time: from incision /puncture of the skin to inflation of the cuff success rate: device in the correct position in $<300 \mathrm{~s}$

incidence of major tracheal and laryngeal injury

insertion time: initial incision to final placement of cannula

accuracy of placement

complication rate

operator preference

incidence of tissue damage or balloon rupture

size of largest tube able to pass

time to definitive airway: not defined

size of largest tube able to pass

complication rate

operator preference: numeric scale 1 to 4

procedure time: from start to first ventilation

rate of tracheal placement

incidence of laryngotracheal injury

ease of use: from 1 (easiest) to 5 (worst)

insertion time: from incision to removal trocar from the Shiley tube

success rate: within 1st attempt

incidence of major complications

insertion time: from palpation to first ventilation

tracheal placement in the 1st attempt

ease of insertion: 0 (very easy) to 10 (impossible)

time from start of procedure to first ventilation

success rate: through cricothyroid membrane within 1 attempt

incidence of injury

insertion time: from beginning of inspection until complete termination

of procedure

success rate

complication rate

\section{RESULTS}

Melker 71s vs Portex 54s ( $\mathrm{p}=0.01)$

Melker $95 \%$ vs Portex $80 \%$ (NS)

Melker 0\% vs Portex 20\% ( $\mathrm{p}=0.003)$

Melker $75 \mathrm{~s}$ vs surgical $73 \mathrm{~s}(\mathrm{p}=0.86)$

Melker $93 \%$ vs surgical $87 \%(\mathrm{p}=0.05)$

Melker $7 \%$ vs surgical $15 \%$

93\% preferred the Melker

RFSC $16.7 \%$ vs standard surgical $0 \%(<0.05)$

both $7.0 \mathrm{~mm}$ ID

RFSC $33 \mathrm{~s}$ vs standard surgical $52 \mathrm{~s}(\mathrm{p}=0.037)$

RFSC $7.7 \mathrm{~mm}$ ID vs surgical $7.8 \mathrm{~mm}$ ID (NS)

both $0 \%$

Melker least preferred by $78 \%$

Melker 100 s vs surgical $102 \mathrm{~s}$ (NS)

Melker $60 \%$ vs surgical $70 \%$ (NS)

Melker $10 \%$ vs surgical $15 \%$ (NS)

Melker 2.4 vs surgical 2.2 (NS)

RFSC 43s vs standard $134 \mathrm{~s}(\mathrm{p}<0.001)$

RFSC $88 \%$ vs standard $94 \%(p=0.16)$

RFSC $9 \%$ vs standard $3 \%(p=0.32)$

Pertrach $148 \mathrm{~s}$ vs surgical $55 \mathrm{~s}(\mathrm{p}<0.01)$

Pertrach $78 \%$ vs surgical $86 \%(p=0.186)$

Pertrach 5.1 vs surgical $3.0(p<0.01)$

Arndt 109 s vs surgical $137 \mathrm{~s}(\mathrm{p}<0.001)$

Arndt $88 \%$ vs surgical $84 \%$ (NS)

Arndt $0 \%$ vs surgical $6 \%(\mathrm{p}<0.05)$

Crico-scissor 60s vs Melker 135s vs Quicktrach 74s

vs surgical $78 \mathrm{~s}$ (Melker vs surgical $\mathrm{p}<0.05$ )

Crico-scissor $100 \%$ vs Melker $71 \%$ vs Quicktrach $82 \%$

vs surgical $94 \%$ (Melker vs surgical $p<0.05$ )

Crico-scissor 36\% vs Melker 64\% vs Quicktrach 71\%

vs surgical $0 \%$ (Melker vs surgical $p<0.05$ ) 


\begin{tabular}{|c|c|c|c|}
\hline AUTHORS & TECHNIQUES STUDIED & STUDY MODEL & OPERATOR \\
\hline Assmann et al. [65] & $\begin{array}{ll}\circ & \text { Melker } \\
\circ & \text { Portex }\end{array}$ & manikin & anaesthetists $(n=64)$ \\
\hline Dimitriadis et al. [67] & $\begin{array}{ll}\circ & \text { Melker } \\
\circ & \text { Mini-Trach } \\
\circ & \text { Quicktrach } \\
\circ & \text { surgical }\end{array}$ & manikin & EM physicians $(n=23)$ \\
\hline Fikkers et al. [60] & $\begin{array}{l}\circ \text { Mini-Trach } \\
\circ \text { Quicktrach }\end{array}$ & pig-larynx model & anaesthesia and ENT residents $(n=20)$ \\
\hline Hill et al. [89] & $\begin{array}{ll}\circ & \text { RFSC } \\
\circ & \text { RFSC with bougie }\end{array}$ & sheep $(n=21)$ & residents and students $(n=21)$ \\
\hline Keane et al. [83] & $\begin{array}{ll}\circ & \text { Melker } \\
\circ & \text { surgical }\end{array}$ & pig-larynx model & paramedics $(n=22)$ \\
\hline Mariappa et al. [92] & $\begin{array}{ll} & \text { Melker } \\
\circ & \text { Portex } \\
\circ & \text { surgical }\end{array}$ & pig-larynx model & intensivist $(\mathrm{n}=3)$ \\
\hline
\end{tabular}

\begin{tabular}{lll}
\hline Metterlein et al. [62] & $\circ$ Melker & sheep cadaver $(n=16)$ anaesthetists $(n=2)$ \\
& $\circ$ Quicktrach &
\end{tabular}

\begin{tabular}{ll}
\hline Salah et al. [32] & $\circ$ Mini-Trach pig-larynx model anaesthetic trainees $(\mathrm{n}=10)$ \\
& $\circ$ Quicktrac \\
& $\circ$ Ravussin \\
& $\circ$ surgical
\end{tabular}




\section{OUTCOME MEASURES}

insertion time: from palpation of skin to ventilation success rate: insertion of the device in the correct position operator preference

time to first ventilation

\section{RESULTS}

Melker $42 \mathrm{~s}$ vs $33 \mathrm{~s}(\mathrm{p}<0.001)$

Melker $95 \%$ vs Portex $93 \%$ (NS)

$59 \%$ of the operators preferred the Melker

Melker 126s, Mini-Trach 48s, Quicktrach 48s, surgical 34s $(\mathrm{p}<0.0001)$

success rate: correct placement within 210

Melker 74\%, Mini-Trach, Quicktrach and surgical 100\%

operator preference: numeric scale 1 to 4

Insertion time: from inspection of instruments to first

ventilation

success rate: correct position within $240 \mathrm{~s}$

ease of procedure: VAS 0-10

insertion time: from palpation to cuff inflation

success rate: 1 attempt, within $180 \mathrm{~s}$ in correct position

ease of use: 1 (very easy) to 5 (very hard)

procedure time: puncture/incision of the skin to completion

of procedure

success rate

Melker $91 \%$ vs surgical $100 \%(p=0.1)$

Melker least preferred by $78 \%$

Mini-Trach 149.7 s vs Quicktrach 47.9 s ( $p<0.001)$

Mini-Trach $85 \%$ vs Quicktrach 95\% (NS)

Mini-Trach 5.5 vs Quicktrach $2.1(\mathrm{p}<0.001)$

RFSC $149 \mathrm{~s}$ vs with bougie $67 \mathrm{~s}(\mathrm{p}=0.002)$

RFSC $73 \%$ vs with bougie $90 \%$

RFSC 3 vs with bougie $2(p=0.04)$

Melker 123 s vs surgical 29 s $(p<0.001)$

Melker $47 \mathrm{~s}$ vs Portex 63s vs surgical 50 s (NS)

time to achieve patent airway: from location of cricothyroid

membrane to first ventilation

success rate: intraluminal placement with resistance free ventilation

incidence of posterior wall injury

time from the decision to start of procedure and time from

incision/puncture to first successful ventilation

success rate: within 180 seconds

incidence injury posterior wall

incidence and severity of tissue damage tracheal site or CTM

Melker $0 \%$ vs Portex $55 \%$ vs surgical $20 \%(p<0.001)$

tissue injury more frequent when procedure is performed
Melker $100 \%$ vs Portex $30 \%$ vs surgical $55 \%(p \leq 0.001)$

Melker 53s vs Quicktrach 32s $(p<0.05)$

Melker $100 \%$ vs Quicktrach 63\% ( $\mathrm{p}<0.05)$

Melker $13 \%$ vs Quicktrach 63\% at tracheal site compared to CTM with Quicktrach and surgical

rank order: surgical=Quicktrach $>$ Mini-Trach=Ravussin compression more common at tracheal site compared to cricothyroid membrane

rank order: Quicktrach>surgical>Mini-Trach $>$ Ravussin 


\begin{tabular}{l|l|l|l} 
AUTHORS & TECHNIQUES STUDIED & STUDY MODEL & OPERATOR \\
\hline Manoach et al. [43] & $\circ$ narrow-bore cannula & sheep $(\mathrm{n}=12)$ & researchers $(\mathrm{n}=2)$ \\
& $\circ$ surgical & \\
\hline Murphy et al. [61] & $\circ$ Melker & pig-larynx model & anaesthetists $(\mathrm{n}=20)$ \\
& $\circ$ Portex & & \\
& $\circ$ Quicktrach & & \\
& $\circ$ surgical &
\end{tabular}

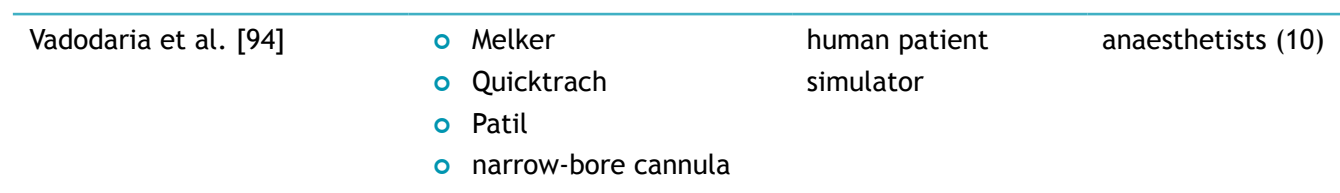

Table 4 An overview of the randomised control trials concerning cricothyroidotomy insertion and ventilation. 


\section{OUTCOME MEASURES}

procedure time: start procedure (at oxygen saturation of $80 \%$ )

to initiation of ventilation

respiratory and hemodynamic parameters

insertion time: from opening the cricothyroidotomy kit until

placement of device in the trachea

success rate: placement in the trachea within 300 s

ease of use: 0 (very easy) to 10 (very difficult)

operator preference: ranking 1 to 4

Incidence of posterior wall damage

tidal volumes

success rate: placement in the trachea within 300 s

ease of use: 0 (very easy) to 10 (very difficult)

operator preference: ranking 1 to 4

minute volume

time required to achieve a patent airway

time required to achieve a $\mathrm{PaO}_{2}$ exceeding $13.3 \mathrm{kPa}$

success rate: correct tracheal placement within 300 s and

achieving $\mathrm{PaO}_{2}>13.3 \mathrm{kPa}$

incidence of posterior wall injury

operator preference

\section{RESULTS}

narrow-bore cannula $20 \mathrm{~s}$ vs surgical $24 \mathrm{~s}(\mathrm{p}=0.69)$

no significant differences

Melker $94 \mathrm{~s}$ vs Portex $182 \mathrm{~s}$ vs Quicktrach 52 s vs surgical $59 \mathrm{~s}$

Melker $100 \%$ vs Portex $60 \%$ vs Quicktrach $95 \%$ vs surgical $95 \%$

Melker 2.8 vs Portex 5.7 vs Quicktrach 4.8 vs surgical 3.1

Melker was most preferred technique

Melker $40 \%$ vs Portex $70 \%$ vs Quicktrach $15 \%$, vs surgical $45 \%$ no significant difference

Melker $100 \%$ vs Portex $60 \%$ vs Quicktrach $95 \%$ vs surgical $95 \%$

Melker 2.8 vs Portex 5.7 vs Quicktrach 4.8 vs surgical 3.1

Melker was most preferred technique

Melker cuffed 6.6 l.min-1 vs Melker uncuffed 0.3 l.min-1 vs surgical $6.5{\mathrm{l} . \mathrm{min}^{-1}}^{-1}$

Melker 38 s vs Quicktrach 51 s vs Patil 123 s vs narrow-bore cannula 102s

Melker 130 s vs Quicktrach 58 s vs Patil 140 s vs narrow-bore cannula $185 \mathrm{~s}$

Melker $100 \%$ vs Quicktrach $100 \%$ vs Patil $60 \%$ vs narrow-bore cannula $40 \%$

$20 \%$ for each technique

60\% preferred Quicktrach and 40\% Melker 
40 


\section{Chapter 1}

B Aims of this thesis 
In this thesis the potential negative side effects of emergency ventilation through a narrow-bore cannula are discussed and a new ventilation mode, expiratory ventilation assistance (EVA), is developed and studied from bench to in vivo evaluation. 


\section{Aim 1: Are self-assembled emergency jet- ventilation devices safe?}

Several self-assembled devices, usually consisting of a threeway stopcock connected to a high-pressure oxygen source, have been used for percutaneous rescue ventilation through a narrow-bore cannula. Combined with a high oxygen flow, these devices are generally supposed to provide emergency re-oxygenation. However, as a three-way stopcock acts as a 'flow splitter' it will never ensure total flow and pressure release through the open side port. When connected to a patient with an obstructed upper airway, this technique can result in airtrapping and barotrauma. In chapter 2 of this thesis, the results of a bench study on the efficacy of flow and pressure release of three currently used self-assembled ventilation devices and one commercially available tool, are described.

\section{Aim 2: Which emergency jet-ventilation device can act as a bidirectional airway?}

When used in case of an obstructed upper airway, an emergency ventilator connected to a percutaneous airway cannula has to allow both the insufflation of oxygen and the egress of gas to be used safely. In chapter 3 , the capability to allow bidirectional airflow of two self-assembled, threeway stopcock based ventilation devices and the Oxygen Flow Modulator are studied.

\section{Aim 3: Feasibilty of expiration through a narrow- bore airway catheter}

Our group developed a new ventilation concept: Expiratory Ventilation Assistance (EVA). In Chapter 4 the concept of EVA is introduced and first results of a feasibility study are described and critically discussed.

\section{Aim 4: Technical features to optimize the entrainment effect for Expiratory Ventilation Assistance (EVA)}

The technical features and abilities of two novel ejector-based ventilation devices are described in chapter 5 . The features to optimize the entrainment effect for EVA are discussed.

\section{Aim 5: The efficiency of EVA to restore oxygenation and ventilation}

In vitro EVA seemed promising and therefore in vivo evaluation was the next logical step. The efficiency of EVA on restoring oxygenation and ventilation in a pig model of acute hypoxia was studied and is presented and discussed in chapter 6.

\section{Aim 6: Evaluation of the efficacy of a commercially available emergency EVA ventilator (Ventrain ${ }^{\circledR}$ )}

Based on the optimized prototype for EVA (chapter 5), a portable, flow-regulated, manually operated, and ergonomically shaped ventilation device was developed: Ventrain ${ }^{\circ}$ (Dolphys Medical BV, Eindhoven, The Netherlands). The results of a bench study of the Ventrain ${ }^{\circledR}$ are presented in chapter 7.

Chapter 8, the general discussion, focuses on the possible role of expiratory ventilation assistance (EVA) by Ventrain ${ }^{\circledR}$ in emergency ventilation and on potential future applications of EVA as a new ventilation mode. 
44 


\section{Chapter 2}

Potential hazard unrevealed 


\section{Summary}

Several self-assembled devices, consisting of a three-way stopcock connected to a high-pressure oxygen source, have been proposed for transtracheal jet ventilation in an emergency situation. As a three-way stopcock acts as a 'flow splitter' it will, when connected to a continuous oxygen flow, never ensure total flow and pressure release through its side port. The aim of the present study was to measure the efficacy of flow and pressure release of three previously described self-assembled jet devices and one commercially available tool.

In a laboratory setting simulating an obstructed upper airway the generated pressure at the cannula tip (PACT) during the expiration phase was measured in three self-assembled jet devices consisting of a three-way stopcock with an inner diameter of $2 \mathrm{~mm}$ (device A), $2.5 \mathrm{~mm}$ (device B), and $3 \mathrm{~mm}$ (device C), respectively, and in the Oxygen Flow Modulator (OFM) at oxygen flows of $6,9,12$, and $15 l \cdot \mathrm{min}^{-1}$.

The PACT of device A at on oxygen flow of $15 \mathrm{Il} \cdot \mathrm{min}^{-1}$ was $71.1( \pm 0.08) \mathrm{cmH}_{2} \mathrm{O}$. At a reduced flow of $9 l \cdot \mathrm{min}^{-1}$ the PACT of device $A$ was still $25.8( \pm 0.08) \mathrm{cmH}_{2} \mathrm{O}$. In device $B$ and $C$ the PACT was $35.6( \pm 0.04)$ and $17.6( \pm 0.04) \mathrm{cmH}_{2} \mathrm{O}$, respectively, at an oxygen flow of $15 \mathrm{l} \cdot \mathrm{min}^{-1}$. In contrast, the PACT in the OFM (five side holes open) was $4.4( \pm 0.02) \mathrm{cmH}_{2} \mathrm{O}$ at the same flow.

In case of complete upper airway obstruction the OFM provides sufficient flow and pressure release, whereas the self-assembled jet devices tested are inherently dangerous constructions. 


\section{Introduction}

Transtracheal jet ventilation (TTJV) is a generally accepted technique to oxygenate a patient in case bag-mask ventilation, supraglottic airway devices and / or endotracheal intubation attempts have failed [1,2]. In order to overcome the resistance of a narrow cannula, a high-pressure oxygen source is necessary for TTJV. Because an automated or hand-triggered jet injector may not be immediately available, various simple, self-assembled devices made of a three-way stopcock and oxygen tubing have been proposed for emergency jet ventilation $[3,4]$. When connected to a high-pressure flow-regulated oxygen source these devices are supposed to transmit sufficient pressure and flow to allow effective low frequent jet ventilation by intermittent occlusion of the side port of the three-way stopcock $[4,5]$.

Based on its geometry, however, a three-way stopcock acts as a 'flow splitter'. This means that when this self-assembled device is connected to a continuous oxygen flow the three-way stopcock, even with the side port completely opened, will never ensure total flow and pressure release through this side port. Consequently, a relevant flow of oxygen to the lungs of the patient cannot be avoided [6]. In a completely obstructed upper airway, this oxygen flow will inevitably create a positive end-expiratory pressure (PEEP) that can lead to barotrauma [7] and hemodynamic instability [8].

Sufficient gas flow and pressure release via the side port of the jet ventilation device is crucial to avoid high levels of PEEP. The ability of flow and pressure release via the side port of the jet device thus determines whether a self-assembled device can be used safely for TTJV. Therefore, the aim of our study was to measure the efficacy of flow and pressure release in three previously described self-assembled emergency devices and one commercially available emergency tool.

\section{Methods}

Four devices were tested in the laboratory. Self-assembled device A, as described by Schaefer et al. [5], consisted of a three-way stopcock with an inner diameter of $2 \mathrm{~mm}$ (Discofix ${ }^{\circledR}$ C, B. Braun Melsungen AG, Melsungen, Germany) connected in-line to a transtracheal airway cannula and a noncompliant oxygen tubing (Figure 1). In device $B$ and $C$ the standard three-way stopcock was replaced by a modified stopcock with all passages drilled to an inner diameter of 2.5 and $3 \mathrm{~mm}$, respectively. The Oxygen Flow Modulator (OFM; Cook Medical, Bloomington, IN, USA) is a short, noncompliant $5 \mathrm{~mm}$ tubing having five openings with a diameter of $4 \mathrm{~mm}$ each (Figure 2).

All devices were tested separately with three different, currently and widely available transtracheal cannulas: a $16 \mathrm{G}$ (50 $\mathrm{mm}$ long with an inner diameter of $1.3 \mathrm{~mm}$ ) and a $13 \mathrm{G}$ (78 mm long with an inner diameter of $1.7 \mathrm{~mm}$ ) Ravussin needle (VBM Medizintechnik GmbH, Sulz, Germany) and a $6 \mathrm{Fr}(80 \mathrm{~mm}$ long with an inner diameter of $2 \mathrm{~mm}$ ) transtracheal catheter (TTC; Cook Medical, Bloomington, IN, USA). The same $4 \mathrm{~mm}$ oxygen tubing was used to connect all devices to a calibrated, pressure-compensated oxygen flow meter (Dräger Medical AG \&Co. KG, Lübeck, Germany) attached to a wall outlet delivering oxygen at a maximum pressure of 5 bar $( \pm 73$ psi).

In devices A, B, and $C$ the pressure was measured at the tip of the transtracheal cannula with the side port of the three-way stopcock in the open position. We shall refer to this as the 'pressure at cannula tip' (PACT). In the OFM 
the PACT was first determined with only one $4 \mathrm{~mm}$ opening released, then again with all five side holes opened.

Pressure measurements were obtained using the Calibration Analyzer series RT-200 (Timeter Instrument Corporation, St. Louis, MO, USA). In order to prevent gas leakage, care was taken to keep a tight fit of the transtracheal airway cannula in the aperture of the Calibration Analyzer (Figure 3). Prior to every measurement the flow meter reading was

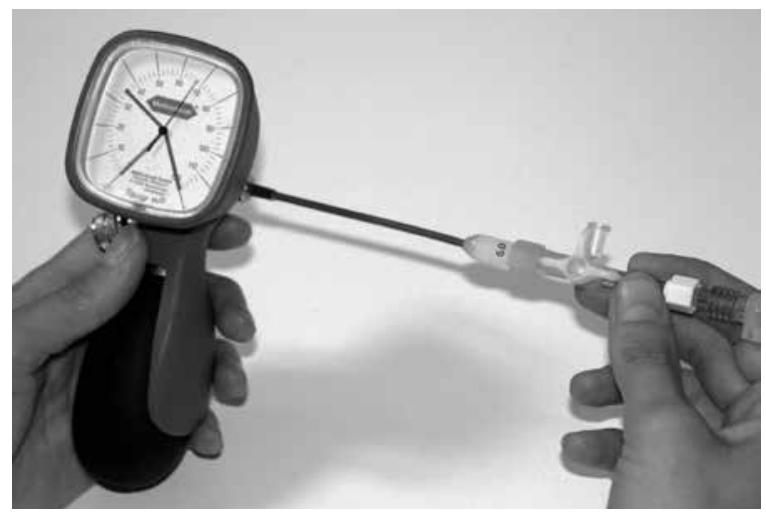

Figure 1 The pressure at the cannula tip can easily be checked with a conventional manometer for cuff pressure measurement.

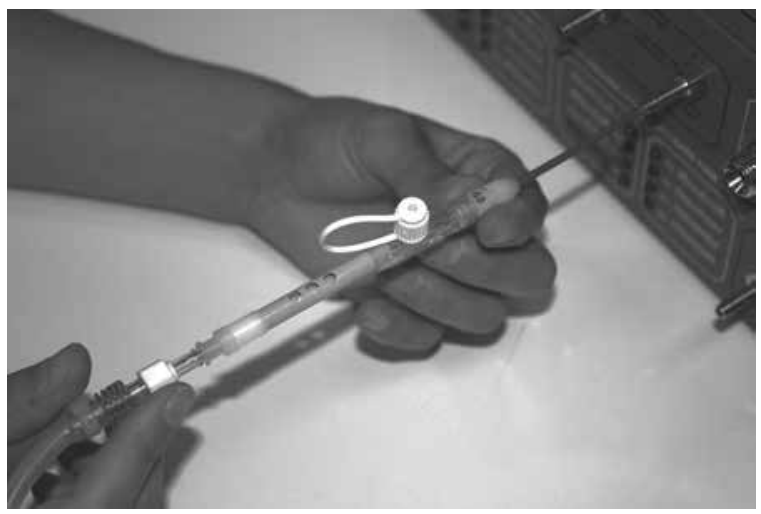

Figure 2 The oxygen flow modulator connected to a transtracheal catheter with all five openings released during measurements in the experimental setting. In the shadow the two openings at the bottom of the device can be seen. checked. After calibration, the generated PACT of all devices in combination with the three different catheters was determined at oxygen flows of $6,9,12$, and $151 \cdot \mathrm{min}^{-1}$, respectively. Five repetitive measurements were performed. The mean and the standard deviation of these five pressure values were calculated and used for further analysis.

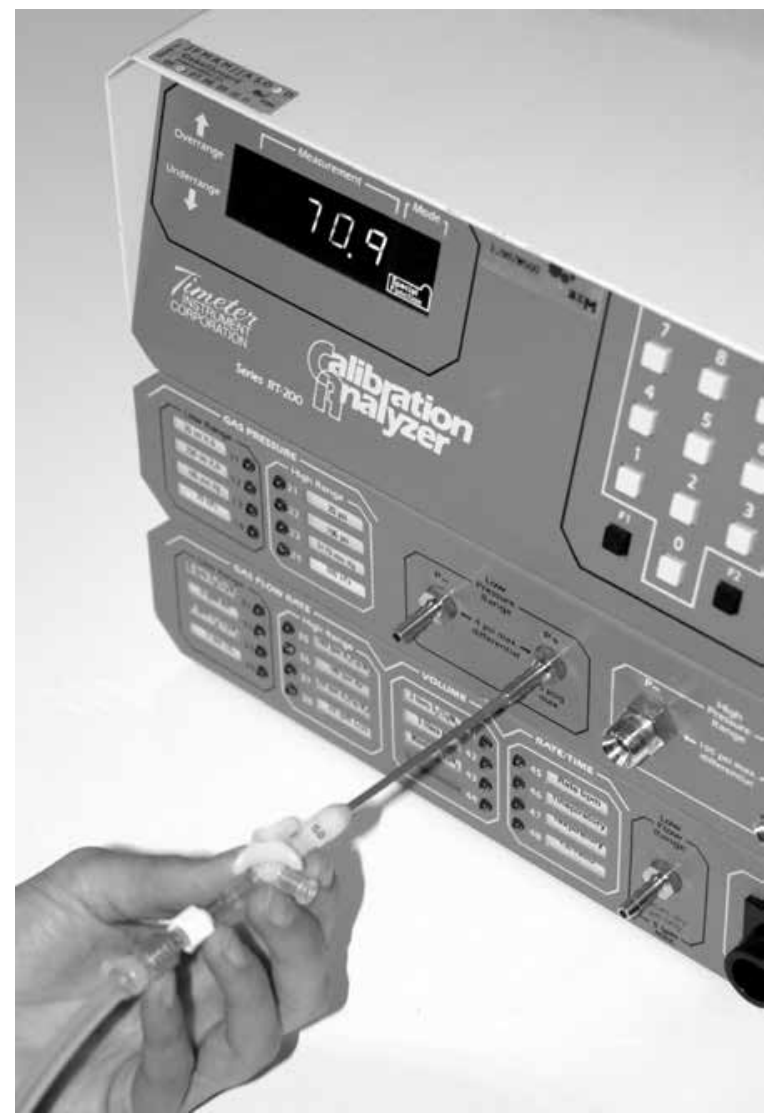

Figure 3 Use of a conventional three-way stopcock (ID $2 \mathrm{~mm}$ ) for emergency jet ventilation at a flow of $15 \mathrm{l} \cdot \mathrm{min}^{-1}$ results with the side port open in a pressure at the catheter tip of about $70 \mathrm{cmH}_{2} \mathrm{O}$. 


\section{Results}

The generated PACT for each device in combination with the three catheters at the four different oxygen flows is listed in Table 1.

An oxygen flow of $15 \mathrm{l} \cdot \mathrm{min}^{-1}$ applied to device A with the side port of the three-way stopcock (cross sectional area $3.14 \mathrm{~mm}^{2}$ ) in the open position resulted in a pressure of 71.1 $( \pm 0.8) \mathrm{CmH}_{2} \mathrm{O}$ at the tip of the TTC (Figure 4). Although low- ering the oxygen flow attenuated this pressure, a reduced oxygen flow of $91 \cdot \mathrm{min}^{-1}$ still generated a PACT of $25.8( \pm 0.09)$ $\mathrm{CmH}_{2} \mathrm{O}$.

A larger cross sectional area of the side port as in device $B\left(4.91 \mathrm{~mm}^{2}\right)$ and device $C\left(7.07 \mathrm{~mm}^{2}\right)$ led to a better flow release and subsequently a lower PACT. In device B the pressure measured at the tip of the TTC at an oxygen flow of $15 \mathrm{l} \cdot \mathrm{min}^{-1}$ was $35.6( \pm 0.04) \mathrm{cmH}_{2} \mathrm{O}$. The PACT of device $\mathrm{C}$ in combination with the TTC was $17.6( \pm 0.04) \mathrm{cmH}_{2} \mathrm{O}$.

\begin{tabular}{|c|c|c|c|c|}
\hline & $6 \mathrm{~L} \cdot \mathrm{MIN}^{-1}$ & $9 \mathrm{~L} \cdot \mathrm{MIN}^{-1}$ & $12 \mathrm{~L} \cdot \mathrm{MIN}^{-1}$ & $15 \mathrm{~L} \cdot \mathrm{MIN}^{-1}$ \\
\hline \multicolumn{5}{|c|}{ Device A (ID 2 mm) } \\
\hline Ravussin 16 G & $10.62( \pm 0.04)$ & $23.60( \pm 0.10)$ & $44.08( \pm 0.16)$ & $66.86( \pm 0.68)$ \\
\hline Ravussin $13 \mathrm{G}$ & $10.84( \pm 0.05)$ & $23.68( \pm 0.04)$ & $44.18( \pm 0.04)$ & $66.36( \pm 0.05)$ \\
\hline TTC $6 \mathrm{Fr}$ & $12.33( \pm 0.09)$ & $25.84( \pm 0.09)$ & $47.14( \pm 0.11)$ & $71.08( \pm 0.76)$ \\
\hline \multicolumn{5}{|c|}{ Device B (ID 2.5 mm) } \\
\hline Ravussin $16 \mathrm{G}$ & $5.48( \pm 0.04)$ & $11.98( \pm 0.04)$ & $22.34( \pm 0.05)$ & $33.74( \pm 0.05)$ \\
\hline Ravussin $13 \mathrm{G}$ & $5.18( \pm 0.04)$ & $12.04( \pm 0.05)$ & $22.38( \pm 0.04)$ & $33.78( \pm 0.04)$ \\
\hline TTC 6 Fr & $5.72( \pm 0.11)$ & $12.70( \pm 0.00)$ & $23.76( \pm 0.05)$ & $35.58( \pm 0.04)$ \\
\hline \multicolumn{5}{|c|}{ Device C (ID 3 mm) } \\
\hline Ravussin 16 G & $2.56( \pm 0.05)$ & $6.04( \pm 0.05)$ & $11.52( \pm 0.04)$ & $18.52( \pm 0.08)$ \\
\hline Ravussin $13 \mathrm{G}$ & $2.52( \pm 0.04)$ & $6.02( \pm 0.04)$ & $11.42( \pm 0.04)$ & $18.16( \pm 0.11)$ \\
\hline TTC 6 Fr & $2.74( \pm 0.05)$ & $6.18( \pm 0.04)$ & $11.44( \pm 0.05)$ & $17.56( \pm 0.04)$ \\
\hline \multicolumn{5}{|c|}{ OFM (1 hole open) } \\
\hline Ravussin 16 G & $1.06( \pm 0.01)$ & $2.40( \pm 0.00)$ & $4.44( \pm 0.01)$ & $7.00( \pm 0.02)$ \\
\hline Ravussin $13 \mathrm{G}$ & $1.07( \pm 0.01)$ & $2.40( \pm 0.01)$ & $4.43( \pm 0.01)$ & $6.81( \pm 0.02)$ \\
\hline TTC $6 \mathrm{Fr}$ & $1.10( \pm 0.01)$ & $2.50( \pm 0.01)$ & $4.86( \pm 0.02)$ & $6.79( \pm 0.05)$ \\
\hline \multicolumn{5}{|c|}{ OFM (5 holes open) } \\
\hline Ravussin 16 G & $0.50( \pm 0.01)$ & $1.15( \pm 0.01)$ & $2.12( \pm 0.01)$ & $3.38( \pm 0.01)$ \\
\hline Ravussin $13 \mathrm{G}$ & $0.49( \pm 0.00)$ & $1.14( \pm 0.00)$ & $2.09( \pm 0.01)$ & $3.29( \pm 0.00)$ \\
\hline TTC 6 Fr & $0.74( \pm 0.02)$ & $1.58( \pm 0.01)$ & $3.02( \pm 0.02)$ & $4.40( \pm 0.02)$ \\
\hline
\end{tabular}

Table 1 Pressure measured at the tip of a $16 \mathrm{G}$ and $13 \mathrm{G}$ Ravussin needle and a $6 \mathrm{Fr}$ transtracheal catheter in $\mathrm{cmH}_{2} \mathrm{O}$ (mean \pm standard deviation) at different oxygen flows. 


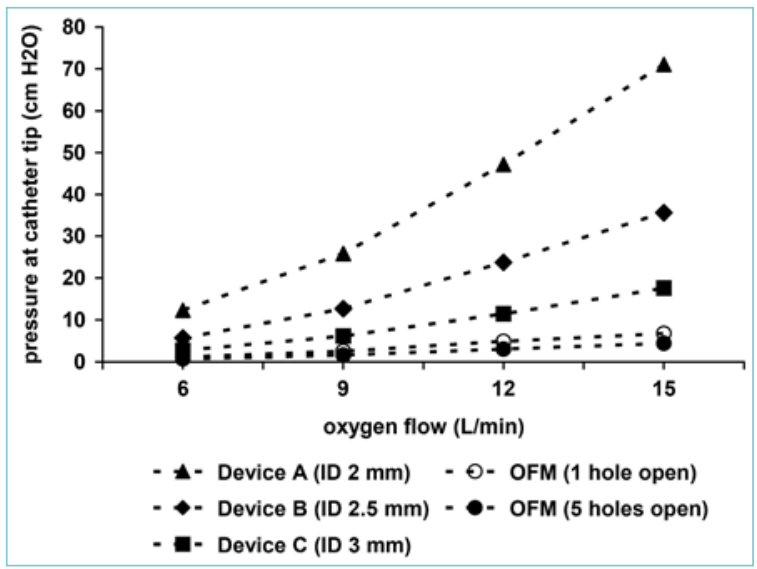

Figure 4 Pressure measured at the tip of a $16 \mathrm{G}$ and $13 \mathrm{G}$ Ravussin needle and a 6 Fr transtracheal catheter using three self-assembled devices consisting of a three-way stopcock with different inner diameters (device A, B, and C) and the oxygen flow modulator.

Release of one $4 \mathrm{~mm}$ opening (cross sectional area 12.56 $\mathrm{mm}^{2}$ ) of the OFM at a flow of $15 \mathrm{l} \cdot \mathrm{min}^{-1}$ resulted in a PACT of $6.8( \pm 0.05) \mathrm{cmH}_{2} \mathrm{O}$ and with all side holes open (total cross sectional area $\left.62.80 \mathrm{~mm}^{2}\right)$ the pressure fell to $4.4( \pm 0.02)$ $\mathrm{CmH}_{2} \mathrm{O}$.

As could be expected from the static situation the pressure measurements with both the $16 \mathrm{G}$ and $13 \mathrm{G}$ Ravussin needle did not differ in a clinically relevant way from the PACT of the jet devices in combination with the TTC.

\section{Discussion}

The present study shows that the use of a three-way stopcock as a device to control the oxygen flow during emergency jet ventilation has a potentially dangerous drawback. Connecting a high-pressure oxygen flow to a conventional three-way stopcock with a released side port results in a high PACT, which in case of a completely obstructed upper airway will inevitably lead to hazardous levels of PEEP.

Jet ventilation should never be used if the egress of gas is not secured. In an emergency situation one can never be sure whether an obstructed upper airway will open up after initiation of TTJV or will stay blocked. It is mandatory that when using TTJV, the flow coming from the oxygen source either is stopped or adequately released through the side port of the emergency jet device during the expiration phase. In contrast to devices that allow a complete stop of the oxygen flow (e.g. the Manujet ${ }^{\circledR}$; VBM Medizintechnik $\mathrm{GmbH}$, Sulz, Germany), a three-way stopcock can only act as a 'flow splitter'.

Inadequate flow release via the open side port of the three-way stopcock causes a relevant gas flow to the patient. The PACT resulting from this flow to the patient for a given 'flow splitter' jet device is determined by the set flow rate and the resistance of the open side port of the three-way stopcock (essentially defined by its inner diameter) whereas the resistance of the transtracheal cannula (defined by its inner diameter and length) does not influence the PACT in a static situation as in our setting.

The present study reveals that high PACT in jet devices made of a three-way stopcock can be avoided by reducing the oxygen flow rate to $6 \mathrm{l} \cdot \mathrm{min}^{-1}$. However, Bould et al. recently showed that in adults a flow rate of at least $15 \mathrm{l} \cdot \mathrm{min}^{-1}$ was necessary to achieve adequate flow and pressure for low-frequency jet ventilation using a three-way stopcock [4]. Thus, although a reduced flow rate will minimize the risk of hazardous levels of PEEP, ventilation may become inefficient.

The flow and pressure release in a 'flow splitter' jet device is proportionally related to the cross-sectional area and length of its side port or side holes. The results of the 
present study show that only a jet device having at least a 4 $\mathrm{mm}$ side port (like the OFM with one side hole open) can assure adequate flow release when connected to oxygen flows up to $15 l \cdot \mathrm{min}^{-1}$.

Our study has several limitations. Although the stability of the model is confirmed by the low variability between repeated measurements, we appreciate the limitations of applying results from this static model of complete upper airway obstruction to clinical practice. In the individual patient airway patency is variable. Due to the positive intrapulmonary pressure resulting from TTJV, an obstructed upper airway may open up thereby allowing the egress of gas. However, in up to $14 \%$ of the 'cannot intubate, cannot ventilate' (CICV) crises the upper airway remains obstructed and exhalation is compromised due to the distorted anatomy, oedema, or laryngospasm [9]. Another limitation is that this is not a clinical study. Only the PACT of the tested devices, but not the resulting PEEP, was measured in a laboratory setting. Nevertheless, in a completely obstructed upper airway PEEP will approach the PACT at equilibration.

High levels of PEEP have been shown to produce barotrauma [7] and to be detrimental to haemodynamics [8]. Increased intrathoracic pressure can decrease venous return and restrict cardiac filling, which may result in reduced cardiac output and hypotension. In a controlled trial of graded airway obstruction in dogs with 45 psi inflation pressure through a $13 \mathrm{G}$ catheter, tracheal pressures of $24 \mathrm{cmH}_{2} \mathrm{O}$ were already associated with decreasing blood pressure and increased central venous pressure [10].

Because of the small size of the cricothyroid space a surgical cricothyroidotomy should not be attempted in children under the age of 5 years [11]. A needle cricothyroidotomy, however, is considered to be an option in emergency situations even in neonates, provided the landmarks can be correctly identified and the procedure is converted to a tracheostomy as soon as possible [12]. In elective surgical cases complications with the use of jet ventilation are well known [13]. Due to the narrow upper airway children are more prone to air trapping and their smaller lung volumes increase the risk of subsequent barotrauma following injection of oxygen. The results of our study unmask an additional, underestimated risk of self-assembled jet devices: By merely connecting these to a high-pressure oxygen source set at a continuous oxygen flow of more than $91 \cdot \mathrm{min}^{-1}$ dangerously high airway pressures are inevitable in the event of upper airway obstruction. This automatism will be disastrous in children even quicker.

Although a CICV situation is very rare, every anaesthetist must be prepared for this emergency. A delay of even a few seconds can contribute to increased morbidity and mortality. Therefore, an emergency device should be preassembled, readily applicable and easy to handle. Unintentional closure of the side port of a self-assembled jet device can lead to severe barotrauma in only a few seconds. As a safety feature the closure of all five openings of the OFM and subsequent high gas flow to the patient is only achievable by an intentional digital manoeuver.

In a true clinical emergency one can only speculate whether the airway of the patient opens up at a higher airway pressure. Therefore, it is crucial that any device employed in a CICV situation is able to provide effective flow release and pressure control. This avoids high PACT and the subsequent risk of high PEEP in an obstructed upper airway. Small differences in physical characteristics between emergency jet devices can have huge clinical consequences.

Generally, self-assembled devices have not been tested thoroughly. Although they may resemble dedicated systems in many situations, they can carry intrinsic weaknesses (e.g. 
not providing enough flow or pressure) and risks (e.g. creating too much flow or pressure) depending upon the technical environment and the kind of patient they are used in. Of the tested devices, only the OFM ensures sufficient flow and pressure release. Based on our findings, the self-assembled jet devices studied should not be used in clinical practice.

\section{References}

1. Henderson JJ, Popat MT, Latto IP et al. Difficult Airway Society guidelines for management of the unanticipated difficult intubation. Anaesthesia 2004; 59: 675-694.

2. Caplan RA, Benumof JL, Berry FA et al. Practice guidelines for the management of difficult airway. An updated report by the American Society of Anesthesiologists Task Force on the Management of the Difficult Airway. Anesthesiology 2003; 98: 1269-1277.

3. Gal TJ. Airway management. In: Miller RD, ed. Miller's Anesthesia, 6th edn. Philadelphia, PA: Elsevier, 2005: 1637-1639.

4. Bould MD, Bearfield P. Techniques for emergency ventilation through a needle cricothyroidotomy. Anaesthesia 2008; 63: 535-539.

5. Schaefer R, Hueter L, Preussler NP et al. Percutaneous transtracheal emergency ventilation with a self-made device in an animal model. Pediatr Anesth 2007; 17: 972-976.

6. Hamaekers AE, Borg PA, Enk D. Limitations of self-made jet devices. Pediatr Anesth 2008; 18: 983.

7. Acosta P, Santisbon E, Varon J. The use of positive end-expiratory pressure in mechanical ventilation. Crit Care Clin 2007; 23: 251-261.
8. Toth I, Leiner T, Mikor A et al. Hemodynamic and respiratory changes during lung recruitment and descending optimal positive end-expiratory pressure titration in patients with acute respiratory distress syndrome. Crit Care Med 2007; 35: 787-793.

9. Smith RB, Babinski M, Klain $M$ et al. Percutaneous transtracheal ventilation. JACEP 1976; 5: 765-770.

10. Carl MR, Rhee KJ, Schelegle ES et al. Effects of graded upper airway obstruction on pulmonary mechanics during transtracheal jet ventilation in dogs. Ann Emerg Med 1994; 24: 1137-1143.

11. Boon JM, Abrahams PH, Meiring JH et al. Cricothyroidotomy: a clinical anatomy review. Clin Anat 2004; 17: 478-486.

12. Navsa N, Tossel G, Boon JM. Dimensions of the neonatal cricothyroid membrane - how feasible is a surgical cricothyroidotomy? Pediatr Anesth 2005; 15: 402-406.

13. Jaquet $\mathrm{Y}$, Monnier $\mathrm{Ph}$, Van Melle $\mathrm{G}$ et al. Complications of different ventilation strategies in endoscopic laryngeal surgery. Anesthesiology 2006; 104: 52-59. 


\section{Chapter 3}

\section{Important safety feature of a high-pressure ventilation device}

A bench study of two self-assembled jet devices and the Oxygen Flow Modulator in a simulated upper airway obstruction

Ankie Hamaekers MD, Pieter Borg DA and Dietmar Enk MD PhD

Published in Anaesthesia 2009, 64(12): 1353-8 


\section{Summary}

In managing an obstructed upper airway, an emergency transtracheal ventilation device needs to function as a bidirectional airway, allowing both insufflation of oxygen and egress of gas. The aim of the present study was to determine the capability of two self-assembled, three-way stopcock based jet devices and the Oxygen Flow Modulator to function as a bidirectional airway in conjunction with a small lumen catheter. For each device the effective pressures at the catheter's tip during the expiratory phase and the achievable minute volumes were determined in a laboratory set-up. Using the three-way stopcock based jet devices, changing the connection position of the transtracheal catheter from the in-line port to the side port of the three-way stopcock resulted in a decrease of expiratory pressure at the catheter's tip from a dangerous mean (SD) of $71.1(0.08) \mathrm{CmH}_{2} \mathrm{O}$ to -14.71 (0.05) $\mathrm{CmH}_{2} \mathrm{O}$. Yet this negative expiratory pressure did not facilitate the egress of gas. All devices tested impeded the expiratory outflow and hence decreased the achievable minute volume. This decrease in minute volume was smallest with the Oxygen Flow Modulator. 


\section{Introduction}

Cricothyroidotomy is one of the last options to restore oxygenation while managing a 'cannot intubate, cannot ventilate' situation and should be performed without delay [1, 2]. Introduction of a small-bore catheter or cannula through the cricothyroid membrane is a simple, quick and relatively safe technique but controversy exists on how best to provide effective oxygenation and ventilation [3-6].

Due to the high flow resistance of a small lumen transtracheal catheter or cannula, a high-pressure oxygen source is needed to ensure adequate oxygen insufflation. Several self-assembled devices have been proposed when an automated or hand-triggered jet injector is not available. In current anaesthesia textbooks [7] and in recent literature $[8,9]$ a three-way stopcock connected in-line to a transtracheal catheter and non-compliant oxygen tubing is recommended as an emergency ventilation system.

Connected to an oxygen flow meter set at $15 \mathrm{l} \cdot \mathrm{min}^{-1}$, this self-assembled device creates an adequate jet injection when the side port of the three-way stopcock is occluded [9], resulting in efficient ventilation in a small pig model [8]

However, in-between jet injections, inadequate pressure and flow release through the open side port of this device results in a continuous flow of oxygen to the patient [10]. In a patient with an obstructed upper airway, merely connecting such a device attached to an oxygen flow of 15 $l \cdot \min ^{-1}$ can cause a dangerously high intrathoracic pressure [11].

In principle, due to its geometry a three-way stopcock can behave like a Venturi device. Therefore, one may speculate that if the transtracheal catheter is not connected inline to the three-way stopcock and the oxygen tubing, as is generally suggested [7-9], but instead to its side port, the oxygen flow through the end port of the three-way stopcock will create a negative pressure at the side port and thus at the tip of the catheter.

Our primary hypothesis was that changing the position of the transtracheal catheter in relation to the oxygen flow results in a negative expiratory pressure. This would transform the adapted self-assembled device into a safer option for transtracheal oxygenation with regard to flow and pressure release during the expiratory phase.

Furthermore, the generated negative pressure may support expiration. In a completely obstructed upper airway, devices providing a Venturi-assisted expiration can be expected to achieve a higher minute volume than is known for flow splitter devices, such as the Oxygen

Flow Modulator (OFM; Cook Medical, Bloomington, IN, USA), a commercially available emergency tool for transtracheal oxygenation [12]. We tested these two hypotheses in vitro in a mechanical lung model and compared two selfmade devices made from standard three-way stopcocks to the OFM.

\section{Material and methods}

\section{Part 1}

In the first part of the study the effective 'Pressure At the Catheter's Tip' (PACT) during the expiratory phase was measured at different oxygen flows. Device A consisted of a 2-mm ID standard three-way stopcock (Discofix ${ }^{\oplus}$ C, B. Braun Melsungen AG, Melsungen, Germany) connected in-line to a $75 \mathrm{~mm}$ long, $2 \mathrm{~mm}$ ID transtracheal airway catheter (Cook Medical) and a noncompliant oxygen tubing (Fig. 1) as previously described [7-9]. In device $B$ the transtracheal airway catheter was not connected in-line to the three-way 
stopcock as in device A, but to its side port (Fig. 2). The third device tested, the Oxygen Flow Modulator consists of a short, non-compliant tubing having five openings located at opposite sites with a diameter of $4 \mathrm{~mm}$ each and a distal Luer lock connector (Fig. 3), to which the transtracheal catheter was attached.

All devices were connected with 4-mm oxygen tubing to a calibrated, pressure-compensated oxygen flow meter (Dräger Medical AG \& Co. KG, Lübeck, Germany) plugged

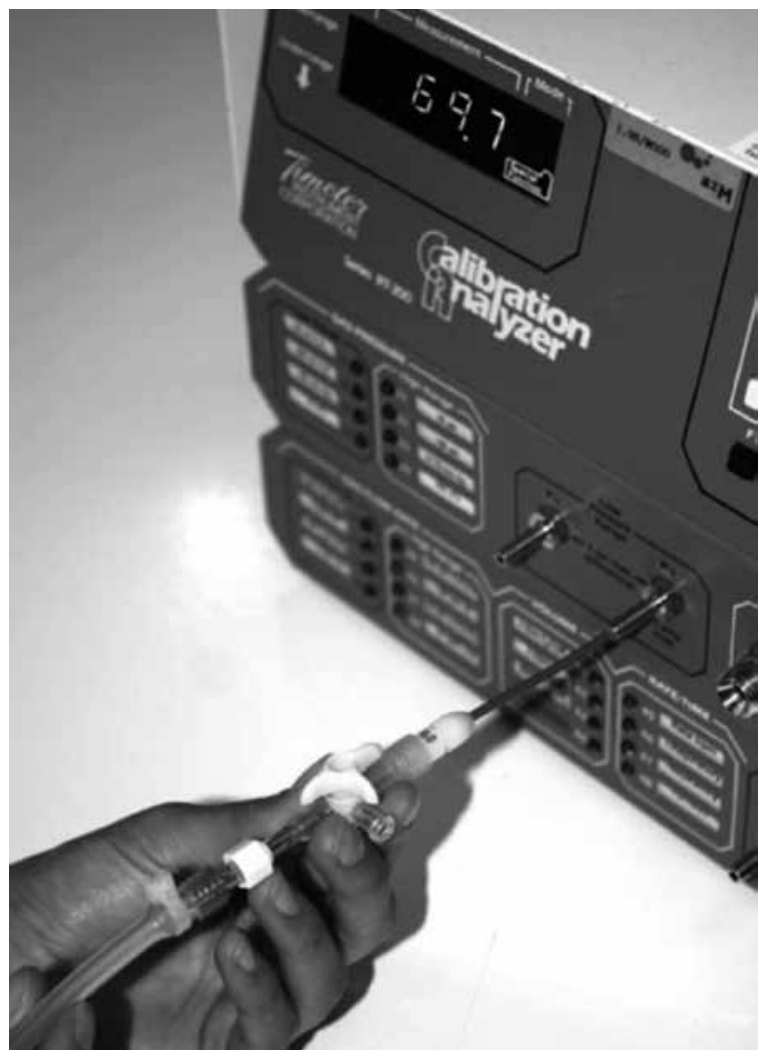

Figure 1 Device A: a 2-mm ID standard three-way stopcock connected in-line to the 2-mm ID transtracheal catheter. The transtracheal catheter is tightly fitted into the orifice for low range positive pressure measurement of the monitor. into a wall outlet delivering oxygen at a maximum pressure of 5 bar $( \pm 73$ psi).

The generated PACTs of devices A and B and the OFM, with the side port / holes open, were measured at oxygen flows of $6,9,12$ and $15 l \cdot \mathrm{min}^{-1}$, respectively.

Pressure measurements were obtained with the Calibration Analyzer series RT-200 pressure and flow monitor (Timeter Instruments Corporation, St Louis, MO, USA). In order to prevent gas leakage, care was taken to keep a tight fit of the transtracheal catheter in the designated orifice of the Calibration Analyzer (Figs 1-3), assuring correct pressure measurements in a static 'no flow' situation. Before every measurement the flow meter reading was checked. Four measurements were performed at each flow rate.

\section{Part 2}

The achievable minute volumes of device B and the OFM in simulated upper airway obstruction were determined using an LS800 lung simulator (Dräger Medical AG \& Co. KG) set at different compliances $\left(100,50,30\right.$ and $\left.10 \mathrm{ml} \cdot \mathrm{cmH}_{2} \mathrm{O}^{-1}\right)$ and resistances $\left(2,8\right.$ and $\left.32 \mathrm{cmH}_{2} \mathrm{O} \cdot \mathrm{l}^{-1} \cdot \mathrm{s}^{-1}\right)$, representing healthy and compromised lungs, with the transtracheal catheter tightly fitted in the proximal tube orifice of the mechanical lung.

The time for insufflation of $1000 \mathrm{ml}$ of oxygen by occluding the in-line port of device $B$ (thereby redirecting the flow of oxygen through its side port) and by complete closure of all five openings of the OFM, and the time needed for backflow of this volume through the transtracheal catheter and the attached devices were measured at oxygen flows of 12 and $15 l \cdot \mathrm{min}^{-1}$. In addition, the inspiration time with the oxygen tubing directly connected to the transtracheal catheter and the expiration time through the transtracheal catheter, without any device connected to it, were also determined. 
Four repeat tests were performed and achievable minute volumes and inspiration : expiration ratios (I:E ratio) were calculated.

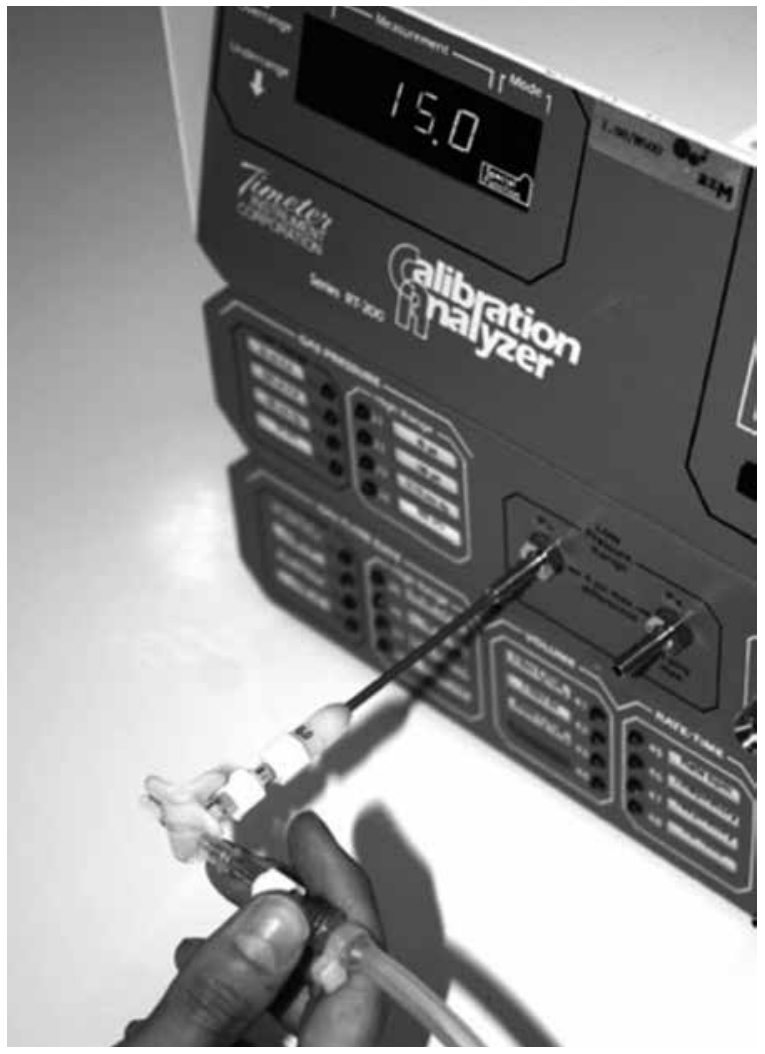

Figure 2 Device B: a 2-mm ID standard three-way stopcock connected to the 2-mm ID transtracheal catheter via the side port. Note that the transtracheal catheter is put into the orifice for low range negative pressure measurement, thus the value indicates a negative pressure.

\section{Statistical analysis}

Statistical analysis was performed using version 10.0 of SPSS for Windows software package (SPSS Inc., Chicago, IL, USA). Linear regression analysis was performed with expiration time as the dependent variable and pulmonary settings, oxygen flow rates, and devices as independent variables to determine the correlation of different pulmonary settings, oxygen flow, and expiration time in device $B$ and the OFM. A p value of $<0.05$ was considered to be statistically significant.

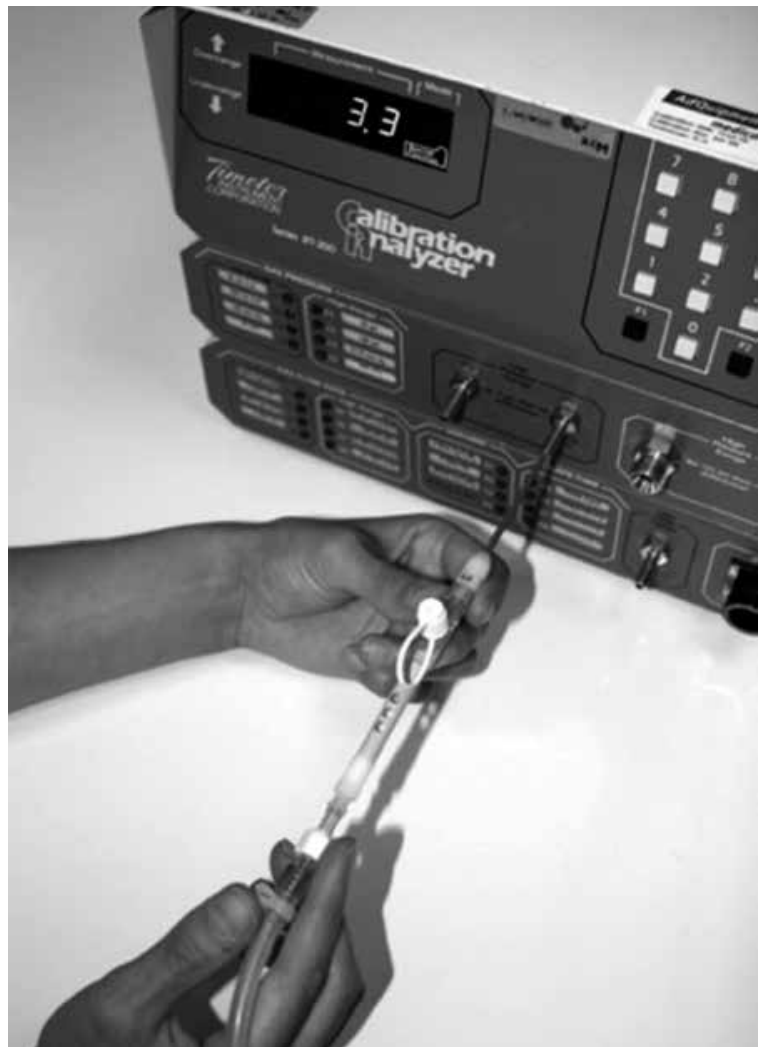

Figure 3 The Oxygen Flow Modulator connected to the 2-mm ID transtracheal catheter with all five openings released during measurements in the first part of the experiments. In the shadow the two openings at the reverse side of the device can be seen. 


\section{Results}

\section{Part 1}

An oxygen flow of $15 \mathrm{l} \cdot \mathrm{min}^{-1}$ applied to device $\mathrm{A}$ with the side port of the three-way stopcock open resulted in a mean (SD) pressure of $71.1(0.8) \mathrm{cmH}_{2} \mathrm{O}$ at the tip of the transtracheal catheter. A reduced oxygen flow of $91 \cdot \mathrm{min}^{-1}$ still generated a PACT of $25.8(0.08) \mathrm{CmH}_{2} \mathrm{O}$ (Fig. 4), identical to measurements previously reported [11].

Attachment of device B to a continuous flow of oxygen resulted in a negative PACT. This pressure was inversely proportional to the oxygen flow rate. At an oxygen flow of $15 \mathrm{l} \cdot \mathrm{min}^{-1}$ the PACT was $-14.71(0.05) \mathrm{cmH}_{2} \mathrm{O}$ and this fell to $-1.75(0.03) \mathrm{CmH}_{2} \mathrm{O}$ at a flow rate of $6 \mathrm{l} \cdot \mathrm{min}^{-1}$.

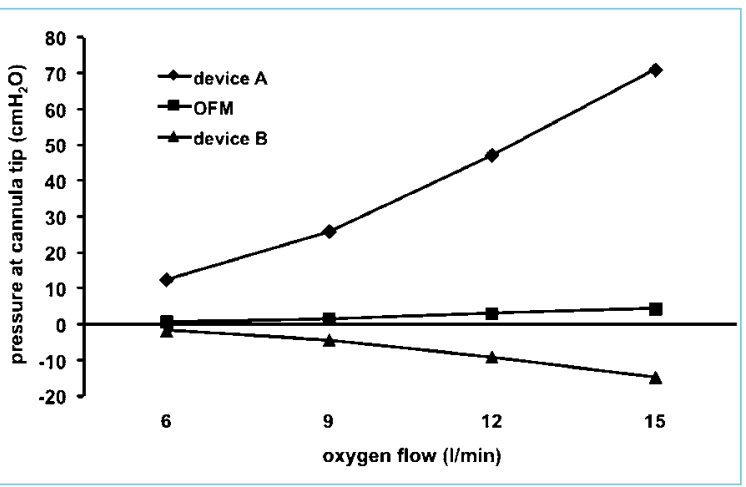

Figure 4 Pressures measured at the tip of the 2-mm ID transtracheal catheter with different oxygen flows in device $A$ (consisting of a 2-mm ID standard three-way stopcock connected in-line to the transtracheal catheter), device $B$ (the transtracheal catheter connected to the side port of the 2-mm ID standard three-way stopcock) and the Oxygen Flow Modulator with all five holes open.

\begin{tabular}{|c|c|c|c|c|c|c|c|c|c|c|c|c|c|c|}
\hline \multirow{2}{*}{\multicolumn{3}{|c|}{$\begin{array}{l}\text { COMPLIANCE }\left(\mathrm{ML} \cdot \mathrm{CMH}_{2} \mathrm{O}^{-1}\right) \\
\text { RESISTANCE }\left(\mathrm{CMH}_{2} \mathrm{O} \cdot \mathrm{L}^{-1} \cdot \mathrm{S}^{-1}\right)\end{array}$}} & \multicolumn{2}{|c|}{100} & \multicolumn{2}{|r|}{50} & \multicolumn{2}{|c|}{30} & \multicolumn{2}{|c|}{30} & \multicolumn{2}{|r|}{30} & \multicolumn{2}{|r|}{10} \\
\hline & & & & 2 & & 2 & & 2 & & 8 & & 32 & & 32 \\
\hline & no & IT (s) & 4.95 & $(0.06)$ & 5.13 & $(0.06)$ & 5.40 & $(0.1)$ & 5.38 & $(0.06)$ & 5.35 & $(0.04)$ & 6.64 & $(0.12)$ \\
\hline & device & ET (s) & 13.39 & $(0.03)$ & 9.90 & $(0.1)$ & 7.75 & $(0.09)$ & 7.92 & $(0.12)$ & 8.02 & $(0.06)$ & 5.61 & $(0.23)$ \\
\hline 12 & device & IT (s) & 4.99 & $(0.05)$ & 5.15 & $(0.06)$ & 5.43 & $(0.12)$ & 5.37 & $(0.07)$ & 5.34 & $(0.05)$ & 6.56 & $(0.10)$ \\
\hline $1 \cdot \min ^{-1}$ oxygen & B & ET (s) & 23.91 & $(0.11)$ & 19.06 & $(0.04)$ & 15.22 & (0.07) & 15.47 & $(0.08)$ & 15.42 & $(0.04)$ & 10.12 & $(0.03)$ \\
\hline & & IT (s) & 4.91 & $(0.05)$ & 5.11 & $(0.05)$ & 5.37 & $(0.04)$ & 5.40 & $(0.04)$ & 5.36 & $(0.01)$ & 6.72 & $(0.08)$ \\
\hline & $U \mathrm{r}$ & ET (s) & 19.78 & $(0.09)$ & 14.00 & $(0.1)$ & 10.60 & $(0.06)$ & 10.67 & $(0.06)$ & 10.70 & $(0.05)$ & 6.94 & $(0.04)$ \\
\hline & no & IT (s) & 3.94 & $(0.06)$ & 4.07 & $(0.08)$ & 4.25 & $(0.07)$ & 4.26 & $(0.03)$ & 4.25 & $(0.07)$ & 5.24 & $(0.13)$ \\
\hline & device & ET (s) & 13.39 & $(0.03)$ & 9.90 & $(0.1)$ & 7.75 & (0.09) & 7.92 & $(0.12)$ & 8.02 & $(0.06)$ & 5.61 & $(0.23)$ \\
\hline 15 & device & IT (s) & 3.97 & $(0.07)$ & 4.05 & $(0.11)$ & 4.24 & $(0.09)$ & 4.26 & $(0.04)$ & 4.19 & $(0.04)$ & 5.13 & $(0.07)$ \\
\hline $1 \cdot \min ^{-1}$ oxygen & B & ET (s) & 22.78 & $(0.12)$ & 18.75 & $(0.12)$ & 15.71 & $(0.15)$ & 15.71 & $(0.17)$ & 15.65 & $(0.20)$ & 10.63 & $(0.10)$ \\
\hline & & IT (s) & 3.91 & $(0.01)$ & 4.09 & $(0.03)$ & 4.27 & $(0.03)$ & 4.26 & $(0.01)$ & 4.30 & $(0.01)$ & 5.36 & $(0.03)$ \\
\hline & 政 & ET (s) & 21.83 & $(0.11)$ & 14.33 & $(0.11)$ & 10.85 & $(0.06)$ & 10.81 & $(0.06)$ & 11.09 & $(0.07)$ & 7.05 & $(0.09)$ \\
\hline
\end{tabular}

Table 1 Inspiration times (IT) of $1000 \mathrm{ml}$ oxygen and egress (ET, expiration time) of the same volume through the $2 \mathrm{~mm}$ ID transtracheal catheter from the lung simulator in simulated upper airway obstruction without any device connected to the transtracheal catheter or with device $\mathrm{B}$ or the Oxygen Flow Modulator (OFM) attached at oxygen flows of 12 or $15 l \cdot \mathrm{min}^{-1}$, respectively. Values are mean (SD). 
Connected to the OFM with all five holes open an oxygen flow of $15 \mathrm{l} \cdot \mathrm{min}^{-1}$ resulted in a PACT of $4.4(0.02) \mathrm{cmH}_{2} \mathrm{O}$, which is identical to earlier findings [11].

\section{Part 2}

At the highest compliance $\left(100 \mathrm{ml} \cdot \mathrm{cmH}_{2} \mathrm{O}^{-1}\right)$ and the lowest resistance $\left(2 \mathrm{cmH}_{2} \mathrm{O} \cdot \mathrm{l}^{-1} \cdot \mathrm{s}^{-1}\right)$ tested, the egress of $1000 \mathrm{ml}$ of oxygen through the transtracheal catheter without any device connected to it took 13.39 (0.03)s (Table 1). The calculated minute volume at an insufflation flow rate of $15 \mathrm{l} \cdot \mathrm{min}^{-1}$ was thus $3.46 \mathrm{l} \cdot \mathrm{min}^{-1}$. Decreasing compliance increased the calculated minute volume to a maximum of $5.591 \cdot \mathrm{min}^{-1}$ (Table 2).

Connecting device $\mathrm{B}$ to the transtracheal catheter resulted in slower expiration and therefore in a decrease of the calculated minute volume depending on the compliances, resistances, and flow rates set. At a compliance of $10 \mathrm{ml} \cdot \mathrm{cmH}_{2} \mathrm{O}^{-1}$ and a resistance of $32 \mathrm{cmH}_{2} \mathrm{O} \cdot \mathrm{l}^{-1} \cdot \mathrm{s}^{-1}$ the maximally achievable minute volume with device $B$ was $3.811 \cdot \mathrm{min}^{-1}$.

Attachment of the OFM to the transtracheal catheter also hindered the egress of gas and increased the expiration

\begin{tabular}{|c|c|c|c|c|c|c|c|c|}
\hline \multirow{2}{*}{\multicolumn{3}{|c|}{$\begin{array}{l}\text { COMPLIANCE }\left(\mathrm{ML} \cdot \mathrm{CMH}_{2} \mathrm{O}^{-1}\right) \\
\text { RESISTANCE }\left(\mathrm{CMH}_{2} \mathrm{O} \cdot \mathrm{L}^{-1} \cdot \mathrm{S}^{-1}\right)\end{array}$}} & 100 & 50 & 30 & 30 & 30 & 10 \\
\hline & & & 2 & 2 & 2 & 0 & 52 & 32 \\
\hline \multirow{8}{*}{$\begin{array}{c}12 \\
1 \cdot \min -1 \text { oxygen }\end{array}$} & \multirow{2}{*}{$\begin{array}{c}\text { no } \\
\text { device }\end{array}$} & $\left(l \cdot \min ^{-1}\right)$ & 3.27 & 3.99 & 4.55 & 4.52 & 4.49 & 4.93 \\
\hline & & I/E-ratio & $1 / 2.68$ & $1 / 1.92$ & $1 / 1.43$ & $1 / 1.48$ & $1 / 1.50$ & $1 / 0.85$ \\
\hline & \multirow{3}{*}{$\begin{array}{c}\text { device } \\
\text { B }\end{array}$} & $\left(l \cdot \min ^{-1}\right)$ & 2.08 & 2.48 & 2.91 & 2.88 & 2.89 & 3.60 \\
\hline & & MV-difference $\left(l \cdot \mathrm{min}^{-1}\right)$ & -1.19 & -1.51 & -1.65 & -1.64 & -1.60 & -1.33 \\
\hline & & I/E-ratio & $1 / 4.79$ & $1 / 3.70$ & $1 / 2.80$ & $1 / 2.88$ & $1 / 2.89$ & $1 / 1.54$ \\
\hline & \multirow{3}{*}{ OFM } & $\left(l \cdot \min ^{-1}\right)$ & 2.43 & 3.14 & 3.76 & 3.73 & 3.74 & 4.39 \\
\hline & & MV-difference $\left(l \cdot \mathrm{min}^{-1}\right)$ & -0.85 & -0.86 & -0.81 & -0.77 & -0.75 & -0.47 \\
\hline & & I/E-ratio & $1 / 4.03$ & $1 / 2.74$ & $1 / 1.97$ & $1 / 1.98$ & $1 / 2.00$ & $1 / 1.03$ \\
\hline \multirow{8}{*}{$\begin{array}{c}15 \\
\text { l-min-1 oxygen }\end{array}$} & \multirow{2}{*}{$\begin{array}{c}\text { no } \\
\text { device }\end{array}$} & $\left(l \cdot \min ^{-1}\right)$ & 3.46 & 4.30 & 5.00 & 4.93 & 4.92 & 5.59 \\
\hline & & I/E-ratio & $1 / 3.37$ & $1 / 2.44$ & $1 / 1.83$ & $1 / 1.86$ & $1 / 1.91$ & $1 / 1.09$ \\
\hline & \multirow{3}{*}{$\begin{array}{c}\text { device } \\
\text { B }\end{array}$} & $\left(l \cdot \min ^{-1}\right)$ & 2.24 & 2.63 & 3.01 & 3.01 & 3.02 & 3.81 \\
\hline & & MV-difference $\left(l \cdot \mathrm{min}^{-1}\right)$ & -1.21 & -1.67 & -2.00 & -1.92 & -1.89 & -1.78 \\
\hline & & I/E-ratio & $1 / 5.73$ & $1 / 4.63$ & $1 / 3.71$ & $1 / 3.69$ & $1 / 3.73$ & $1 / 2.07$ \\
\hline & \multirow{3}{*}{ OFM } & $\left(l \cdot \min ^{-1}\right)$ & 2.33 & 3.24 & 3.97 & 3.98 & 3.90 & 4.84 \\
\hline & & MV-difference $\left(l \cdot \mathrm{min}^{-1}\right)$ & -1.14 & -1.05 & -1.02 & -0.95 & -0.97 & -0.64 \\
\hline & & I/E-ratio & $1 / 5.58$ & $1 / 3.53$ & $1 / 2.54$ & $1 / 2.54$ & $1 / 2.58$ & $1 / 1.31$ \\
\hline
\end{tabular}

Table 2 Calculated achievable minute volumes (MV) and inspiration:expiration ratios (I:E ratios) based on the time needed for insufflation of $1000 \mathrm{ml}$ oxygen and egress of the same volume through the 2-mm ID transtracheal catheter without any device connected to it or with device B or the Oxygen Flow Modulator (OFM) attached at oxygen flows of 12 or $15 \mathrm{l} \cdot \mathrm{min}^{-1}$, respectively. 
time. However, linear regression modelling showed this increase to be significantly lower compared with device $B$ ( $p$ $<0.001$ ). Subsequently, the achievable minute volume with the OFM was higher and a maximal minute volume of 4.84 l. $\mathrm{min}^{-1}$ was calculated (Table 2 ).

\section{Discussion}

In case of an obstructed airway the emergency ventilation technique should ideally act as a bidirectional airway, so that both the delivery of oxygen to the lungs and the egress of respiratory gas can take place via the same lumen. A bidirectional airway requires the backpressure of any ventilation system to be sufficiently low to ensure the egress of gas is not compromised.

As a small lumen catheter or cannula has a high flow resistance, a high driving pressure is needed to achieve adequate gas flow $[9,13,14]$. Our data show that device $A$ and the OFM (so-called flow splitters) will never ensure complete flow and pressure release in between jet injections. Inevitably, this results in a continuous oxygen flow to the patient. Only flow splitters that ensure a low expiratory pressure at the catheter tip (e.g. the OFM) will allow slow exhalation through the transtracheal catheter or cannula $[10,11]$. In the first part of the study, high pressures at the tip of the transtracheal catheter during the expiratory phase were measured when using device $A$. This makes device $A$ an unsuitable and even potentially dangerous device in an obstructed upper airway $[15,16]$. We therefore did not test device A further in the second part of our study.

Changing the connecting position of the transtracheal catheter on the three-way stopcock from the in-line port to the side port (device $B$ ) resulted, by the Venturi effect, in a slightly negative pressure at the catheter's tip. This improves the safety of the self-assembled device B compared to device A.

In contrast to devices that fully block the egress of gas through the catheter during the expiratory phase, such as device A or jet ventilators (e.g. Sander's injector or Manujet), both device $B$ and the OFM can act as a bidirectional airway. As the driving pressure during the expiration is mainly determined by the elasticity of the chest wall, the lung, and the intra-abdominal pressure, only slow egress of gas can be expected via small-bore catheters. The time necessary for the egress of $1000 \mathrm{ml}$ of oxygen via a catheter with an internal diameter of $2 \mathrm{~mm}$ was $>13 \mathrm{~s}$ in case of high compliance, whereas a low compliance assisted expiration considerably.

The concept of expiratory ventilation assistance by suction has already been proven to be effective, also in an obstructed upper airway [17, 18]. However, despite the negative pressure at the tip of device $B$ in a static setting, passive backflow through the transtracheal catheter without any ventilation system connected to it was still quicker, meaning that device $B$ impedes the egress of gas in a dynamic situation instead of supporting expiration.

The apparent explanation is a relatively high inner flow resistance of device $B$, an effect that is stronger than the expiratory support by negative pressure. All devices tested impeded the expiratory outflow and hence the achievable minute volume. Repetitively connecting and disconnecting oxygen tubing and transtracheal catheter resulted in the highest calculated minute volume in every simulated situation. However, in clinical emergencies this is impractical. With regard to the risk of dislodging the transtracheal catheter, a continuously connected ventilation system is preferable, even though the egress of gas via the catheter is com- 
promised. The decrease in minute volume was smallest with the OFM. At a compliance of $50 \mathrm{ml} \cdot \mathrm{cmH}_{2} \mathrm{O}^{-1}$ a minute volume of $3.24 \mathrm{l} \cdot \mathrm{min}^{-1}$ could be achieved with the OFM. Although hypercapnia seems inevitable in this situation, even limited minute ventilation will increase the oxygen content of the lungs and may (slowly) re-establish adequate oxygenation of the patient.

As demonstrated in this study small differences in physical characteristics between emergency jet devices can have huge clinical consequences. Self-assembled devices have mostly not been thoroughly tested (in relation to their physical properties) and although they may resemble working systems in many situations, potential risks may not be immediately apparent. With a simple modification of current proposals [7-9], three-way stopcock based jet devices for emergency jet ventilation can be made safer.

However, regardless of the negative pressure that can be created at the side port by an in-line flow of oxygen through a three-way stopcock, the efficiency of such selfmade devices is disappointing compared with the OFM.

\section{Conflicts of interest and acknowledgements}

D Enk is the inventor of the Oxygen Flow Modulator and receives royalty payments from Cook Medical. The authors would like to thank $M$ Theunissen for competent advice in statistical analysis and $T$ Götz for helpful assistance in data retrieval. 


\section{References}

1. Henderson JJ, Popat MT, Latto IP, Pearce AC. Difficult Airway Society guidelines for management of the unanticipated difficult intubation. Anaesthesia 2004; 59: 675- 94.

2. Caplan RA, Benumof JL, Berry FA, et al. Practice guidelines for the management of difficult airway. An updated report by the American Society of Anesthesiologists Task Force on the Management of the Difficult Airway. Anesthesiology 2003; 98: 1269-77.

3. Patel RG. Percutaneous transtracheal jet ventilation. Chest 1999; 116: 1689-94.

4. Ridgway S, Hodzovic I, Woollard M, Latto IP. Prehospital airway management in Ambulance Services in the United Kingdom. Anaesthesia 2004; 59: 1091-4.

5. Wong DT, Lai K, Chung FF, Ho RY. Cannot intubate - cannot ventilate and difficult intubation strategies: results of a Canadian national survey. Anesthesia and Analgesia 2005; 100: $1439-46$.

6. Scrase I, Woollard M. Needle vs surgical cricothyroidotomy: a short cut to effective ventilation. Anaesthesia 2006; 61: $962-74$.

7. Gal TJ. Airway management. In: Miller RD, ed. Miller's Anesthesia, 6th edn. Philadelphia, PA: Elsevier, 2005: 1637-9.

8. Schaefer R, Hueter L, Preussler NP, Schreiber T, Schwarzkopf K. Percutaneous transtracheal emergency ventilation with a self-made device in an animal model. Pediatric Anesthesia 2007; 17: 972-6.

9. Bould MD, Bearfield P. Techniques for emergency ventilation through a needle cricothyroidotomy. Anaesthesia 2008; 63: 535-9.
10. Hamaekers AE, Borg PA, Enk D. Limitations of self-made jet devices. Pediatric Anesthesia 2008; 18: 983.

11. Hamaekers AE, Borg PA, Enk D. The importance of flow and pressure release in emergency jet ventilation devices. Pediatric Anesthesia 2009; 19: 452-7.

12. Preussler NP, Schreiber T, Hueter L, et al. Percutaneous transtracheal ventilation: effects of a new oxygen flow modulator on oxygenation and ventilation in pigs compared with a hand triggered emergency jet injector. Resuscitation 2003; 56: 329-33.

13. Enk D, Hamaekers AE, Borg PA. Pressure and (flow)meter. Anesthesiology 2009; 110: 1187.

14. Rone CA, Pavlin EG, Cummings CW, Weymuller EA. Studies in transtracheal ventilation catheters. Laryngoscope 1982; 92: 1259-63.

15. Neff CC, Pfister RC, van Sonnenberg E. Percutaneous transtracheal ventilation: experimental and practical aspects. The Journal of Trauma 1983; 23: 84-90.

16. Stothert JC, Stout MJ, Lewis LM, Keltner RM. High pressure percutaneous transtracheal ventilation: the use of large gauge intravenous-type catheters in the totally obstructed airway. American Journal of Emergency Medicine 1990; 8: 184-9.

17. Dunlap LB, Oregon E. A modified, simple device for the emergency administration of percutaneous transtracheal ventilation. Journal of the American College of Emergency Physicians 1978; 7: 42-6.

18. Schapera A, Bainton CR, Kraemer R, Lee K. A pressurized injection / suction system for ventilation in the presence of complete airway obstruction. Critical Care Medicine 1994; 22: 326-33. 


\section{Chapter 4}

\section{The introduction of the concept of Expiratory Ventilation Assistance}




\section{Summary}

Needle cricothyrotomy and subsequent transtracheal jet ventilation (TTJV) is one of the last options to restore oxygenation while managing an airway emergency. However, in cases of complete upper airway obstruction, conventional TTJV is ineffective and dangerous. We transformed a small, industrial ejector into a simple, manual ventilator providing expiratory ventilation assistance (EVA).

An ejector pump was modified to allow both insufflation of oxygen and jet- assisted expiration through an attached $75 \mathrm{~mm}$ long transtracheal catheter (TTC) with an inner diameter (ID) of $2 \mathrm{~mm}$ by alternately occluding and releasing the gas outlet of the ejector pump. In a lung simulator, the modified ejector pump was tested at different compliances and resistances. Inspiration and expiration times were measured and achievable minute volumes (MVs) were calculated to determine the effect of EVA.

The modified ejector pump shortened the expiration time and an MV up to 6.6 $1 \cdot$ min $^{-1}$ could be achieved through a $2 \mathrm{~mm}$ ID TTC in a simulated obstructed airway. The principle of ejector-based EVA seems promising and deserves further evaluation. 


\section{Introduction}

Needle cricothyrotomy is often suggested as a last option to restore oxygenation while managing an airway emergency. The disadvantage of a small lumen cannula, however, is its high resistance to gas flow [1] and hence the need for a high driving pressure to achieve adequate flow. Several types of high-pressure jet ventilators, able to generate an adequate inspiratory flow through a small lumen cannula, are available: for example, the manual Sanders injector or an automated high-frequency jet ventilator. In these ventilation devices, a one-way mechanical valve is incorporated, so only injection of oxygen through the cannula is assured and a patent upper airway is mandatory for the egress of gas. When the upper airway is obstructed, conventional high-pressure jet ventilation results in gas trapping as insufflated oxygen is unable to escape during the expiratory phase, leading to increased end-expiratory intrathoracic pressures, failure to further generate tidal volumes [2], lung damage by over-distension, and haemodynamic instability [3, 4]

In the case of complete upper airway obstruction, an ideal emergency ventilation system would act as a bidirectional airway, so both the injection of oxygen and the egress of gas can take place through the same lumen [5]. The sole driving force for the egress of gas is the respiratory system's compliance, which results from the elasticity of the lungs and the chest wall. Therefore, passive outflow through a small lumen catheter is limited [6].

Dunlap and Oregon [7] in 1978 suggested applying subatmospheric pressures to augment expiration. Several suction devices to support expiration have been introduced since then, but none has found its way into clinical practice, probably because of the complicated technical set-up [8,9].

Bernoulli's [10] principle states that for an inviscid flow of a non-compressible (or, with restrictions, a compressible) fluid, an increase in velocity at a constriction in a tube leads to an increase in dynamic pressure (and thus kinetic energy) and a corresponding decrease in static pressure (and potential energy), obeying the first law of thermodynamics (conservation of energy). An industrial ejector is a multi-purpose device able to create subatmospheric pressure based on Bernoulli's principle. Comparable with a Venturi nozzle, the driving gas flowing through an ejector entrains gas (e.g. ambient air) through a side port [11]. Application of this principle might facilitate expiration through a small lumen catheter.

We adapted a small industrial ejector into a simple, manual ventilation device providing expiratory ventilation assistance (EVA). The aim of this study was to test the capability of this modified ejector to aid in achieving adequate minute ventilation through a $2 \mathrm{~mm}$ ID transtracheal catheter (TTC) in an artificial lung with a completely obstructed upper airway.

\section{Methods}

An industrial ejector (SBP 07, J. Schmalz GmbH, Glatten, Germany) with a $0.7 \mathrm{~mm}$ ID jet orifice (Fig. 1), weighing 7.5 $\mathrm{g}$, was modified to allow both insufflation of oxygen and assisted expiration (Fig. 2A and B). The silencer was removed in order to be able to redirect the flow by occluding the outlet of the ejector. To control the flow to the lung simulator, a T-piece with an extra $4 \mathrm{~mm}$ side hole was attached as a bypass and functioned as an on-off switch. In a pre-test bench study, it was shown that with the side hole open, sufficient flow and pressure release occurs and the device thereby is functionally switched off, with no relevant flows and pres- 
sures acting in the direction of the artificial lung. However, if the side hole is closed, the ejector becomes 'active'. By then simply occluding and releasing the gas outlet of the ejector, either an oxygen flow can be directed to the lung simulator or a subatmospheric pressure can be created (by the Bernoulli principle) to assist expiration. The modified ejector was connected to a pressure-compensated oxygen flow meter (Dräger Medical AG \& Co. KG, Lübeck, Germany) by $4 \mathrm{~mm}$ ID standard silicone tubing.

In an LS800 lung simulator (Dräger Medical AG \& Co. $K G)$, the $M V$ of the modified ejector through a $2 \mathrm{~mm} I D$, $75 \mathrm{~mm}$ long TTC (Cook Medical, Bloomington, IN, USA) in a simulated obstructed upper airway was determined at dif-

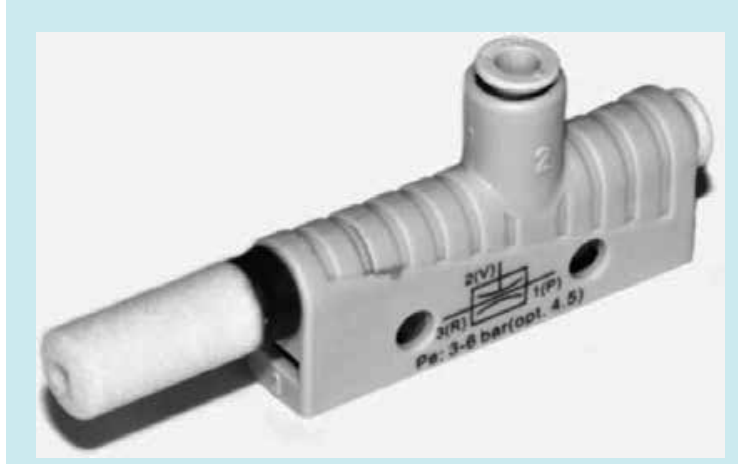

Figure 1 An industrial ejector with a $0.7 \mathrm{~mm}$ ID jet orifice (SBP 07, J. Schmalz GmbH; length $45 \mathrm{~mm}$ without the silencer, weight $7.5 \mathrm{~g}$ ) was modified into an EVA device.

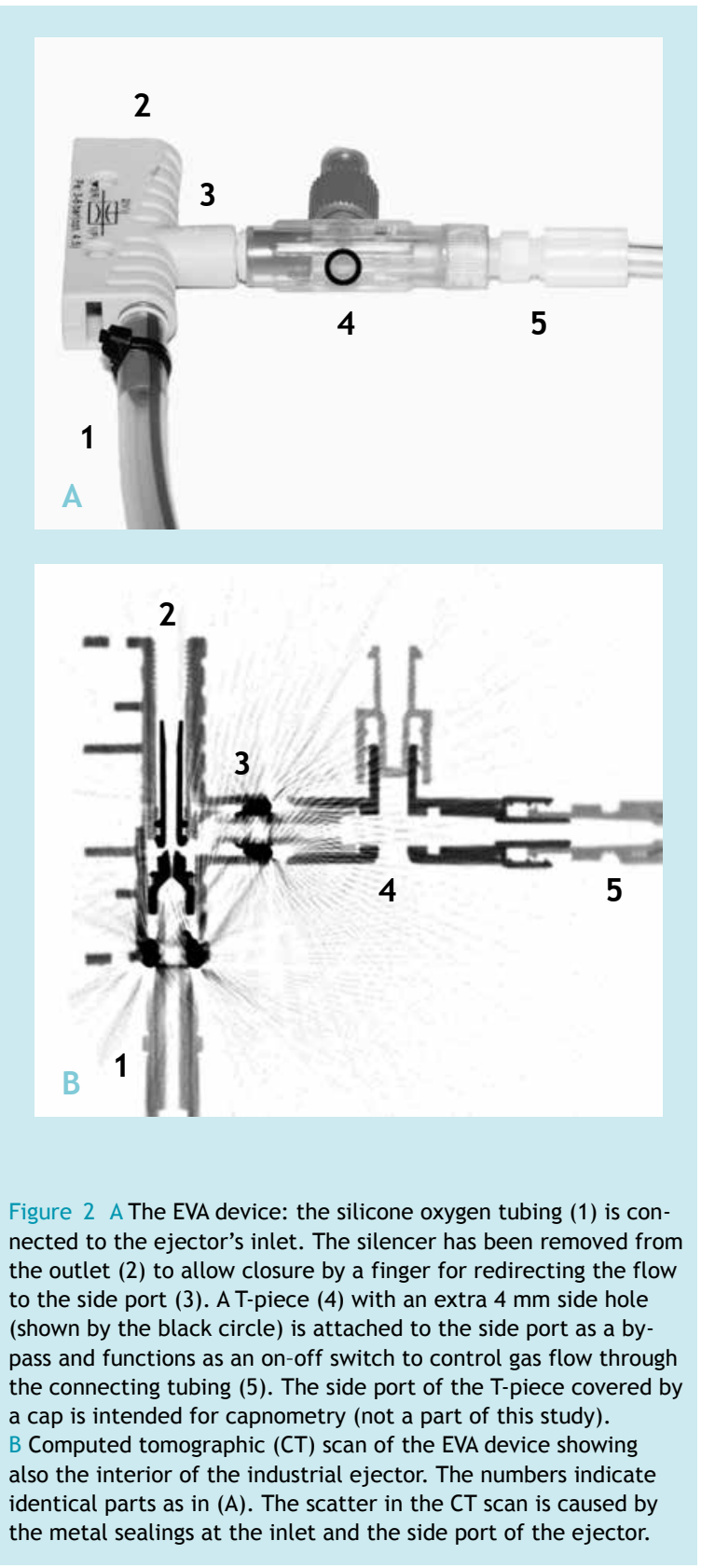

the introduction of the concept of expiratory ventilation assistance 
ferent compliances $\left(100,50,30\right.$, and $\left.10 \mathrm{ml} \cdot \mathrm{cmH}_{2} \mathrm{O}^{-1}\right)$ and resistances $\left(2,8\right.$, and $\left.32 \mathrm{cmH}_{2} \mathrm{O} \cdot \mathrm{l}^{-1} \cdot \mathrm{s}^{-1}\right)$, representing healthy and compromised lungs. The catheter was tightly fitted in the proximal tube orifice of the lung simulator, ensuring that the entire gas flow into and out of the artificial lung was directed through the catheter. The time required for insufflation of $1000 \mathrm{ml}$ of oxygen and the time needed for passive backflow of this volume through the catheter and for assisted expiration were measured at oxygen flows of 12 and $15 \mathrm{l} \cdot \mathrm{min}^{-1}$. Timings were recorded by a second operator using a digital stopwatch while observing the bellows' readings.

At a compliance of 100,50 , and $30 \mathrm{ml} \cdot \mathrm{CmH}_{2} \mathrm{O}^{-1}$, only one bellow of the lung simulator was insufflated. Time meas- urement was started at a bellow volume of $500 \mathrm{ml}$ and, during insufflation on the way to $2000 \mathrm{ml}$, stopped at $1500 \mathrm{ml}$. Owing to high-pressure build-up, both bellows of the lung simulator had to be used at a compliance of $10 \mathrm{ml} \cdot \mathrm{cmH}_{2} \mathrm{O}^{-1}$ to guarantee correct compliance. Using both bellows, 500 $\mathrm{ml}$ was taken as zero and $1000 \mathrm{ml}$ as the endpoint for time measurement. The flow meter was calibrated before the experiments using the Calibration Analyzer series RT-200 pressure and flow monitor (Timeter Instruments Corporation, St Louis, MO, USA). The flow meter reading was checked before each measurement, each test was repeated four times, and minute volumes (MVs) and inspiration/expiration (I/E) ratios were then calculated.

\begin{tabular}{|c|c|c|c|c|c|c|c|c|c|c|c|c|}
\hline 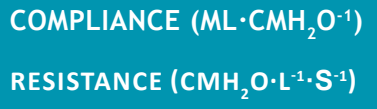 & \multicolumn{2}{|c|}{$\begin{array}{r}100 \\
2\end{array}$} & \multicolumn{2}{|c|}{$\begin{array}{r}50 \\
2\end{array}$} & \multicolumn{2}{|c|}{$\begin{array}{r}30 \\
2\end{array}$} & \multicolumn{2}{|c|}{$\begin{array}{r}30 \\
8\end{array}$} & \multicolumn{2}{|c|}{$\begin{array}{l}30 \\
32\end{array}$} & \multicolumn{2}{|c|}{$\begin{array}{l}10 \\
32\end{array}$} \\
\hline \multicolumn{13}{|l|}{ Flow $121 \cdot \mathrm{min}^{-1}$} \\
\hline Insufflation time (s) & 4.9 & $(0.04)$ & 5.1 & $(0.07)$ & 5.4 & $(0.04)$ & 5.4 & $(0.03)$ & 5.4 & $(0.09)$ & 6.7 & $(0.06)$ \\
\hline Passive backflow (s) & 13.4 & $(0.03)$ & 9.9 & $(0.1)$ & 7.8 & $(0.09)$ & 7.9 & $(0.12)$ & 8.0 & $(0.06)$ & 5.6 & $(0.23)$ \\
\hline Assisted expiration (s) & 5.6 & $(0.04)$ & 5.6 & $(0.07)$ & 5.8 & $(0.03)$ & 5.7 & $(0.02)$ & 5.7 & $(0.03)$ & 6.3 & $(0.05)$ \\
\hline \multicolumn{13}{|l|}{ Flow $15 \mathrm{l} \cdot \mathrm{min}^{-1}$} \\
\hline Insufflation time (s) & 4.0 & $(0.08)$ & 4.1 & $(0.06)$ & 4.3 & $(0.09)$ & 4.3 & $(0.06)$ & 4.2 & $(0.04)$ & 5.4 & $(0.11)$ \\
\hline Passive backflow (s) & 13.4 & $(0.03)$ & 9.9 & $(0.1)$ & 7.8 & $(0.09)$ & 7.9 & $(0.12)$ & 8.0 & $(0.06)$ & 5.6 & $(0.23)$ \\
\hline Assisted expiration (s) & 5.1 & $(0.08)$ & 5.1 & $(0.02)$ & 5.3 & $(0.03)$ & 5.2 & $(0.05)$ & 5.3 & $(0.05)$ & 5.9 & $(0.08)$ \\
\hline
\end{tabular}

Table 1 Mean (SD) times needed for insufflation of $1000 \mathrm{ml}$ oxygen at different compliances and resistances at a flow rate of 12 or $15 \mathrm{l} \cdot \mathrm{min}{ }^{-1}$ and for the same volume of oxygen to egress through a $2 \mathrm{~mm}$ ID TTC passively (passive backflow) or with EVA (assisted expiration). 


\section{Results}

Data are presented as mean (SD). At a compliance of 100 $\mathrm{ml} \cdot \mathrm{CmH}_{2} \mathrm{O}^{-1}$ and a resistance of $2 \mathrm{cmH}_{2} \mathrm{O} \cdot \mathrm{l}^{-1} \cdot \mathrm{s}^{-1}$, the mean (SD) time needed for passive egress of $1000 \mathrm{ml}$ oxygen through the TTC was $13.4(0.03) \mathrm{s}$ (Table 1$)$. A decrease in lung compliance resulted in a faster passive backflow of gas through the TTC and the expiration time decreased to $7.8(0.09) \mathrm{s}$ at a compliance of $30 \mathrm{ml} \cdot \mathrm{cmH}_{2} \mathrm{O}^{-1}$. An increase in resistance had almost no effect at this compliance. At a compliance of $50 \mathrm{ml} \cdot \mathrm{cmH}_{2} \mathrm{O}^{-1}$ and a resistance of $2 \mathrm{cmH}_{2} \mathrm{O} \cdot \mathrm{l}^{-1} \cdot \mathrm{s}^{-1}$ (representing the lungs of a healthy adult), the passive backflow of
$1000 \mathrm{ml}$ through the TTC took $9.9(0.10) \mathrm{s}$. With assisted expiration using the modified ejector, this time was shortened to $5.6(0.07) \mathrm{s}$ at an oxygen flow of $12 \mathrm{l} \cdot \mathrm{min}^{-1}$ and to 5.1 $(0.02) \mathrm{s}$ at $15 \mathrm{l} \cdot \mathrm{min}^{-1}$. This resulted in an increase in the calculated $\mathrm{MV}$ for this pulmonary setting from 4.0 to $5.6 \mathrm{l} \cdot \mathrm{min}^{-1}$ at $12 \mathrm{l} \cdot \mathrm{min}^{-1}$ oxygen flow and from 4.3 to $6.5 \mathrm{l} \cdot \mathrm{min}^{-1}$ at 15 $1 \cdot \min ^{-1}$ respectively (Table 2 ).

However, at a compliance of $10 \mathrm{ml} \cdot \mathrm{cmH}_{2} \mathrm{O}^{-1}$ and a resistance of $32 \mathrm{cmH}_{2} \mathrm{O} \cdot l^{-1} \cdot \mathrm{s}^{-1}$, the modified ejector prolonged the expiration time with $0.7 \mathrm{~s}$ at an oxygen flow of $12 \mathrm{l} \cdot \mathrm{min}^{-1}$ and $0.3 \mathrm{~s}$ at $15 \mathrm{l} \cdot \mathrm{min}^{-1}$ compared with passive expiration.

\begin{tabular}{|c|c|c|c|c|c|c|}
\hline $\begin{array}{l}\text { COMPLIANCE }\left(\mathrm{ML} \cdot \mathrm{CMH}_{2} \mathrm{O}^{-1}\right) \\
\text { RESISTANCE }\left(\mathrm{CMH}_{2} \mathrm{O} \cdot \mathrm{L}^{-1} \cdot \mathrm{S}^{-1}\right)\end{array}$ & $\begin{array}{r}100 \\
2\end{array}$ & $\begin{array}{r}50 \\
2\end{array}$ & $\begin{array}{r}30 \\
2\end{array}$ & $\begin{array}{r}30 \\
8\end{array}$ & $\begin{array}{l}30 \\
32\end{array}$ & $\begin{array}{l}10 \\
32\end{array}$ \\
\hline \multicolumn{7}{|l|}{ Flow $121 \cdot \mathrm{min}^{-1}$} \\
\hline MV $\quad\left(l \cdot \mathrm{min}^{-1}\right.$, passive backflow $)$ & 3.28 & 4.01 & 4.55 & 4.51 & 4.49 & 4.87 \\
\hline (passive backflow) & $1 / 2.72$ & $1 / 1.95$ & $1 / 1.43$ & $1 / 1.47$ & $1 / 1.50$ & $1 / 0.84$ \\
\hline MV $\quad\left(l \cdot \mathrm{min}^{-1}\right.$, assisted expiration $)$ & 5.73 & 5.60 & 5.37 & 5.42 & 5.43 & 4.60 \\
\hline I/E-ratio (assisted expiration) & $1 / 1.13$ & $1 / 1.11$ & $1 / 1.06$ & $1 / 1.05$ & $1 / 1.06$ & $1 / 0.94$ \\
\hline \multicolumn{7}{|l|}{ Flow $15 \mathrm{l} \cdot \mathrm{min}^{-1}$} \\
\hline MV $\quad\left(l \cdot \mathrm{min}^{-1}\right.$, passive backflow $)$ & 3.46 & 4.27 & 4.98 & 4.92 & 4.90 & 5.47 \\
\hline (passive backflow) & $1 / 3.37$ & $1 / 2.39$ & $1 / 1.81$ & $1 / 1.85$ & $1 / 1.89$ & $1 / 1.04$ \\
\hline MV $\quad\left(l \cdot \mathrm{min}^{-1}\right.$, assisted expiration $)$ & 6.64 & 6.46 & 6.24 & 6.34 & 6.33 & 5.32 \\
\hline (assisted expiration) & $1 / 1.27$ & $1 / 1.24$ & $1 / 1.24$ & $1 / 1.22$ & $1 / 1.24$ & $1 / 1.10$ \\
\hline
\end{tabular}

Table 2 Mean calculated MV and I/E ratios achievable through a $2 \mathrm{~mm}$ ID TTC in a simulated obstructed upper airway by passive backflow and assisted expiration using the modified ejector connected to an oxygen flow of 12 or $15 \mathrm{l} \cdot \mathrm{min}^{-1}$. 


\section{Discussion}

Cricothyroidotomy is one of the last options to restore oxygenation while managing a 'cannot intubate, cannot ventilate' (CICV) situation and should be performed without delay $[12,13]$. Introduction of a small-bore catheter or cannula through the cricothyroid membrane is for most anaesthetists the first-choice infraglottic emergency technique [14] as it is simple, quick [15] and widely available. For ventilation through a small lumen catheter, a high-pressure ventilator is mandatory. In experienced hands, this ventilation technique has a low morbidity as long as the egress of gas is secured [16]. However, in a CICV situation, one can never be sure whether an obstructed upper airway will open up or will stay blocked after initiation of high-pressure jet ventilation. Several cases of barotrauma and circulatory collapse due to obstruction of the upper airway during jet ventilation have been reported [17-19] although the majority of barotraumas probably result from partial airway obstruction with overvigorous transtracheal jet ventilation combined with inadequate expiratory pause. The ideal ventilation system in this setting would act as a bidirectional airway, so both the delivery of oxygen to and the egress of gas from the lungs are controlled.

When an airway catheter is restricted below a critical diameter, exhalation time becomes rapidly prolonged [6]. In our study, the time needed for passive backflow of $1000 \mathrm{ml}$ oxygen through the $2 \mathrm{~mm}$ ID TTC was $13.4 \mathrm{~s}$ at a compliance of $100 \mathrm{ml} \cdot \mathrm{cmH}_{2} \mathrm{O}^{-1}$. One option to accelerate expiration when the upper airway is obstructed is to establish a separate egress pathway by the insertion of an additional transtracheal cannula (preferably large bore).

However, this is not always feasible. Alternatively, the egress of gas through a single, small-lumen catheter can be facilitated by applying suction. Several techniques to apply subatmospheric pressure have been proposed in the past. Dunlap and Oregon demonstrated the efficacy of a thumb-operated three-way valve (actually a simple T-piece) attached to a connector for piped oxygen [7]. Oxygen was insufflated at a rate of $800 \mathrm{ml} \cdot \mathrm{s}^{-1}$ and respiratory gas could be withdrawn from the trachea at about $185 \mathrm{ml} \cdot \mathrm{s}^{-1}(11.1$ $\left(\cdot \min ^{-1}\right)$. Unfortunately, the oxygen consumption for suctioning was very high (almost $\left.50 \mathrm{l} \cdot \mathrm{min}^{-1}\right)$ and the oxygen flow was difficult to control: in both dogs and post-mortem humans s.c. emphysema was described. The computer-controlled pressurized injection/suction ventilation device equipped with separate, highly pressurized injection and suction tubings described by Schapera and colleagues [8] efficiently maintained pulmonary gas exchange in $25-35 \mathrm{~kg}$ dogs through a $2.5 \mathrm{~mm} I D, 45 \mathrm{~cm}$ long ventilating stylet for more than 15 min during a period of total occlusion of the airway except for the passage offered by the catheter. Adequate tidal volumes were also achieved by the 'total laryngeal bypass device', which had an inner cannula to provide high pressure oxygen insufflation and an outer cannula through which suction was applied throughout both inspiratory and expiratory phase [9].

However, none of the above-mentioned techniques and devices found its way into clinical practice, probably because of specific drawbacks and requirements (high oxygen demand, complex set-up, and/or bulky equipment).

Our modified ejector ventilator is portable and ready to use after simply connecting it to a pressure compensated flow meter set at an oxygen flow of $12-15 l \cdot \mathrm{min}^{-1}$. In a simulated upper airway obstruction, an MV of up to $6.61 \cdot \mathrm{min}^{-1}$ can be achieved through a $2 \mathrm{~mm}$ ID TTC over a broad range of different pulmonary conditions. 
Furthermore, gas flow to and from the TTC can easily be controlled by the integrated on-off switch.

We appreciate the limitations of applying results from this simplified in vitro model into clinical practice. The effects of EVA on gas exchange, circulation, and lung tissue have not been studied. Additional in vivo experiments should elucidate this.

Small, industrial ejectors are designed to pick up and hold parts until these are, for example, dropped into feeders of automated assembly lines. These ejectors cannot be expected to work perfectly as a ventilator. As the data demonstrate, the modified ejector/ventilator works most effectively at high compliances. At lower compliances, expiratory assistance becomes less effective, and at a compliance of $10 \mathrm{ml} \cdot \mathrm{cmH}_{2} \mathrm{O}^{-1}$, the ejector does not support expiration, but even slightly prolongs the expiration time. Possible explanations are the build-up of high pressure (up to 100 mbar) in the artificial lung during the inspiratory phase in this extreme setting and a disturbed way of gas egress from the ejector caused by turbulent mixing of the jet flow with the gas pressed back into the ejector by low compliance during the expiratory phase. However, redesigning the ejector might solve this problem.

The principle of expiratory assistance during jet ventilation is not new, although different expressions have been used to describe the concept. The tested modified ejector is, however, the first device that is simple and portable, will work with an oxygen cylinder at flows of 12 to $15 \mathrm{l} \cdot \mathrm{min}^{-1}$ and is capable of achieving an adequate MV through a $2 \mathrm{~mm} I D$ TTC even in the case of an obstructed upper airway. Nevertheless, improvement of the design seems to be required and further in vivo evaluation of the efficiency and safety of EVA is needed.

\section{Acknowledgements}

The authors would like to thank J.E. Wildberger, Department of Radiology, Maastricht University Medical Centre, for the CT scan of the expiratory ventilation assisting device and S. Enk for helpful assistance in preparing the photographs. 


\section{References}

1. Bougas TP, Cook CD. Pressure-flow characteristics of needles suggested for transtracheal resuscitation. $N$ Engl $J$ Med 1960; 262: 511-3

2. Craven RM, Vanner RG. Ventilation of a model lung using various cricothyrotomy devices. Anaesthesia 2004; 59: 595-9

3. Neff CC, Pfister RC, Van Sonnenberg E. Percutaneous transtracheal ventilation: experimental and practical aspects. J Trauma 1983; 23: 84-90

4. Stothert JC Jr, Stout MJ, Lewis LM, Keltner RM Jr. High pressure percutaneous transtracheal ventilation: the use of large gauge intravenous-type catheters in the totally obstructed airway. Am J Emerg Med 1990; 8: 184-9

5. Hamaekers AE, Borg PA, Enk D. A bench study of ventilation via two self-assembled jet devices and the Oxygen Flow Modulator in simulated upper airway obstruction. Anaesthesia 2009; 64: 1353-8

6. Rone CA, Pavlin EG, Cummings CW, Weymuller EA. Studies in transtracheal ventilation catheters. Laryngoscope 1982; 92: $1259-64$

7. Dunlap LB, Oregon E. A modified, simple device for the emergency administration of percutaneous transtracheal ventilation. J Am Coll Emerg Physicians 1978; 7: 42-6

8. Schapera A, Bainton CR, Kraemer R, Lee K. A pressurized injection/ suction system for ventilation in the presence of complete airway obstruction. Crit Care Med 1994; 22: 326-33

9. Garry B, Woo P, Perrault DF Jr, Shapshay SM, Wurm WH. Jet ventilation in upper airway obstruction: description and model lung testing of a new jetting device. Anesth Analg 1998; 87: 915-20

10. Bernoulli D. Hydrodynamica, sive De viribus et motibus fluidorum commentarii. Opus academicum ab auctore, dum Petropoli ageret, congestum. Strasbourg: Johann Reinold Dulsecker, 1738
11. Fluid flow. In: Davis PD, ed. Basic Physics and Measurement in Anaesthesia, 5th Edn. Philadelphia, PA: Elsevier, 2007; $19-20$

12. Henderson JJ, Popat MT, Latto IP, Pearce AC. Difficult Airway Society guidelines for management of the unanticipated difficult intubation. Anaesthesia 2004; 59: 675-94

13. Caplan RA, Benumof JL, Berry FA, et al. Practice guidelines for the management of difficult airway. An updated report by the American Society of Anesthesiologists Task Force on the Management of the Difficult Airway. Anesthesiology 2003; 98: 1269-77

14. Wong DT, Lai K, Chung FF, Ho RY. Cannot intubate-cannot ventilate and difficult intubation strategies: results of a Canadian national survey. Anesth Analg 2005; 100: 1439-46

15. Patel RG. Percutaneous transtracheal jet ventilation. Chest 1999; 116: 1689-94

16. Jaquet $\mathrm{Y}$, Monnier P, Van Melle G, Ravussin P, Spahn DR, Chollet-Rivier M. Complications of different ventilation strategies in endoscopic laryngeal surgery: a 10-year review. Anesthesiology 2006; 104: 52-9

17. Craft TM, Chambers PH, Ward ME, Goat VA. Two cases of barotrauma associated with transtracheal jet ventilation. Br J Anaesth 1990; 64: 524-7

18. Cook TM, Bigwood B, Cranshaw J. A complication of transtracheal jet ventilation and use of the Aintree intubation catheter during airway resuscitation. Anaesthesia 2006; 61: $692-7$

19. Hardy MJ, Huard C, Lundblad TC. Bilateral tension pneumothorax during jet ventilation: a case report. AANA $J$ 2000; 68: $241-4$ 
72 


\section{Chapter 5}

\section{Optimizing Expiratory Ventilation Assistance}

Ventilation through a small-bore catheter: optimizing expiratory ventilation assistance.

Ankie Hamaekers MD, Thomas Götz, Pieter Borg DA and Dietmar Enk MD PhD

Published in Br J Anaesth 2011, 106:403-409 


\section{Summary}

Emergency ventilation through a small-bore transtracheal catheter can be lifesaving in a 'cannot intubate, cannot ventilate' situation. Ejectors, capable of creating suction by the Bernoulli principle, have been proposed to facilitate expiration through small-bore catheters. In this bench study, we compared a novel, purpose-built ventilation ejector (DE 5) with a previously proposed, modified industrial ejector (SBP 07).

The generated insufflation pressures, suction pressures in static and dynamic situations, and also suction capacities and entrainment ratios of the SBP 07 and the DE 5 were determined. The DE 5 was also tested in a lung simulator with a simulated complete upper airway obstruction. Inspiratory and expiratory times through a transtracheal catheter were measured at various flow rates and achievable minute volumes were calculated.

In a static situation, the SBP 07 showed a more negative pressure build-up compared with the DE 5. However, in a dynamic situation, the DE 5 generated a more negative pressure, resulting in a higher suction capacity. Employment of the DE 5 at a flow rate of $181 \cdot \mathrm{min}^{-1}$ allowed a minute volume through the transtracheal catheter of up to $8.27 \mathrm{l} \cdot \mathrm{min}^{-1}$ at a compliance of $100 \mathrm{ml} \cdot \mathrm{CmH}_{2} \mathrm{O}^{-1}$. The efficiency of the DE 5 depended on the flow rate of the driving gas and the compliance of the lung simulator.

In laboratory tests, the DE 5 is an optimized ventilation ejector suitable for applying expiratory ventilation assistance. Further research may confirm the clinical applicability as a portable emergency ventilator for use with small-bore catheters. 
Needle cricothyroidotomy with subsequent transtracheal jet ventilation is one of the last options to restore oxygenation in a 'cannot intubate, cannot ventilate' (CICV) situation [1]. One of the problems associated with jet ventilation is the difficulty in controlling expiration. Outflow of gas has to take place passively through the upper airway. In a CICV situation, one can never be sure whether an obstructed upper airway will open up or will stay blocked after initiation of high-pressure jet ventilation. Obstruction of the outflow tract, insufficient expiratory time, or both can result in air trapping with subsequent barotrauma and haemodynamic instability [2-4]. Oedema, laryngospasm, and the presence of surgical instruments have all been reported to compromise the outflow of gas $[3,5,6]$.

Time needed for passive backflow of gas depends on the resistance of the outflow tract (determined by its diameter and length) and on the driving force (determined by the compliance of the respiratory system which results from the elasticity of the lungs and the chest wall). If the diameter of the natural or artificial airway is restricted below a critical point ( $4 \mathrm{~mm}$ usually being considered as the cut-off point), exhalation time is prolonged exponentially [7]. Air trapping becomes a real danger if the expiratory time in relation to the diameter and length of the outflow tract is too short [8, 9]. Changing the I:E ratio only provides a partial solution to the problem.

A bidirectional ventilatory system that requires only a small-bore airway catheter for both the delivery of oxygen to the lungs and the outflow of gas could completely solve the above-mentioned problems associated with jet ventilation. Application of jet flow generated suction has been proposed to facilitate expiration through large-bore [10] and small-bore paediatric tracheal tubes [11]. Although directly addressing the concern about using jet ventilation in the presence of airway obstruction, other ventilation concepts for adult patients applying suction to small-bore catheters have not found their way into clinical practice [12-14].

Recently, we described a modified industrial ejector (SBP 07) using expiratory ventilation assistance (EVA) based on the Bernoulli principle [15]. Although a minute volume of up to $6 \mathrm{l} \cdot \mathrm{min}^{-1}$ could be achieved through a $75 \mathrm{~mm}$ long, 2 $\mathrm{mm}$ ID transtracheal catheter, this industrial ejector is not specified for ventilation but has been designed to create a maximum negative pressure to pick up and hold parts during industrial manufacturing processes. Therefore, we developed and tested in several bench studies a novel ejector-based ventilation device (DE 5) designed to provide an optimized entrainment effect for EVA [16].

The aims of this study were to compare the generated pressures, suction capacities, and entrainment ratios of the modified SBP 07 and the DE 5 and to determine the achievable minute volumes through a small-bore catheter in a simulated obstructed upper airway.

\section{Methods}

The modified SBP 07 (Figs $1 \mathrm{~A}$ and 2A) has been described previously [15]. The modification of the original industrial device involved both removal of the silencer and connection of a modified T-piece as a flow control unit. The DE 5 consists of a specifically designed ejector with a $0.7 \mathrm{~mm}$ jet needle and an identical T-piece (Figs $1 \mathrm{~B}$ and $2 \mathrm{~B}$ ). The driving gas, coming from a calibrated, pressure-compensated oxygen flow meter, is highly accelerated by being forced through the jet needle and creates a negative pressure downstream of this needle. This effect is based on the Bernoulli principle and results in entrainment of gas through the side port 

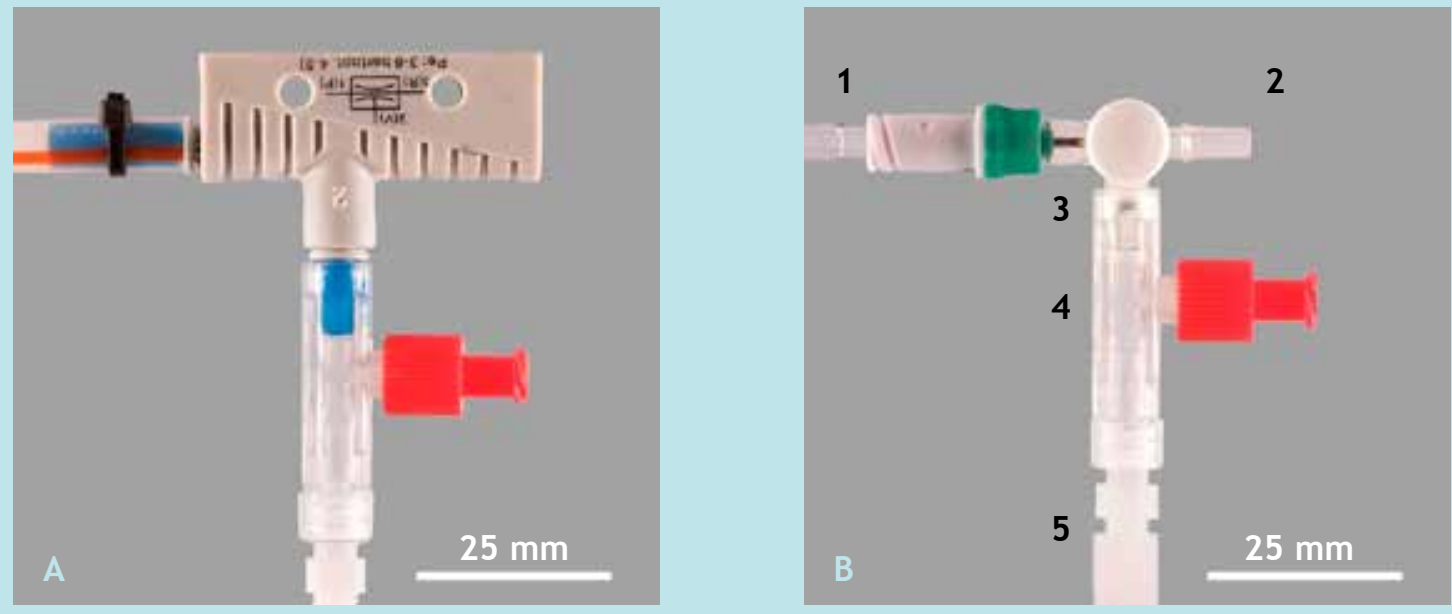

Figure 1 A The modified industrial SBP 07 as previously described [15]. Silicone oxygen tubing from a pressure-compensated flow meter is attached to the ejector's inlet. The silencer has been removed from the outlet to allow closure by a finger for redirecting the flow to the side port. A T-piece with an extra $4 \mathrm{~mm}$ side hole at the lateral surface (not visible in this picture) is attached to the side port as a bypass. This side hole functions as an on/off switch to control gas flow through the connecting tubing to the transtracheal catheter.

B The ventilationejector DE 5: silicone oxygen tubing from a pressure-compensated flow meter is connected to the ejector's inlet (1). Gas

flow is directed through a $0.7 \mathrm{~mm} \mathrm{ID}$ jet needle to the outlet (2). Closure of the outlet ( jet/EVA switch) by the finger allows redirection of the flow to the side port (3). The T-piece with the extra $4 \mathrm{~mm}$ side hole (4) and the connecting tubing (5) are identical to those of the SBP 07.
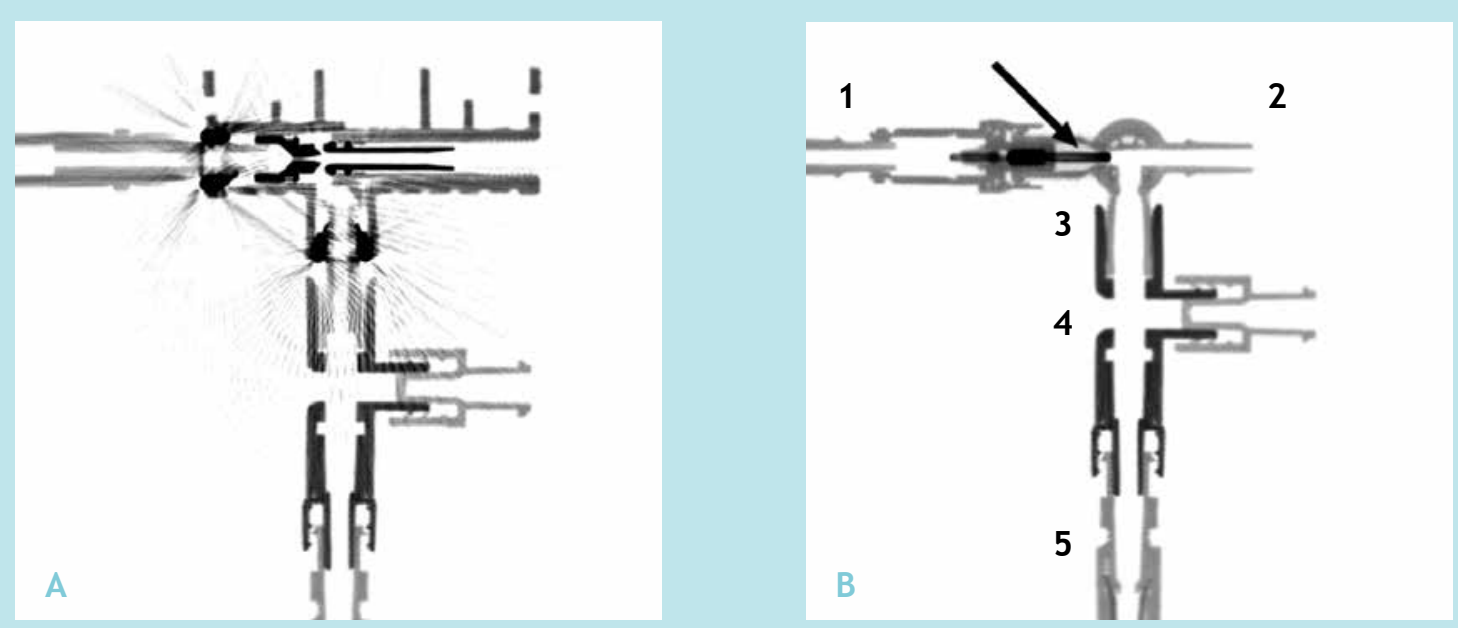

Figure 2 A CT scan of the modified SBP 07 . The orientation is the same as in Figure 1A. The scatter is produced by metal parts of the SBP 07. B CT scan of the DE 5. The orientation is the same and the numbers refer to identical structures as in Figure $1 \mathrm{~B}$. The outflow pipe with the jet/EVA switch (2) and the on/off switch (4) can clearly be identified. The arrow indicates the $0.7 \mathrm{~mm}$ ID jet needle. 
( 3 in Figs 1B and 2B). By simply occluding the outlet (jet/EVA switch; 2 in Figs $1 B$ and $2 B$ ) of the ejector, the oxygen flow can be redirected to the transtracheal catheter (connected to 5 in Figs $1 \mathrm{~B}$ and $2 \mathrm{~B}$ ).

To control the expiratory and inspiratory flows, a T-piece (part number 84048, Qosina, Edgewood, NY, USA) with an extra $4 \mathrm{~mm}$ side hole (on/off switch; 4 in Figs 1B and $2 \mathrm{~B}$ ) is attached to the side port of the ejector and functions as the flow control unit of the ventilation device.

In a pre-test bench study, it was shown that with the on/ off switch open, sufficient flow and pressure release is established and both the SBP 07 and the DE 5 thereby are functionally switched off, with no relevant flows and pressures acting downstream of the flow control unit. However, if the on/off switch is closed, the ejectors become active. By then alternately occluding and releasing the jet/EVA switch, either the oxygen flow is directed to the transtra- cheal catheter or a subatmospheric pressure is created to assist expiration (Fig. 3A and B).

\section{Part 1: insufflation and suction pressures}

In the first part of our study, the generated pressures of the modified SBP 07 and the DE 5 were studied. Both ejectors were connected to a calibrated, pressure-compensated flow meter (Dräger Medical AG \& Co. KG, Lübeck, Germany) and attached to a transtracheal catheter $(75 \mathrm{~mm}$ length, $2 \mathrm{~mm}$ ID; Cook Medical, Bloomington, IN, USA) by a $15 \mathrm{~cm}$ long, $3 \mathrm{~mm}$ ID connecting tubing including a distal T-piece (see Fig. S1 in the Supplementary material at British Journal of online).

At oxygen flows of $6,9,12,15$, and $18 \mathrm{l} \cdot \mathrm{min}^{-1}$, the insufflation and suction pressures were measured at the distal T-piece, while simulating a static (no gas entrainment with the catheter tip closed) and a dynamic situation (continuous

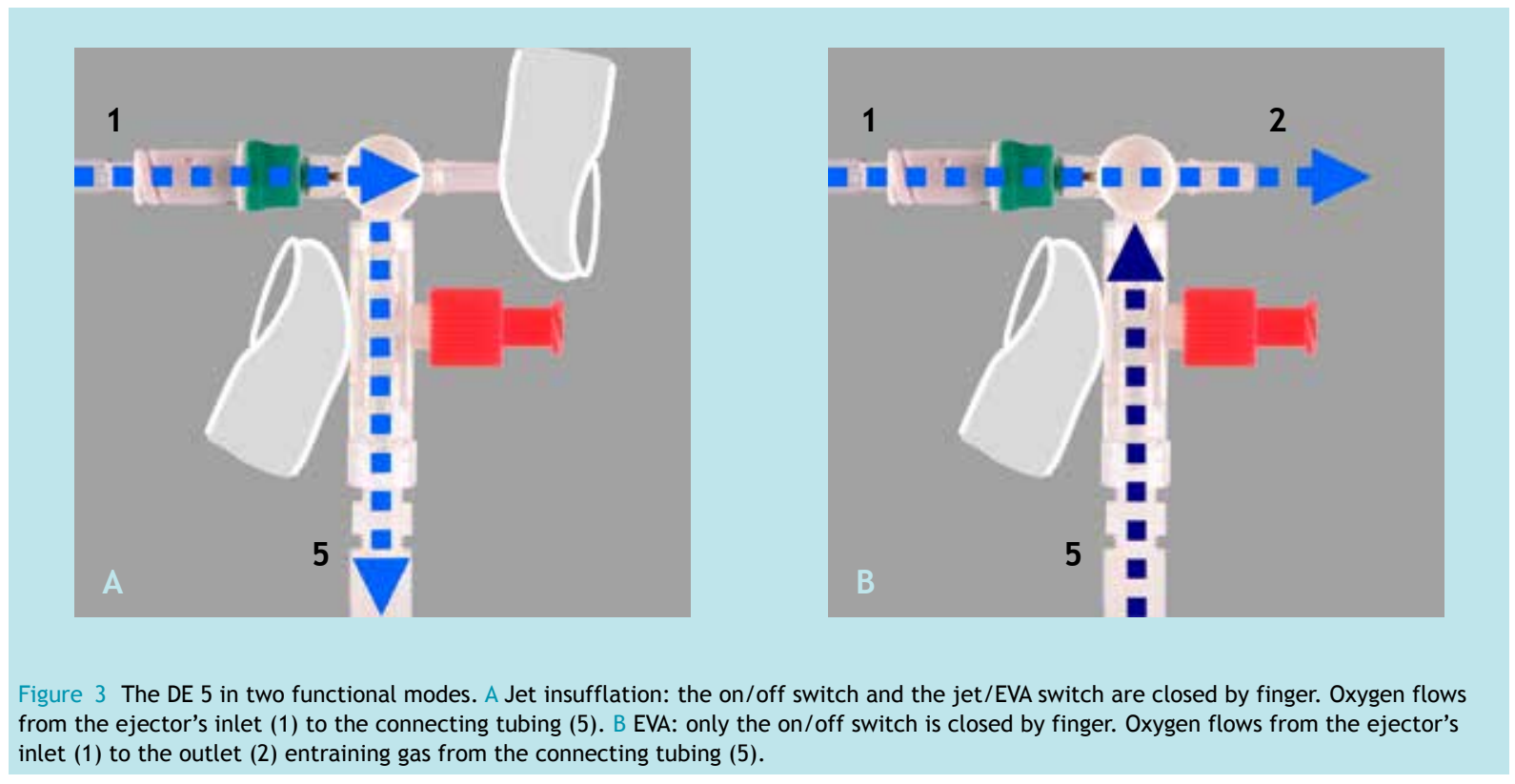




\begin{tabular}{|c|c|c|c|c|c|c|c|c|c|}
\hline \multirow[b]{2}{*}{ SBP 07} & \multirow{2}{*}{$\begin{array}{c}\text { FLOW } \\
\left(L \cdot M I N^{-1}\right) \\
6\end{array}$} & \multicolumn{2}{|c|}{$\begin{array}{l}\text { PINSP } \\
\left(\mathrm{CMH}_{2} \mathrm{O}\right)\end{array}$} & \multicolumn{2}{|c|}{$\begin{array}{l}\text { PSTAT } \\
\left(\mathrm{CMH}_{2} 0\right)\end{array}$} & \multicolumn{2}{|c|}{$\begin{array}{l}\text { PDYN } \\
\left(\mathrm{CMH}_{2} \mathrm{O}\right)\end{array}$} & \multirow{2}{*}{$\begin{array}{c}\mathrm{SC} \\
\left(\mathrm{L} \cdot \mathrm{MIN}^{-1}\right) \\
4.1\end{array}$} & \multirow{2}{*}{$\begin{array}{c}\text { ER } \\
0.68\end{array}$} \\
\hline & & 19.4 & $(0.24)$ & -53.8 & (1.14) & 9.8 & $(0.14)$ & & \\
\hline & 9 & 43.6 & $(0.38)$ & -196.1 & (1.23) & -31.3 & $(0.21)$ & 7.8 & 0.87 \\
\hline & 12 & 75.4 & $(0.41)$ & -377.3 & (0) & -51.0 & $(0.29)$ & 10.1 & 0.84 \\
\hline & 15 & 113.0 & $(0.32)$ & -540.4 & (0) & -63.1 & $(0.14)$ & 11.4 & 0.76 \\
\hline & 18 & 148.8 & $(0.71)$ & -660.3 & (5.1) & -70.4 & $(0.24)$ & 12.5 & 0.69 \\
\hline \multirow[t]{5}{*}{ DE 5} & 6 & 19.8 & $(0.39)$ & -70.6 & $(0.92)$ & -22.9 & $(0.43)$ & 6.8 & 1.13 \\
\hline & 9 & 43.7 & $(0.1)$ & -161.9 & $(0.54)$ & -49.0 & $(0.38)$ & 10.2 & 1.13 \\
\hline & 12 & 75.5 & $(0.41)$ & -263.5 & $(0.75)$ & -76.4 & $(0.34)$ & 12.6 & 1.05 \\
\hline & 15 & 110.9 & $(0.5)$ & -346.7 & (0) & -94.7 & $(0.23)$ & 14.3 & 0.95 \\
\hline & 18 & 147.2 & $(2.06)$ & -400.2 & (5.1) & ${ }^{-1} 08.5$ & $(0.19)$ & 15.9 & 0.88 \\
\hline
\end{tabular}

Table 1 Results of Part 1: insufflation and suction pressures and Part 2: suction capacities and entrainment ratios. Pinsp, Pstat, and Pdyn indicate pressures during inspiration and during expiration in a static situation (no gas entrainment with the catheter tip closed) and a dynamic situation (continuous gas entrainment with the catheter tip open to the atmosphere), respectively, using flow rates of $6-18 \mathrm{l} \cdot \mathrm{min}^{-1}$. Data given as mean (SD). Suction capacity (SC) and entrainment ratio (ER 1/4entrained flow/driving flow) are calculated values.

gas entrainment with the catheter tip open to the atmosphere). Four repetitive pressure measurements were done using the Calibration Analyzer series RT-200 (Timeter Instrument Corporation, St Louis, MO, USA). Before each measurement, the flow meter reading was checked.

\section{Part 2: suction capacities and entrainment ratios}

The suction capacities and entrainment ratios (= entrained flow/driving flow) of both devices through the $75 \mathrm{~mm}$ long, $2 \mathrm{~mm}$ ID transtracheal catheter were determined at oxygen flows of $6,9,12,15$, and $18 l \cdot \mathrm{min}^{-1}$ by insufflation and desufflation of a common 35 litre plastic garbage bag (product number 136146, Albert Heijn, Zaandam, The Netherlands) as a closed ventilation model with an infinite compliance. Four repetitive trials were performed by insufflating the plastic bag for $1 \mathrm{~min}$ and measuring the time it took to completely empty the bag by suction.

\section{Part 3: inspiratory and expiratory times and minute volumes}

In the third part of the study, the efficacy of the DE 5 at different pulmonary compliances and resistances was tested in an LS800 lung simulator (Dräger Medical AG \& Co. KG) with a simulated complete upper airway obstruction. The $75 \mathrm{~mm}$ long, $2 \mathrm{~mm}$ ID transtracheal catheter was tightly fitted in the proximal tube orifice of the lung simulator ensuring that the entire gas flow into and out of the bellows was guided through the catheter.

To determine minute volumes, the times required for insufflation of $1000 \mathrm{ml}$ of oxygen and the times needed for passive backflow of this volume through the catheter and for assisted expiration using the DE 5 were measured as previously described [15]. Four repetitive tests were performed at different compliances $\left(100,50,30\right.$, and $\left.10 \mathrm{ml} \cdot \mathrm{cmH}_{2} \mathrm{O}^{-1}\right)$, resistances (2 and $32 \mathrm{cmH}_{2} \mathrm{O} \cdot \mathrm{l}^{-1} \cdot \mathrm{s}^{-1}$ ), and different oxygen flows $\left(6,9,12,15\right.$, and $18\left(\cdot \mathrm{min}^{-1}\right)$. 


\begin{tabular}{|c|c|c|c|c|c|c|c|c|c|c|}
\hline $\begin{array}{l}\text { COMPLIANCE }\left(\mathrm{ML} \cdot \mathrm{CMH}_{2} \mathrm{O}^{-1}\right) \\
\text { RESISTANCE }\left(\mathrm{CMH}_{2} \mathrm{O} \cdot \mathrm{L}^{-1} \cdot \mathrm{S}^{-1}\right)\end{array}$ & \multicolumn{2}{|c|}{$\begin{array}{r}100 \\
2\end{array}$} & \multicolumn{2}{|c|}{$\begin{array}{r}50 \\
2\end{array}$} & \multicolumn{2}{|c|}{$\begin{array}{r}30 \\
2\end{array}$} & \multicolumn{2}{|c|}{$\begin{array}{l}30 \\
32\end{array}$} & \multicolumn{2}{|c|}{$\begin{array}{l}10 \\
32\end{array}$} \\
\hline \multicolumn{11}{|l|}{ Inspiratory time (s) } \\
\hline $61 \cdot \mathrm{min}^{-1}$ & 10.2 & $(0.03)$ & 10.6 & $(0.09)$ & 11.2 & $(0.04)$ & 11.2 & $(0.08)$ & 14.1 & $(0.12)$ \\
\hline $91 \cdot \mathrm{min}^{-1}$ & 6.7 & $(0.05)$ & 6.9 & $(0.04)$ & 7.3 & $(0.03)$ & 7.3 & $(0.03)$ & 9.1 & $(0.30)$ \\
\hline $12 l \cdot \mathrm{min}^{-1}$ & 5.0 & $(0.05)$ & 5.1 & $(0.07)$ & 5.4 & $(0.02)$ & 5.3 & $(0.09)$ & 6.7 & $(0.08)$ \\
\hline $15 l \cdot \mathrm{min}^{-1}$ & 4.0 & $(0.06)$ & 4.2 & $(0.03)$ & 4.4 & $(0.11)$ & 4.4 & $(0.05)$ & 5.4 & $(0.04)$ \\
\hline $18 \mathrm{l} \cdot \mathrm{min}^{-1}$ & 3.4 & $(0.03)$ & 3.6 & $(0.02)$ & 3.8 & $(0.04)$ & 3.7 & $(0.04)$ & 4.6 & $(0.04)$ \\
\hline Expiratory time passive (s) & 13.4 & $(0.03)$ & 9.9 & $(0.10)$ & 7.8 & $(0.09)$ & 8.0 & $(0.06)$ & 5.6 & $(0.23)$ \\
\hline \multicolumn{11}{|l|}{ Expiratory time EVA (s) } \\
\hline $6 l \cdot \min ^{-1}$ & 8.0 & $(0.10)$ & 7.7 & $(0.06)$ & 7.23 & $(0.06)$ & 7.3 & $(0.06)$ & 6.7 & $(0.07)$ \\
\hline $91 \cdot \mathrm{min}^{-1}$ & 5.6 & $(0.06)$ & 5.6 & $(0.05)$ & 5.5 & $(0.10)$ & 5.6 & $(0.07)$ & 5.6 & $(0.04)$ \\
\hline $12 l \cdot \mathrm{min}^{-1}$ & 4.5 & $(0.09)$ & 4.5 & $(0.06)$ & 4.5 & $(0.02)$ & 4.5 & $(0.05)$ & 4.9 & $(0.20)$ \\
\hline $151 \cdot \min ^{-1}$ & 4.0 & $(0.07)$ & 4.1 & $(0.03)$ & 4.1 & $(0.01)$ & 4.1 & $(0.04)$ & 4.4 & $(0.17)$ \\
\hline $18 \mathrm{l} \cdot \mathrm{min}^{-1}$ & 3.9 & $(0.06)$ & 4.0 & $(0.02)$ & 4.1 & $(0.03)$ & 4.1 & $(0.02)$ & 4.5 & $(0.06)$ \\
\hline
\end{tabular}

Table 2 Results of Part 3: inspiratory and expiratory times. Times needed for insufflation of 1 litre oxygen at different compliances and resistances using flow rates of $6-18 \mathrm{l} \cdot \mathrm{min}^{-1}$ and for the same volume to egress through the $75 \mathrm{~mm}$ long, $2 \mathrm{~mm}$ ID transtracheal catheter passively (expiratory time passive) or with expiratory ventilation assistance (expiratory time EVA). Data are given as mean (SD).

\section{Statistical analysis}

For descriptive statistics, MS-Excel 2002 SP3 was used. Results are presented as mean (SD). Suction capacities, entrainment ratios, and achievable minute volumes were calculated.

\section{Results}

\section{Part 1: insufflation and suction pressures}

The modified SBP 07 and the DE 5 generated similar insufflation pressures proportional to the flow rate of the driving gas (Table 1). Subatmospheric pressures in both the static and the dynamic settings were proportional to the flow rate of the driving gas. In all static situations, except at a flow rate of $6 l \cdot \mathrm{min}^{-1}$, the subatmospheric pressure generated by the $\mathrm{DE} 5$ was less negative compared with that generated by the SBP 07 at the same flow rate. However, in all dynamic situations, the DE 5 maintained a more negative pressure.

\section{Part 2: suction capacities and entrainment ratios}

The suction capacity of the DE 5 was higher compared with that of the SBP 07 and ranged from 6.8 to $15.91 \cdot \mathrm{min}^{-1} \mathrm{de}$ pending on the flow rate of the driving gas (Table 1 ). Consequently, also the entrainment ratio of the DE 5 was higher than that of the SBP 07 at all flow rates.

\section{Part 3: inspiratory and expiratory times and} minute volumes

Applying EVA using the DE 5 at a flow rate of $61 \cdot \mathrm{min}^{-1}$ resulted, at a compliance of $100 \mathrm{ml} \cdot \mathrm{cmH}_{2} \mathrm{O}^{-1}$ and a resistance of 


\begin{tabular}{|c|c|c|c|c|c|}
\hline $\begin{array}{l}\text { COMPLIANCE }\left(\mathrm{ML}^{\mathrm{C}} \mathrm{CMH}_{2} \mathrm{O}^{-1}\right) \\
\text { RESISTANCE }\left(\mathrm{CMH}_{2} \mathrm{O} \cdot \mathrm{L}^{-1} \cdot \mathrm{S}^{-1}\right)\end{array}$ & $\begin{array}{r}100 \\
2\end{array}$ & $\begin{array}{r}50 \\
2\end{array}$ & $\begin{array}{r}30 \\
2\end{array}$ & $\begin{array}{l}30 \\
32\end{array}$ & $\begin{array}{l}10 \\
32\end{array}$ \\
\hline \multicolumn{6}{|l|}{$6 l \cdot \min -1$} \\
\hline MV passive $\left(l \cdot \mathrm{min}^{-1}\right)$ & 2.55 & 2.92 & 3.17 & 3.13 & 3.04 \\
\hline MV EVA $\left(l \cdot \mathrm{min}^{-1}\right)$ & 3.30 & 3.27 & 3.26 & 3.25 & 2.87 \\
\hline$\Delta M V\left(l \cdot \mathrm{min}^{-1}\right)$ & 0.75 & 0.35 & 0.09 & 0.12 & -0.17 \\
\hline \multicolumn{6}{|l|}{$9 \mathrm{l} \cdot \min -1$} \\
\hline MV passive $\left(l \cdot \mathrm{min}^{-1}\right)$ & 2.99 & 3.57 & 3.98 & 3.93 & 4.09 \\
\hline MV EVA $\left(l \cdot \mathrm{min}^{-1}\right)$ & 4.89 & 4.80 & 4.69 & 4.66 & 4.08 \\
\hline$\Delta M V\left(I \cdot \mathrm{min}^{-1}\right)$ & 1.89 & 1.23 & 0.71 & 0.74 & 0.00 \\
\hline \multicolumn{6}{|l|}{$121 \cdot \min -1$} \\
\hline MV passive $\left(l \cdot \mathrm{min}^{-1}\right)$ & 3.27 & 4.00 & 4.56 & 4.49 & 4.88 \\
\hline MV EVA $\left(l \cdot \min ^{-1}\right)$ & 6.35 & 6.26 & 6.06 & 6.07 & 5.17 \\
\hline$\Delta M V\left(I \cdot \mathrm{min}^{-1}\right)$ & 3.07 & 2.27 & 1.49 & 1.58 & 0.29 \\
\hline \multicolumn{6}{|l|}{$15 \mathrm{l} \cdot \mathrm{min}-1$} \\
\hline MV passive $\left(l \cdot \mathrm{min}^{-1}\right)$ & 3.45 & 4.27 & 4.95 & 4.83 & 5.45 \\
\hline MV EVA $\left(l \cdot \mathrm{min}^{-1}\right)$ & 7.48 & 7.30 & 7.09 & 7.05 & 6.10 \\
\hline$\Delta M V\left(l \cdot \mathrm{min}^{-1}\right)$ & 4.04 & 3.03 & 2.15 & 2.22 & 0.65 \\
\hline \multicolumn{6}{|l|}{$18 \mathrm{l} \cdot \min -1$} \\
\hline MV passive $\left(l \cdot \min ^{-1}\right)$ & 3.58 & 4.46 & 5.21 & 5.12 & 5.87 \\
\hline MV EVA $\left(l \cdot \mathrm{min}^{-1}\right)$ & 8.27 & 7.97 & 7.68 & 7.68 & 6.55 \\
\hline$\Delta M V\left(l \cdot \mathrm{min}^{-1}\right)$ & 4.69 & 3.50 & 2.47 & 2.57 & 0.68 \\
\hline
\end{tabular}

Table 3 Results of Part 3: minute volumes. Achievable minute volumes at different compliances and resistances using flow rates of 6-18 l. $\mathrm{min}^{-1}$ through the $75 \mathrm{~mm}$ long, $2 \mathrm{~mm}$ ID transtracheal catheter with passive expiration (MV passive) and expiratory ventilation assistance (MV EVA), DMV=MV EVA - MV passive

$2 \mathrm{cmH}_{2} \mathrm{O} \cdot \mathrm{l}^{-1} \cdot \mathrm{s}^{-1}$, in a decrease in the expiratory time from $13.4(0.03)$ to $8.0(0.10) \mathrm{s}$ (Table 2$)$. Raising the flow rate of oxygen resulted in a further decrease in expiratory times and consequently in an increase in the calculated MV, achievable through the transtracheal catheter for this pulmonary setting, from 3.58 to $8.27 \mathrm{l} \cdot \mathrm{min}^{-1}$ (Table 3 ). The maximum effect of the DE 5 on the expiratory time was reached at $15 \mathrm{l} \cdot \mathrm{min}^{-1}$ (Table 2 ). The increase in the achievable minute volume at a flow rate of $18 \mathrm{l} \cdot \mathrm{min}^{-1}$ compared with that at a flow rate of $151 \cdot \mathrm{min}^{-1}$ only resulted from a shorter inspiratory time due to the higher flow rate of the driving gas. A decrease in compliance reduced the effect of EVA (Table $3)$. At a compliance of $10 \mathrm{ml} \cdot \mathrm{cmH}_{2} \mathrm{O}^{-1}$, the expiratory time with EVA using the DE 5 at a flow rate of $6 l \cdot \mathrm{min}^{-1}$ was $1.1 \mathrm{~s}$ longer compared with passive backflow (Table 2 ), resulting in a decrease in calculated minute volume of $170 \mathrm{ml} \cdot \mathrm{min}^{-1}$ 
(Table 3). The increase in the achievable minute volume at a flow rate of $18 \mathrm{l} \cdot \mathrm{min}^{-1}$ compared with that at a flow rate of $15 \mathrm{l} \cdot \mathrm{min}^{-1}$ only resulted from a shorter inspiratory time due to the higher flow rate of the driving gas.

A decrease in compliance reduced the effect of EVA (Table 3). At a compliance of $10 \mathrm{ml} \cdot \mathrm{cmH}_{2} \mathrm{O}^{-1}$, the expiratory time with EVA using the DE 5 at a flow rate of $61 \cdot \mathrm{min}^{-1}$ was $1.1 \mathrm{~s}$ longer compared with passive backflow (Table 2 ), resulting in a decrease in calculated minute volume of 170 $\mathrm{ml} \cdot \mathrm{min}^{-1}$ (Table 3 ). At higher flow rates, the minute volume achieved by EVA at this low compliance was similar (at 9 (. $\left.\mathrm{min}^{-1}\right)$ or slightly higher compared with passive backflow.

Further data relating to the experimental set up and results using cannulas of different sizes and non-compliant tubing ( $2 \mathrm{~mm}$ ID) are found in the supplementary material.

\section{Discussion}

Employment of Bernoulli's principle can facilitate expiration through a small-bore transtracheal catheter. The results of the present study show that the novel ventilation ejector (DE 5) is more suitable for ventilation purposes than the modified industrial ejector (SBP 07). The DE 5 substantially shortened the required expiratory time and achieved a minute volume of up to $8.27 \mathrm{l} \cdot \mathrm{min}^{-1}$ through a $75 \mathrm{~mm}$ long, $2 \mathrm{~mm}$ ID transtracheal catheter.

At a pulmonary setting representing a healthy adult (compliance $50 \mathrm{ml} \cdot \mathrm{cmH}_{2} \mathrm{O}^{-1}$, resistance of $2 \mathrm{cmH}_{2} \mathrm{O} \cdot \mathrm{l}^{-1} \cdot \mathrm{s}^{-1}$ ), passive backflow of $1000 \mathrm{ml}$ oxygen through the transtracheal catheter takes $9.9(0.10) \mathrm{s}$ [15]. Thus, at an oxygen flow of $15 \mathrm{l} \cdot \mathrm{min}^{-1}$ repetitively connecting and disconnecting the oxygen tubing and the transtracheal catheter could result in a theoretical minute volume of $4.27 \mathrm{l} \cdot \mathrm{min}^{-1}$. However, in an emergency situation, a continuously connected bidirectional ventilation system is highly preferable, because of the risk of dislodging the transtracheal catheter by manipulations. The Oxygen Flow Modulator (OFM; Cook Medical) is a bidirectional emergency tool for transtracheal oxygenation. In an in vitro study, it achieved a calculated minute volume of $3.241 \cdot \mathrm{min}^{-1}$ in case of a completely obstructed upper airway [17]. Although this minute volume would be sufficient to re-establish oxygenation, hypercapnia seems to be inevitable.

To speed up expiration through a small-bore catheter, the driving force can be increased, for example, by applying compression to the thorax, abdomen, or both. The resistance of the outflow tract may also be diminished by inserting an additional transtracheal catheter to facilitate expiration $[6,18,19]$. To minimize trauma to the airway and to get more control over the expiration, it has also been suggested to augment the outflow of gas through a single small-bore catheter by the application of suction $[12,14)$.

The mechanism of both tested devices (modified SBP 07 and DE 5) is based on the ejector's principle. An ejector is a multipurpose device able to create a subatmospheric pressure by the Bernoulli principle and to entrain air from a side port. The amount of entrainment and consequently the degree of expiratory assistance depend on the velocity of the driving gas and the resistance of the ejector. Although an ejector's resistance to flow is primarily defined by its inner geometry, the velocity of the driving gas jet passing through the ejector modulates the effective resistance while the ejector is active. If, at a given flow, the velocity of the driving gas is decreased (e.g. by turbulent mixing with entrained gas), an ejector will become less efficient.

The SBP 07 was modified and the DE 5 was specifically designed to serve as emergency ventilation ejectors, 
allowing both insufflation of oxygen and EVA. Although the modified SBP 07 has previously been reported to achieve a minute volume of more than $6 l \cdot \mathrm{min}^{-1}$ through a $75 \mathrm{~mm}$ long, $2 \mathrm{~mm}$ ID transtracheal catheter [15], this industrial ejector has been designed to create a maximum negative pressure to pick up and hold parts during manufacturing processes in industrial assembly lines and is not specified for ventilation.

The results of this study show that the SBP 07 is indeed capable of generating a high negative pressure in a static situation, that is, no gas is entrained. However, in a dynamic situation, when gas is continuously entrained through the transtracheal catheter, the generated pressure was considerably less negative. Compared with the SBP 07, the DE 5 built up a less negative pressure in a static situation, but maintained a higher negative pressure in a dynamic situation, leading to an improved suction capacity and a higher entrainment ratio. The differences in test results prove that the design of the DE 5 turns it into being better suited for ventilation purposes than the SBP 07.

As shown in Figure $2 A$ and $B$, the outflow tract and the side port of the SBP 07 and the DE 5 are designed differently. The outflow tube of the SBP 07, having a constant diameter over three-quarters of its length, has an optimal shape for creating a maximum negative pressure build-up in a static situation. In contrast, the slightly conical shape of the outflow pipe of the DE 5 has a length and an internal diameter that were designed to maximize entrainment from the side port while minimizing inner turbulence and thus optimizing the egress of entrained gas.

We are aware of the fact that application of results from this in vitro study into clinical practice has its limita- tions. Completely blocking the upper airway is an extreme simplification of clinical reality. The diameter of the upper airway is dynamically variable, and in clinical practice, it will open up at a certain intratracheal (intrathoracic) pressure in most cases. Although this situation resembles a relatively rare event, we decided to simulate a completely blocked upper airway as the best experimental setting for the evaluation of the DE 5. Thus, the current study did not address the usefulness of the DE 5 in various degrees of upper airway obstruction and did not determine the influence of patency of the upper airway on the effect of EVA. Furthermore, the effects of EVA on gas exchange, lung tissue, and circulation have not yet been fully studied. Ongoing in vivo experiments will have to address these clinical questions.

In summary, our novel EVA applying ventilation ejector DE 5 is capable of achieving an adequate minute volume through a small-bore transtracheal catheter. If further research confirms the safety and applicability of EVA in vivo, the DE 5 might be used as a portable emergency ventilator for small-bore catheters in the future.

\section{Acknowledgements}

The authors would like to thank J.E. Wildberger, Department of Radiology, Maastricht University Medical Centre, Maastricht, The Netherlands, for the CT scans and S. Enk for helpful assistance in preparing the photographs.

\section{Conflict of interest}

D.E. is the inventor of the Oxygen Flow Modulator and receives royalty payments from Cook Medical. Furthermore, D.E. has applied for a patent on the DE 5 .

\section{Funding}

This work was supported by European funding, OP-Zuid (31R104). 


\section{References}

1. Henderson JJ, Popat MT, Latto IP, Pearce AC, Difficult Airway Society. Difficult Airway Society guidelines for management of the unanticipated difficult intubation. Anaesthesia 2004; 59: 675-94

2. Cook TM, Bigwood B, Cranshaw J. A complication of transtracheal jet ventilation and use of the Aintree intubation catheter during airway resuscitation. Anaesthesia 2006; 61: 692-7

3. Craft TM, Chambers PH, Ward ME, Goat VA. Two cases of barotrauma associated with transtracheal jet ventilation. Br J Anaesth 1990; 64: 524-7

4. Hardy MJ, Huard C, Lundblad TC. Bilateral tension pneumothorax during jet ventilation: a case report. AANA J 2000; 68: 241-4

5. Schumacher P, Stotz G, Schneider M, Urwyler A. Laryngospasm during transtracheal high frequency jet ventilation. Anaesthesia 1992; 47: 855-6

6. Russell WC, Maguire AM, Jones GW. Cricothyroidotomy and transtracheal high frequency jet ventilation for elective laryngeal surgery. An audit of 90 cases. Anaesth Intensive Care 2000; 28: 62-7

7. Dworkin R, Benumof JL, Benumof R, Karagianes TG. The effective tracheal diameter that causes air trapping during jet ventilation. J Cardiothorac Anesth 1990; 4: 731-6

8. Ng A, Russell WC, Harvey N, Thompson JP. Comparing methods of administering high-frequency jet ventilation in a model of laryngotracheal stenosis. Anesth Analg 2002; 95: 764-9

9. Lim MW, Benham SW. Relationship of inspiratory and expiratory times to upper airway resistance during pulsatile needle cricothyrotomy ventilation with generic delivery circuit. Br J Anaesth 2010; 104: 98-107
10. Eger El, Hamilton WK. Positive-negative pressure ventilation with a modified Ayre's T-piece. Anesthesiology 1958; 19: $611-8$

11. Keuskamp DH. Automatic ventilation in paediatric anaesthesia using a modified Ayre's T-piece with negative pressure during expiratory phase. Anaesthesia 1963; 18: 46-56

12. Dunlap LB, Oregon E. A modified, simple device for the emergency administration of percutaneous transtracheal ventilation. JACEP 1978; 7: 42-6

13. Garry B, Woo P, Perrault DF Jr, Shapshay SM, Wurm WH. Jet ventilation in upper airway obstruction: description and model lung testing of a new jetting device. Anesth Analg 1998; 87: $915-20$

14. Schapera A, Bainton CR, Kraemer R, Lee K. A pressurized injection/suction system for ventilation in the presence of complete airway obstruction. Crit Care Med 1994; 22: 326-33

15. Hamaekers AE, Go " tz T, Borg PA, Enk D. Achieving an adequate minute volume through a $2 \mathrm{~mm}$ transtracheal catheter in simulated upper airway obstruction using a modified industrial ejector. Br J Anaesth 2010; 104: 382-6

16. Enk D. Patent application (10 2007013 385.7). German Patent Office, March 16, 2007

17. Hamaekers AE, Borg PA, Enk D. A bench study of ventilation via two self-assembled jet devices and the Oxygen Flow Modulator in simulated upper airway obstruction. Anaesthesia 2009; 64: 1353-8

18. Dallen LT, Wine R, Benumof JL. Spontaneous ventilation via transtracheal large-bore intravenous catheters is possible. Anesthesiology 1991; 75: 531-3

19. Jacobs HB. Emergency percutaneous transtracheal catheter and ventilator. $J$ Trauma 1972; 12: 50-5 
84 


\section{Chapter 6}

\section{The effect of expiratory ventilation assistance on re-oxygenation and ventilation}

Emergency ventilation through a small-bore transtracheal cannula in severe hypoxic pigs using expiratory ventilation assistance (EVA) Ankie Hamaekers MD, Tim van der Beek (MD), Maurice Theunissen, Dietmar Enk MD PhD Prof. 


\section{Summary}

Background. Suction-generated expiratory ventilation assistance (EVA) has been proposed to facilitate bidirectional ventilation through a small-lumen transtracheal cannula. The aim of this study was to investigate the efficiency of EVA on restoring oxygenation and ventilation in an acute hypoxic pig model.

Methods. After approval by the local Animal Welfare Committee six pigs (61-76 $\mathrm{kg}$ ) were anaesthetized and ventilated (IPPV) via a cuffed endotracheal tube (ET). Monitoring lines were placed and a $75 \mathrm{~mm}$ long, $2 \mathrm{~mm}$ ID TC was inserted. After baseline recordings the ventilator was disconnected. After two minutes of apnoea re-oxygenation with EVA was initiated through the TC and continued for 15 minutes with the ET occluded. In the second part of the study the experiment was repeated with the ET either partially obstructed or left open. Airway pressures and hemodynamic data were recorded and blood samples were collected. Descriptive statistical analysis was performed.

Results. With a completely or partially obstructed upper airway EVA restored oxygenation in all animals within 20 seconds. $\mathrm{PCO}_{2}$ remained stable over 15 minutes in case of a completely obstructed airway. As airway patency increased re-oxygenation was delayed. In the completely open airway 2 out of 6 animals had a $\mathrm{pO}_{2}$ below $85 \mathrm{mmHg}$ even after 15 minutes and mean $\mathrm{pCO}_{2}$ was $90 \mathrm{mmHg}$ after 15 minutes of EVA

Conclusions. In severe hypoxic pigs EVA restored oxygenation quickly in case of a completely as well as a partially obstructed upper airway. Re-oxygenation and ventilation by EVA was less effective in case of an open upper airway. 
In a 'cannot intubate, cannot oxygenate' (CICO) situation a percutaneous cricothyroidotomy should be performed rapidly to restore oxygenation and avoid brain damage or death $[1,2]$. This life-saving procedure can be performed with either a small-bore (inner diameter (ID) $\leq 2 \mathrm{~mm}$ ) or a (cuffed) wide-bore cannula (ID of $4 \mathrm{~mm}$ or larger) [3]. Survey studies have demonstrated that a majority of anaesthetists prefer a small-bore cannula technique when performing an emergency cricothyroidotomy [4, 5], as insertion might be easier and less traumatic. However, providing effective re-oxygenation and ventilation through such a narrow cannula may be difficult $[6,7]$ and not without risks. As resistance to gas flow is inversely related to the internal diameter (ID) a high-pressure oxygen source is mandatory to create an adequate flow through a small-bore cannula [8]. Additionally, passive expiratory outflow through a small-bore airway cannula is limited [9] and egress of gas must take place through the upper airway. Obstruction of the upper airway (e.g. due to edema, laryngospasm or tumour) and / or insufficient expiratory time can result in airtrapping. Several reports of barotrauma and circulatory collapse resulting from high-pressure ventilation can be found in the literature [10-13].

Various techniques have been proposed to facilitate the egress of gas through a small-bore cannula: applying thoracic and abdominal compression, inserting an additional cannula $[14,15]$ or applying suction to the airway cannula during the expiratory phase [16, 17]. Previously, we described a, manually operated ventilation ejector (DE 5) which uses high velocity gas flow to create expiratory ventilation assistance (EVA) and thus controls both the inspiratory and expiratory phase. (figure $1 \mathrm{~A}+\mathrm{B}$ ) [18].

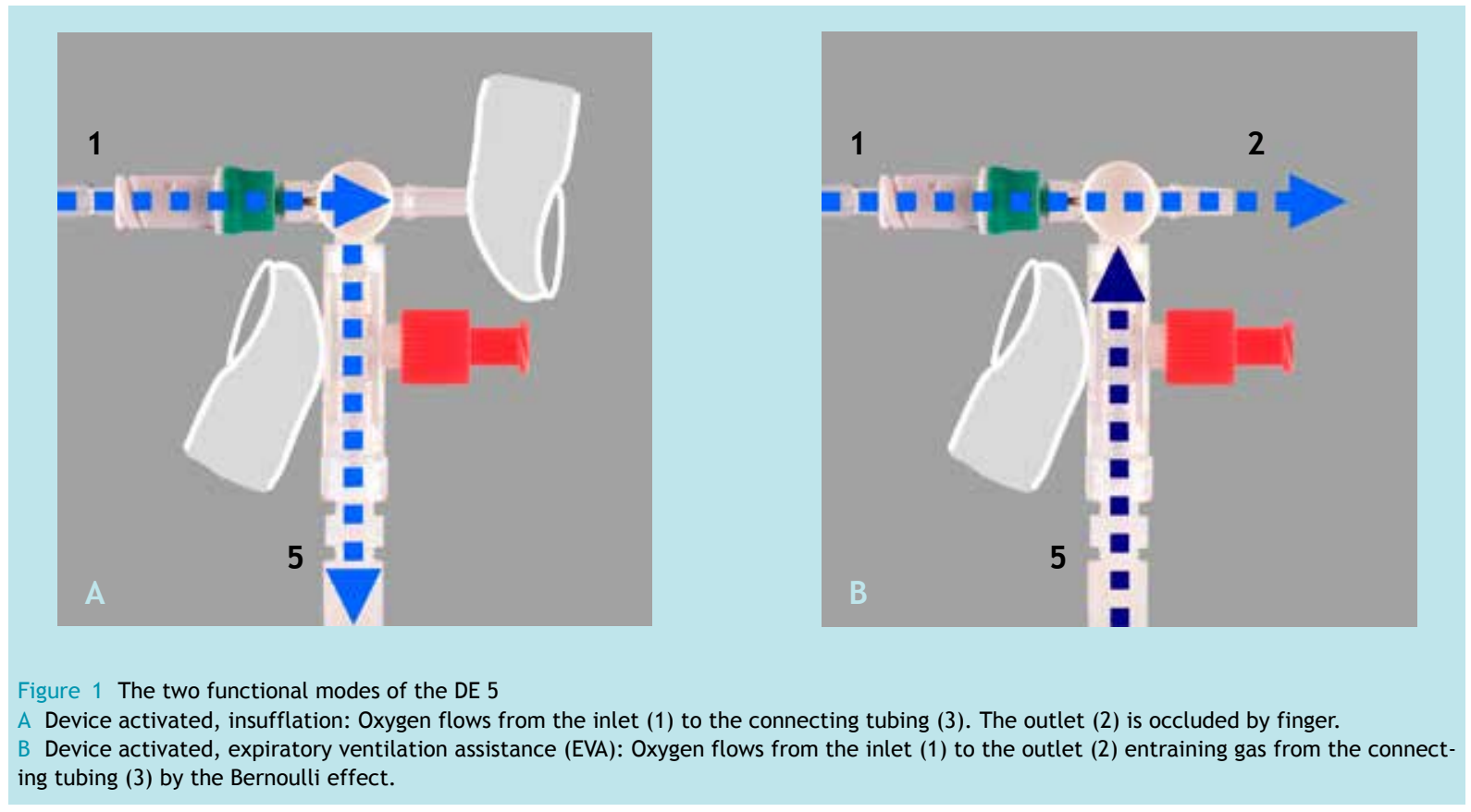


This emergency ventilation device achieved a calculated minute volume up to $8.3 \mathrm{l} \cdot \mathrm{min}^{-1}$ through a $2 \mathrm{~mm}$ ID transtracheal cannula in an artificial lung model with complete outflow obstruction [19]. Although EVA in vitro appears promising, in vivo evaluation is mandatory. The primary aim of the present study was to determine the efficiency of EVA regarding re-oxygenation in an acute hypoxic pig model with an obstructed upper airway. Additionally, we studied the influence of upper airway patency on re-oxygenation and ventilation by EVA.

\section{Methods}

\section{Experimental Set-Up}

The study was approved by the Animal Welfare Committee of the University of Maastricht (DEC number 2009-070). After overnight fasting with free access to water, six pigs (61$76 \mathrm{~kg}$ ) were premedicated with intramuscular tiletamine / zolazepam $\left(6 \mathrm{mg} \cdot \mathrm{kg}^{-1}\right)$ and atropine $\left(0.05 \mathrm{mg} \cdot \mathrm{kg}^{-1}\right)$. Anaesthesia was induced with propofol $4-8 \mathrm{mg} \cdot \mathrm{kg}^{-1}$ and sufentanil $1 \mu \mathrm{g} \cdot \mathrm{kg}^{-1}$ via an intravenous catheter inserted in a vein in the animals' ear. The trachea was intubated with a $9.0 \mathrm{~mm}$ ID cuffed endotracheal tube. The pigs were mechanically ventilated (intermittent positive pressure ventilation (IPPV)) with a tidal volume of $10 \mathrm{ml} \cdot \mathrm{kg}^{-1}$. The respiratory rate was adjusted to establish an etPaCO $\mathrm{C}_{2}$ around $40 \mathrm{mmHg}$. $\mathrm{FiO}_{2}$ was set at 0.40 . Anaesthesia was maintained by continuous infusions of sufentanil $\left(8 \mu \mathrm{g} \cdot \mathrm{kg}^{-1} \cdot \mathrm{h}^{-1}\right)$, propofol $\left(9 \mathrm{mg} \cdot \mathrm{kg}^{-1} \cdot \mathrm{h}^{-1}\right)$ and pancuronium $\left(0.3 \mathrm{mg} \cdot \mathrm{kg}^{-1} \cdot \mathrm{h}^{-1}\right)$. A $9 \mathrm{Fr}$ sheath (ref AH-09801, Arrow, Reading, PA, USA) was inserted in the right jugular vein and a pulmonary artery catheter (ref 746HF8, Edwards Lifesciences Corporation, Irvine, CA, USA) was positioned. Both femoral arteries were cannulated with an $18 \mathrm{G}$ arterial catheter (ref FA-04018, Arrow, Reading, PA, USA) for continuous arterial pressure monitoring and arterial blood sampling. The trachea was surgically exposed with a mid-line incision and a $75 \mathrm{~mm}$ long, $2 \mathrm{~mm}$ ID transtracheal cannula (TC; Emergency Transtracheal Airway Catheter, Cook Medical, Bloomington, IN, USA) was inserted into the trachea between the 3rd and 4th cartilage ring under bronchoscopic guidance. Intratracheal pressure was measured continuously using a modified epidural catheter inserted via the tracheal tube and positioned $2 \mathrm{~cm}$ above the carina with bronchoscopic guidance. All pressure catheters were connected via pressure transducers to a multichannel recorder and a digital data acquisition system (IDEEQ-system, University Maastricht, Maastricht, The Netherlands) and were recorded continuously throughout the experiment.

\section{Part 1}

Following stable baseline recordings including arterial blood gases for at least 30 minutes the ventilator was disconnected, leaving the tracheal tube open to room air. After 2 minutes of apnoea the tracheal tube was occluded and re-oxygenation was initiated through the TC. EVA was applied using the DE 5, connected to a pressure-compensated oxygen flow meter set at $15 \mathrm{l} \cdot \mathrm{min}^{-1}$. Employing an $30 \mathrm{~min}^{-1}$ rate, an initial inspiration/expiration-ratio (I/E-ratio) of 1 to 1 was adjusted to keep the end-expiratory intratracheal pressure between 0 and $10 \mathrm{cmH}_{2} \mathrm{O}$. Arterial blood samples were collected at baseline (prior to the apnoea period of 2 minutes), at the start of EVA (0) and after 10, 20, 30, 60, 180, 300, 600, and 900 seconds (s). After 15 minutes EVA was stopped and the pigs were mechanically ventilated through the ET. After completion of the experiment a bronchoscopic evaluation of the airway was performed. 


\section{Part 2}

In the second part of the study the experiment was repeated with varying degrees of tracheal tube obstruction simulating different levels of upper airway patency. After stable baseline recordings for 30 minutes the mechanical ventilator was again disconnected and after 2 minutes of apnoea EVA was initiated in random order with the ET either left open to room air or partially obstructed using a capping device with either a $3 \mathrm{~mm}$ orifice or a $50 \mathrm{~mm}$ long, $2 \mathrm{~mm}$ ID catheter. EVA was applied using the DE 5 at a rate of $30 \cdot \mathrm{min}^{-1}$ with an I/E-ratio of 1 to 1 . Arterial blood samples were collected at baseline (prior to apnoea for 2 minutes), at the start of EVA (0) and after 10, 20, 30, 60, 180, 300, 600, and $900 \mathrm{~s}$. The animals were mechanically ventilated and all monitored pressures and blood gas values were allowed to return to normal between experimental runs. Additionally, between each run a bronchoscopic evaluation of the trachea was performed. Upon completion of the experiments the pigs were euthanized with pentobarbital $\left(150 \mathrm{mg} \cdot \mathrm{kg}^{-1}\right)$ and in 4 pigs a sternotomy was performed for macroscopic examination of the lungs.

\section{Statistical Analysis}

Descriptive statistical analysis was performed and the data are presented as median [range].

\section{Results}

At baseline the minute volume during IPPV to achieve normocapnia was $9.9[9.1-12.0] \mathrm{l} \cdot \mathrm{min}^{-1}$. The mean compliance at baseline was $30.5[28.1-33.8] \mathrm{ml} \cdot \mathrm{cmH}_{2} \mathrm{O}^{-1}$.

\section{Part 1: completely obstructed upper airway}

After 2 minutes of apnea the arterial $\mathrm{PaO}_{2}$ fell to a median of $25 \mathrm{mmHg}$ [20-31] and the oxygen saturation was $45 \%$ [3360] (table 1). Within 20 seconds after the initiation of EVA, hypoxemia was corrected $\left(\mathrm{SaO}_{2}>95 \%\right)$ in all animals. During the apnea period $\mathrm{PaCO}_{2}$ rose to a median of $54 \mathrm{~mm} \mathrm{Hg}$ [4656] and did not change significantly during EVA ventilation.

\begin{tabular}{|c|c|c|c|c|c|c|c|}
\hline & $-120 \mathrm{~S}$ & 0 & $10 \mathrm{~s}$ & $20 \mathrm{~S}$ & $60 \mathrm{~S}$ & $180 \mathrm{~S}$ & $900 \mathrm{~S}$ \\
\hline $\begin{array}{c}\mathrm{PaO}_{2} \\
(\mathrm{mmHg})\end{array}$ & $\begin{array}{c}171 \\
{[156-200]}\end{array}$ & $\begin{array}{c}25 \\
{[20-31]}\end{array}$ & $\begin{array}{c}84 \\
{[47-208]}\end{array}$ & $\begin{array}{c}254 \\
{[178-310]}\end{array}$ & $\begin{array}{c}404 \\
{[381-416]}\end{array}$ & $\begin{array}{c}539 \\
{[494-562]}\end{array}$ & $\begin{array}{c}537 \\
{[490-565]}\end{array}$ \\
\hline $\begin{array}{c}\mathrm{SaO}_{2} \\
(\%)\end{array}$ & 100 & $\begin{array}{c}45 \\
{[33-60]}\end{array}$ & $\begin{array}{c}96 \\
{[82-100]}\end{array}$ & 100 & 100 & 100 & 100 \\
\hline $\begin{array}{c}\mathrm{PaCO}_{2} \\
(\mathrm{mmHg})\end{array}$ & $\begin{array}{c}39 \\
{[37-40]}\end{array}$ & $\begin{array}{c}54 \\
{[46-56]}\end{array}$ & $\begin{array}{c}55 \\
{[48-60]}\end{array}$ & $\begin{array}{c}55 \\
{[50-62]}\end{array}$ & $\begin{array}{c}56 \\
{[49-59]}\end{array}$ & $\begin{array}{c}55 \\
{[51-60]}\end{array}$ & $\begin{array}{c}57 \\
{[56-75]}\end{array}$ \\
\hline
\end{tabular}

Table $1 \mathrm{PaO}_{2}$ and $\mathrm{PaCO}_{2}$ at complete upper airway obstruction prior (-120 s) and after two minutes of apnoea (0) and subsequent EVA over 15 minutes (part 1 of the study). Data presented as mean [range]. 


\section{Part 2: increased upper airway patency}

With the ET partially obstructed EVA restored oxygenation within 20 seconds $\left(\mathrm{SaO}_{2}>95 \%\right)$. However, when the airway was left completely open, 2 out of 6 animals had a $\mathrm{pO}_{2}$ below $85 \mathrm{mmHg}$ after 15 minutes. The efficacy of EVA decreased as the ET was less obstructed resulting in protracted re-oxygenation and severe hypercarbia in the open airway (fig. 2A-C).

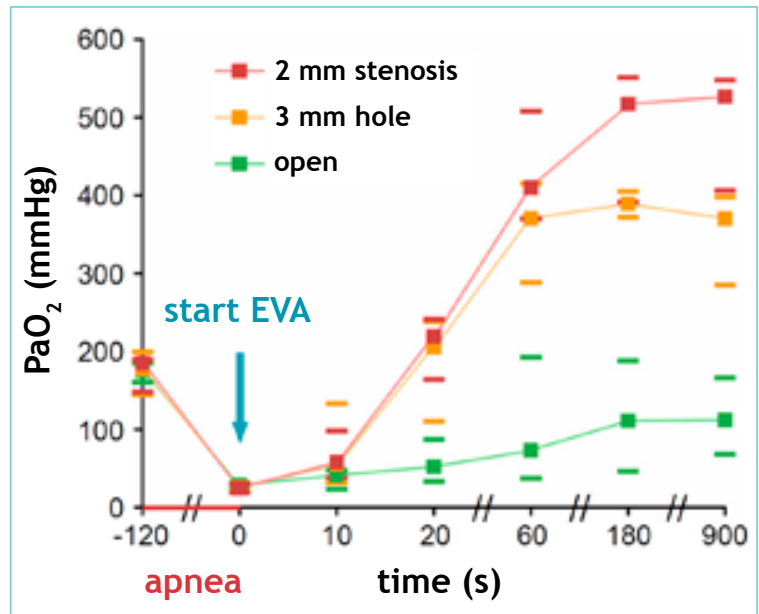

Figure 2A Course of $\mathrm{PaO}_{2}$ at different upper airway patency prior $(-120 \mathrm{~s})$ and after two minutes of apnoea $(0)$ and subsequent EVA over 15 minutes (part 2 of the study). The ET was either fully open or obstructed with a $3 \mathrm{~mm}$ hole or a $50 \mathrm{~mm}$ long, $2 \mathrm{~mm}$ stenosis. Data presented as mean and range.

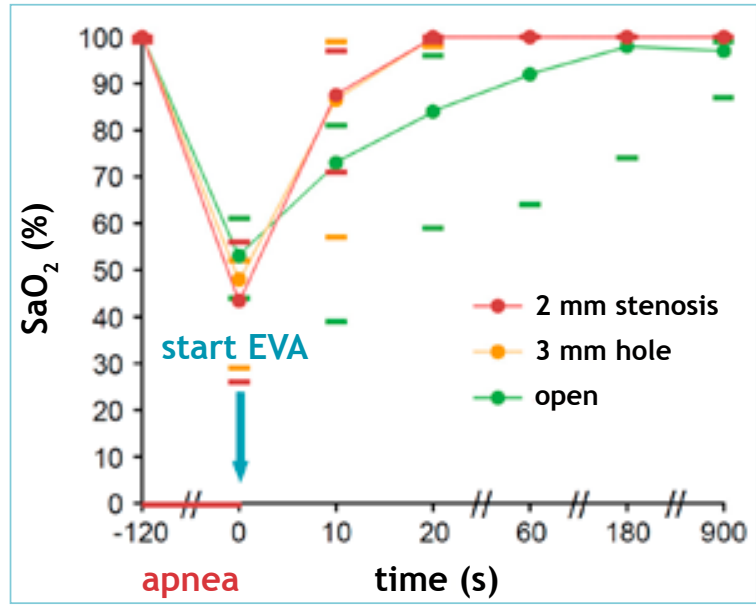

Figure 2B Course of $\mathrm{SaO}_{2}$ at different upper airway patency prior $(-120 \mathrm{~s})$ and after two minutes of apnoea $(0)$ and subsequent EVA over 15 minutes (part 2 of the study). The ET was either fully open or obstructed with a $3 \mathrm{~mm}$ hole or a $50 \mathrm{~mm}$ long, $2 \mathrm{~mm}$ stenosis. Data presented as mean and range.

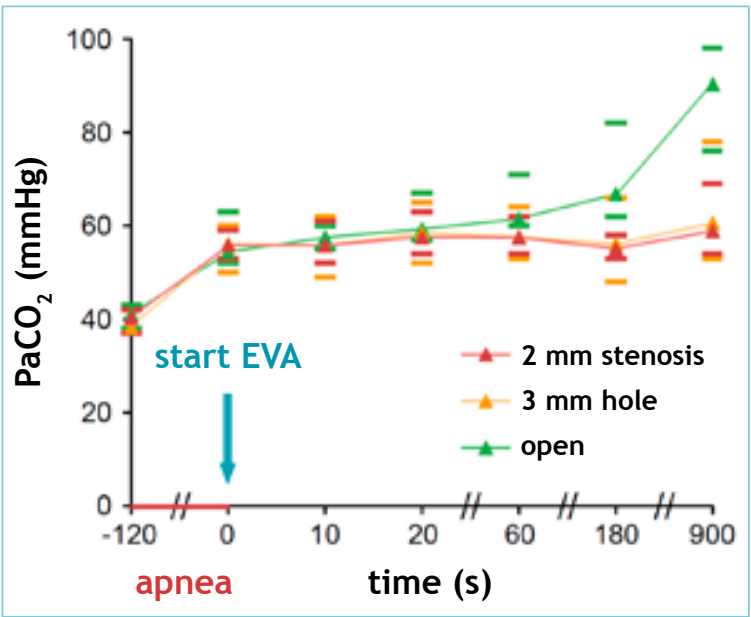

Figure $2 \mathrm{C}$ Course of $\mathrm{PaCO}_{2}$ at different upper airway patency prior (-120 s) and after two minutes of apnoea (0) and subsequent EVA over 15 minutes (part 2 of the study). The ET was either fully open or obstructed with a $3 \mathrm{~mm}$ hole or a $50 \mathrm{~mm}$ long, $2 \mathrm{~mm}$ stenosis. Data presented as mean and range. 


\section{Macroscopic Examination}

Hyperaemia of the posterior tracheal wall at the level of the TC insertion was seen in all patients by trachea-bronchoscopy. There were no lacerations of the mucosa, macroscopically evident oedema or bronchial haemorrhagic secretions. Post-mortem examination revealed no pneumothorax or subcutaneous emphysema.

\section{Discussion}

A CICO scenario will likely result in brain damage or death if not corrected in a timely manner. If oxygenation cannot be maintained by conventional means, an invasive airway must be established without delay. The insertion of a smallbore catheter through the cricothyroid membrane can be performed quickly [20]. EVA, applied by the DE5, restored oxygenation through a small-bore TC in severely hypoxic pigs with a completely as well as partially obstructed upper airway within 20 seconds.

The exact amount and / or flow of oxygen necessary to rapidly re-oxygenate an adult patient is unknown. Flack et al. calculated in a mathematical model that an increase in tidal volume results in faster re-oxygenation [21]. The Difficult Airway Society guidelines recommend using a high-pressure device capable of delivering a high minute volume to re-oxygenate a patient in a $\mathrm{CICO}$ situation following smallbore cricothyroidotomy [22]. In a previous in vitro study the DE5 achieved a calculated minute volume of $7.1 \mathrm{l} \cdot \mathrm{min}^{-1}$ through a TC in a lung model with a compliance of $30 \mathrm{ml} \cdot \mathrm{c}$ $\mathrm{mH}_{2} \mathrm{O}^{-1}$ (similar to the compliance of the pigs) and driven by an oxygen flow of $15 \mathrm{l} \cdot \mathrm{min}^{-1}$ [19]. In an adult this minute volume would not only be enough for swift re-oxygenation, but it would also provide adequate ventilation. Although in our study hypercarbia could be limited over a period of 15 minutes in the animals with an obstructed upper airway, $\mathrm{PaCO}_{2}$ did not returned to baseline levels during ventilation with EVA. A plausible explanation is that during IPPV the pigs required a minute volume of $9.9 \mathrm{l} \cdot \mathrm{min}^{-1}$ for normoventilation (Table 1). This is far above the maximum minute volume achievable with the DE 5 .

In the case of a completely obstructed upper airway and the application of EVA there is a risk of air trapping by over-vigorous TC insufflation and the potential for development of prohibitive subatmospheric pressure by prolonged gas evacuation. In the present study the EVA I/E ratio was varied to keep intratracheal pressures between 0 and $10 \mathrm{~cm}$ $\mathrm{H}_{2} \mathrm{O}$. In clinical resuscitation, such intratracheal pressures are unlikely to be monitored. Attention to chest wall excursion and relaxation in the inspiratory and expiratory phases respectively, may be the only monitor. However, modest subatmospheric end-expiratory pressure may be desirable and improve venous return, and be beneficial for both cardiac and cerebral perfusion [23].

EVA was found to be less efficient in a completely open ET. To achieve sufficient ventilation in an open airway a high driving pressure is mandatory [24]. The driving pressure necessary for "classic" jet ventilation in an adult patient ranges between 1.5 and 3.0 bar. As the inspiratory pressure of the DE5 measured in front of the TC is just about 110 mbar at $151 \cdot \mathrm{min}^{-1}[19]$, it needs to be emphasized that EVA is not just a "modified" type of jet ventilation. Flow-controlled EVA for ventilation through small-bore cannulas or catheters can be considered a new hybrid ventilation mode filling in the gap between "classic" jet ventilation through a smallbore catheter using high-pressures in an open airway and conventional low-pressure ventilation (e.g. IPPV) through a large-bore tube in a closed airway. 
One of the limitations of our study design is that the insertion of the TC was under stable conditions after surgical exposure of the trachea. This study does not address the difficulty of successfully performing a cricothyroidotomy in a CICO situation, which is clearly a problem as became obvious in the fourth national audit project in the UK [25]. Furthermore, EVA was used only for 15 minutes. This resembles the period of time required to re-oxygenate and stabilize a patient in a $\mathrm{CICO}$ situation after getting access to the airway by needle cricothyroidotomy. However, effects of prolonged ventilation with EVA, for instance damage to the mucosa of the respiratory tract because of the ventilation with cold and dry air, have not been studied. The degree of airway patency was modelled using a fixed diameter, which is a simplification of clinical reality. In clinical practice the diameter of the upper airway is dynamically variable and is however, did not determine the influence of EVA on patency of the upper airway.

In summary, EVA restored oxygenation quickly in severely hypoxic animals with a partially or completely obstructed upper airway. The efficacy of EVA decreased in an open airway.

\section{Acknowledgements}

We would like to thank the employees at the animal facilities for their help and support.

\section{Conflict of interest}

Ankie Hamaekers is an unpaid consultant for Ambu and has received free samples of airway equipment for teaching and clinical evaluation from several companies. She has no financial interest in any company.

Dietmar Enk is the inventor of DE5 and receives royalty payments from Dolphys Medical, Eindhoven, The Netherlands.

\section{Funding}

This work was supported by European funding, OP-Zuid (31R104). 


\section{References}

1. Henderson JJ, Popat MT, Latto IP, Pearce AC. Difficult Airway Society guidelines for management of the unanticipated difficult intubation. Anaesthesia 2004; 59: 675-94

2. Caplan RA, Benumof JL, Berry FA, Blitt CD, Bode RH, Cheney FW, Connis RT, Guidry OF, Nickinovich DG, Ovassapian A. Practice guidelines for management of the difficult airway. An updated report by the American Society of Anesthesiologists Task Force on Management of the Difficult Airway. Anesthesiology 2003; 98: 1269-77

3. Hamaekers $\mathrm{AE}$, Henderson JJ. Equipment and strategies for emergency tracheal access in the adult patient. Anaesthesia 2011; 66/S2: 65-80

4. Wong DT, Lai K, Chung FF, Ho RY. Cannot intubate-cannot ventilate and difficult intubation strategies: results of a Canadian national survey. Anesthesia and Analgesia 2005; 100: $1439-46$

5. Ezri T, Szmuk P, Warters RD, Katz J, Hagberg CA. Difficult airway management practice patterns among anesthesiologists practicing in the United States: have we made any progress? Journal of Clinical Anesthesia 2003; 15: 418-22

6. Scrase I, Woollard M. Needle vs surgical cricothyroidotomy: a short cut to effective ventilation. Anaesthesia 2006; 61: $962-74$

7. Cook TM, Nolan JP, Cranshaw J, Magee P. Needle cricothyroidotomy. Anaesthesia 2007; 62: 289-90

8. Flint NJ, Russell WC, Thompson JP. Comparison of different methods of ventilation via cannula cricothyroidotomy in a trachea-lung model. British Journal of Anaesthesia 2009; 103: 891-5

9. Rone CA, Pavlin EG, Cummings CW, Weymuller EA. Studies in transtracheal ventilation catheters. Laryngoscope 1982; 92: 1259-64Rone 1983

10. Craft TM, Chambers PH, Ward ME, Goat VA. Two cases of barotrauma associated with transtracheal jet ventilation. Br J Anaesth 1990; 64: 524-7
11. Kiyama S, Koyama K, Takahashi J, Fukushima K. Tension pneumothorax resulting in cardiac arrest during emergency tracheotomy under transtracheal jet ventilation. Journal of Anesthesia 1991; 5: 427-30

12. Cook TM, Bigwood B, Cranshaw J. A complication of transtracheal jet ventilation and use of the Aintree intubation catheter during airway resuscitation. Anaesthesia 2006; 61: $692-7$

13. Cook TM, Alexander R. Major complications during anaesthesia for elective laryngeal surgery in the UK: a national survey of the use of high-pressure source ventilation. British Journal of Anaesthesia 2008; 101: 266-72

14. Dallen LT, Wine R, Benumof JL: Spontaneous ventilation via transtracheal large bore intravenous catheters is possible. Anesthesiology 1991; 75: 531-3

15. Jacobs HB: Emergency percutaneous transtracheal catheter and ventilator. J Trauma 1972; 12: 50-5

16. Dunlap LB, Oregon E. A modified, simple device for the emergency administration of percutaneous transtracheal ventilation. JACEP 1978; 7: 42-6

17. Schapera A, Bainton CR, Kraemer R, Lee K. A pressurized injection/suction system for ventilation in the presence of complete airway obstruction. Crit Care Med 1994, 22: 326-33

18. Enk D. Gasstromumkehrelement. Patent application (10 2007013 385.7). German Patent Office, 16.3.2007

19. Hamaekers A, Götz T, Borg P, Enk D. Ventilation through a small-bore catheter: Optimizing expiratory ventilation assistance (EVA). Br J Anaesth 2011; 106: 403-9

20. Manoach S, Corinaldi $C$, Paladino $L$ et. al. Percutaneous transcricoid jet ventilation compared with surgical cricothyroidotomy in a sheep airway salvage model. Resuscitation 2004; 62: 79-86

21. Flack S.C., Hardman J.G Rescue ventilation following apnoea - effect of tidal volume. Eur. J. Anaesth. 2010; 27 (47): 246-7 
22. Henderson JJ, Popat MT, Latto IP, Pearce AC. Difficult Airway Society guidelines for management of the unanticipated difficult intubation. Anaesthesia 2004; 59: 675-94

23. Metzger AK, Herman M, McKnite S, Tang W, Yannopoulos D. Improved cerebral perfusion pressures and 24-hr neurological survival in a porcine model of cardiac arrest with active compression-decompression cardiopulmonary resuscitation and augmentation of negative intrathoracic pressure. Crit Care Med. 2012 Jun; 40(6): 1851-6.
24. Bould MD, Bearfield P. Techniques for emergency ventilation through a needle cricothyroidotomy. Anaesthesia 2008; 63: 535-9

25. Cook TM, Woodall N, Frerk C; Fourth National Audit Project. Major complications of airway management in the UK: results of the Fourth National Audit Project of the Royal College of Anaesthetists and the Difficult Airway Society. Part 1: anaesthesia. Br J Anaesth 2011; 106: 617-631 


\section{Chapter}

Implementation of EVA in a commercially available product 


\section{Summary}

A small, flow-regulated, manually operated ventilator designed for ventilation through a narrow-bore transtracheal catheter (TTC) has become available (Ventrain, Dolphys Medical BV, Eindhoven, The Netherlands). It is driven by a predetermined flow of oxygen from a high-pressure source and facilitates expiration by suction. The aim of this bench study was to test the efficacy of this new ventilator.

The driving pressure, generated insufflation, and suction pressures and also the suction capacity of the Ventrain were measured at different oxygen flows. The minute volume achieved in an artificial lung through a TTC with an inner diameter (ID) of $2 \mathrm{~mm}$ was determined at different settings.

Oxygen flows of $6-15 \mathrm{l} \cdot \mathrm{min}^{-1}$ resulted in driving pressures of $0.5-2.3 \mathrm{bar}$. Insufflation pressures, measured proximal to the TTC, ranged from 23 to $138 \mathrm{cmH}_{2} \mathrm{O}$. The maximal subatmospheric pressure build-up was $-217 \mathrm{cmH}_{2} \mathrm{O}$. The suction capacity increased to a maximum of $12.4 \mathrm{l} \cdot \mathrm{min}^{-1}$ at an oxygen flow of $15 \mathrm{l} \cdot \mathrm{min}^{-1}$. At this flow, the achievable minute volume through the TTC ranged from 5.9 to 7.1 litres depending on the compliance of the artificial lung.

The results of this bench study suggest that the Ventrain is capable of achieving a normal minute volume for an average adult through a $2 \mathrm{~mm}$ ID TTC. Further in vivo studies are needed to determine the value of the Ventrain as a portable emergency ventilator in a 'cannot intubate, cannot ventilate' situation. 
Transtracheal cannulation and subsequent high-pressure source ventilation (often called 'jet ventilation') can be lifesaving in a 'cannot intubate, cannot ventilate' (CICV) situation [1, 2]. Although 'jet ventilation' has a low morbidity in elective cases [3], numerous case reports underline the risk of high-pressure source ventilation in emergency situations [4-6]. Safe application of a high-pressure source ventilator requires an open upper airway to allow the gas to flow out during expiration. Obstruction of the upper airway caused by laryngospasm, oedema or anatomical distortion, combined with over-vigorous jet insufflation can result in air trapping with subsequent barotrauma and haemodynamic instability $[7,8]$.

Suction-generated augmentation of expiration has been proposed to minimize the risk of air trapping [9] and to increase the achievable minute volume through a narrow-bore airway catheter [10].

Recently, we described a purpose-built ventilation ejector (DE 5) that achieves in vitro a minute volume up to $7.51 \cdot \mathrm{min}^{-1}$ through a $7.5 \mathrm{~cm}$ long transtracheal catheter (TTC) with an inner diameter (ID) of $2 \mathrm{~mm}$ by using expiratory ventilation assistance (EVA) [11, 12]. In a hypoxic animal model with a completely obstructed airway, this ventilation ejector restored oxygenation through the TTC within $20 \mathrm{~s}$ and limited hypercarbia for over 15 minutes [13]. Based on the construction of the DE 5, a portable, flow-regulated, manually operated, and ergonomically shaped ventilation device was developed: Ventrain (Dolphys Medical BV, Eindhoven, The Netherlands; http://www.ventrain.com). Recently, this ventilation ejector has become commercially available. The aim of this study was to evaluate the Ventrain in vitro.

\section{Methods}

\section{Description of the Ventrain}

The Ventrain is a single-use, manually operated, narrow-bore ventilation device capable of oxygen insufflation and EVA. The functional inner component is a specially designed ejector (Fig. $1 A$ and $B$ ), which is driven by an oxygen flow coming from a high-pressure source with a controllable flow, e.g. a wall-mounted, pressure-compensated flow meter, or an oxygen cylinder with a flow regulator [14]. Before use, the oxygen tubing attached to the ejector's inlet ( 1 in Fig. $1 A$ and $B$ ) must be connected to the oxygen source, and the short connecting tubing at the side port ( 2 in Fig. $1 \mathrm{~A}$ and B) must be attached to the TTC. The oxygen flow coming from the flow meter or flow regulator is accelerated by a 0.7 $\mathrm{mm}$ ID jet nozzle ( 3 in Fig. 1B) and enters the exhaust pipe (4 in Fig. 1B) at high speed. As long as the bypass is open, the device is claimed to be functionally switched off with no clinically relevant flows to and from the patient. Closing the aperture of the bypass activates the Ventrain. The highspeed oxygen flow now creates a subatmospheric pressure and entrains gas from the side port ( 2 in Fig. $1 \mathrm{~B}$ ), thereby facilitating the egress of gas through the narrow-bore catheter. Closing both the bypass and the aperture of the exhaust pipe (inspiration/expiration switch) redirects the flow to the side port and oxygen is insufflated. By alternately occluding and releasing the aperture of the exhaust pipe, while keeping the bypass closed, either oxygen is insufflated or a subatmospheric pressure is created to assist the egress of gas through the attached narrow-bore catheter: EVA (details of how to operate the Ventrain are shown in Supplementary Fig. S1A and B). 


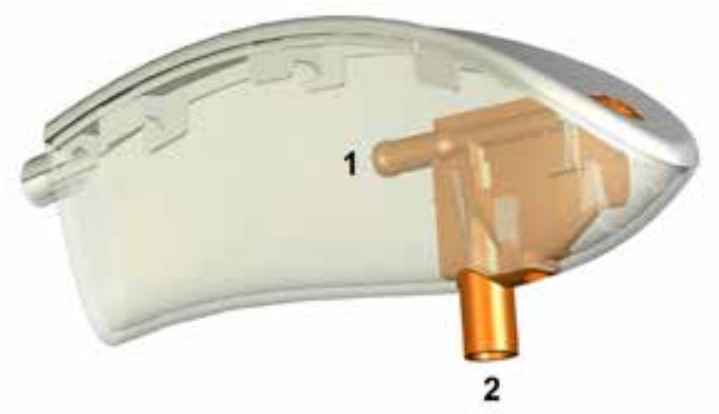

Figure 1A CAD model of the Ventrain. The shell is shown transparently, so the ejector as the functional centrepiece can be seen inside the shell. The oxygen tubing (not shown) is connected to the ejector's inlet (1) and short connecting tubing (not shown) is glued to the side port (2).

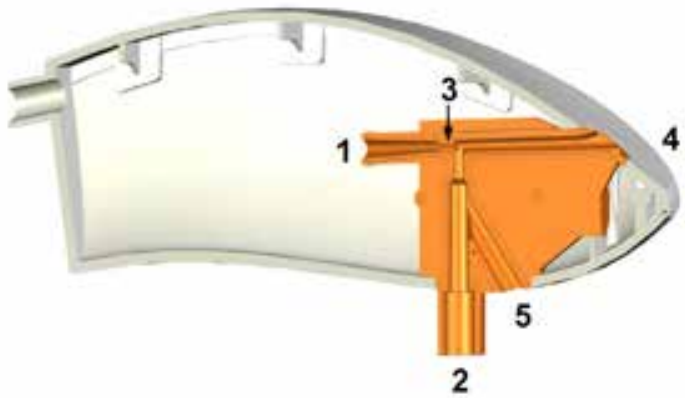

Figure 1B CAD cross-section of the Ventrain. Again, the oxygen and connecting tubing are not shown. The cross-section reveals the inner construction of the ejector: from the inlet (1) to the jet nozzle (3), the diameter decreases. Oxygen passing the jet nozzle is accelerated and enters the slightly conically shaped exhaust pipe (4) at high speed. Thereby, subatmospheric pressure is created at the side port (2) resulting in assisted expiration if the bypass (5) (functioning as an on/off switch) is completely closed. For inspiration, the flow of oxygen can be redirected to the side port by firmly sealing the aperture of the exhaust pipe (functioning as an inspiration/expiration switch).

\section{Experimental set-up}

The experiments were performed in two stages. First, the driving pressure and the pressures generated by the Ventrain were determined using the Calibration Analyzer Series RT200 (Timeter Instrument Corporation, St Louis, MO, USA). A pre-release version of the Ventrain was connected to a calibrated, pressure-compensated flow meter (Dräger Medical AG \& Co. KG, Lübeck, Germany) and attached to a $7.5 \mathrm{~cm}$ long, $2 \mathrm{~mm}$ ID TTC (Cook Medical, Bloomington, IN, USA). The driving pressure was defined as the pressure in the oxygen tubing between the flow meter and the ejector part of the Ventrain. It was measured via the side port of a T-piece placed between the oxygen tubing and the flow meter. To evaluate whether the Ventrain was indeed functionally switched off, pressures at the tip of the TTC were determined with the bypass of the Ventrain open as previously described [15]. The insufflation and suction pressures were measured at the side port of the distal T-piece proximal to the attached catheter. The maximum suction pressure was determined with the tip of the attached catheter blocked. All pressures were measured at oxygen flows of $6,9,12$, and $15 \mathrm{l} \cdot \mathrm{min}^{-1}$.

Furthermore, the suction capacity of the Ventrain was determined for oxygen flows of $6-15 \mathrm{l} \cdot \mathrm{min}^{-1}$ by insufflating a 35 litre plastic garbage bag (product number 136146, Albert Heijn, Zaandam, The Netherlands), as a closed ventilation model with an infinite compliance, for 1 minute and measuring the time to completely empty the bag through the TTC by suction. In addition, entrainment ratios (= entrained flow/oxygen flow) were calculated.

In the second part of the experiment, the efficacy of the Ventrain was studied at different pulmonary compliances and resistances in an LS800 lung simulator (Dräger Medical 
AG \& Co. KG, Lübeck, Germany) with a simulated complete upper airway obstruction. The TTC was tightly fitted in the proximal tube orifice of the lung simulator, ensuring that the entire gas flow into and out of the bellows was directed through the catheter. The measurements were performed at compliances of $100,50,30$, and $10 \mathrm{ml} \cdot \mathrm{cmH}_{2} \mathrm{O}^{-1}$ and resistances of 2,8 , and $32 \mathrm{cmH}_{2} \mathrm{O} \cdot \mathrm{l}^{-1} \cdot \mathrm{s}^{-1}$. The achievable minute volume was determined as previously described [15] by measuring the time required for insufflation of $1000 \mathrm{ml}$ of oxygen and the times needed for passive backflow of this volume through the TTC (with the Ventrain disconnected) and for assisted expiration using the Ventrain connected to oxygen flows of $6,9,12$, and $15 \mathrm{l} \cdot \mathrm{min}^{-1}$.

\section{Statistical analysis}

Each experiment was repeated four times. Means and standard deviations (SDS) were determined and used for further calculations. Suction capacities, entrainment ratios (ER), achievable minute volumes, and inspiration/expiration ratios (I/E ratios) were calculated. For descriptive statistics, MS-Excel 2002 SP3 was used.

\section{Results}

Increasing the oxygen flow created higher driving pressures (Table 1). Values of $2300 \mathrm{cmH}_{2} \mathrm{O}$ (2.3 bar) were measured in the oxygen tubing to the ejector at a flow of $15 \mathrm{l} \cdot \mathrm{min}^{-1}$. With the bypass open (Ventrain 'off'), closure of the exhaust pipe resulted in a maximal pressure at the tip of the TTC of $2.3 \mathrm{cmH}_{2} \mathrm{O}$ at a flow of $15 \mathrm{l} \cdot \mathrm{min}^{-1}$, whereas a slight subatmospheric pressure of $-6.5 \mathrm{cmH}_{2} \mathrm{O}$ was found at this flow rate if the aperture of the exhaust pipe was released (Table 1 ).

The insufflation pressure and the suction pressure of the Ventrain were related to the oxygen flow. At an oxygen flow of $15 \mathrm{l} \cdot \mathrm{min}^{-1}$, the insufflation pressure was $138 \mathrm{cmH}_{2} \mathrm{O}$.

\begin{tabular}{|c|c|c|c|c|c|c|c|c|}
\hline OXYGEN FLOW (L·MIN'-1) & \multicolumn{2}{|c|}{6} & \multicolumn{2}{|c|}{9} & \multicolumn{2}{|c|}{12} & \multicolumn{2}{|c|}{15} \\
\hline Driving pressure $\left(\mathrm{cmH}_{2} \mathrm{O}\right)$ & 459 & [7.2] & 1017 & [8.5] & 1665 & [4.4] & 2297 & {$[8.5]$} \\
\hline \multicolumn{9}{|l|}{ Ventrain “off” (bypass open): } \\
\hline PACT, exhaust pipe closed $\left(\mathrm{cmH}_{2} \mathrm{O}\right)$ & 0.5 & {$[0.06]$} & 0.8 & {$[0.05]$} & 1.9 & {$[0.06]$} & 2.3 & {$[0.10]$} \\
\hline PACT, exhaust pipe open $\left(\mathrm{cmH}_{2} \mathrm{O}\right)$ & -1.7 & {$[0.05]$} & -3.5 & {$[0.05]$} & -5.2 & {$[0.05]$} & -6.5 & {$[0.12]$} \\
\hline \multicolumn{9}{|l|}{ Ventrain “on” (bypass closed): } \\
\hline Insufflation pressure $\left(\mathrm{cmH}_{2} \mathrm{O}\right)$ & 22.5 & {$[0.58]$} & 50.8 & {$[0.50]$} & 90.5 & {$[1.00]$} & 137.8 & [2.06] \\
\hline Suction pressure $\left(\mathrm{cm} \mathrm{H}_{2} \mathrm{O}\right)$ & -25.5 & {$[0.58]$} & -51.3 & {$[0.96]$} & -75.5 & {$[0.58]$} & -96.8 & {$[1.50]$} \\
\hline Maximal suction pressure $\left(\mathrm{cmH}_{2} \mathrm{O}\right)$ & -57.8 & [1.26] & -112.8 & {$[0.50]$} & -171.0 & [2.16] & -217.3 & [3.95] \\
\hline Suction capacity $\left(l \cdot \mathrm{min}^{-1}\right)$ & \multicolumn{2}{|c|}{6.5} & \multicolumn{2}{|c|}{9.3} & \multicolumn{2}{|c|}{11.0} & \multicolumn{2}{|c|}{12.4} \\
\hline Entrainment ratio & \multicolumn{2}{|c|}{1.08} & \multicolumn{2}{|c|}{1.03} & \multicolumn{2}{|c|}{0.92} & \multicolumn{2}{|c|}{0.83} \\
\hline
\end{tabular}

Table 1 Physical characteristics of the Ventrain at different oxygen flows; measured data are presented as mean (SD). 'Driving pressure' indicates the pressure measured in the upstream oxygen tubing with oxygen flowing through the Ventrain, while the device is functionally switched off; 'PACT' means pressure at the TTC's tip; 'insufflation pressure' and 'suction pressure' have been measured proximal of the attached TTC during inspiration and expiration, respectively; 'maximal suction pressure' indicates the maximal subatmospheric pressure build-up that can be created by the Ventrain. 


\begin{tabular}{|c|c|c|c|c|c|c|c|c|}
\hline COMPLIANCE $\left(M L \cdot M^{-1} R^{-1}\right)$ & \multirow{2}{*}{\multicolumn{2}{|c|}{$\begin{array}{r}100 \\
2\end{array}$}} & \multirow{2}{*}{\multicolumn{2}{|c|}{$\begin{array}{r}50 \\
2\end{array}$}} & \multirow{2}{*}{\multicolumn{2}{|c|}{$\begin{array}{r}30 \\
8\end{array}$}} & \multirow{2}{*}{\multicolumn{2}{|c|}{$\begin{array}{l}10 \\
32\end{array}$}} \\
\hline RESISTANCE $\left(M B A R \cdot L^{-1} \cdot S^{-1}\right)$ & & & & & & & & \\
\hline Insufflation time (s) & 4.96 & {$[0.04]$} & 5.14 & {$[0.04]$} & 5.42 & {$[0.04]$} & 6.63 & {$[0.02]$} \\
\hline Expiration time (s), passive & 14.03 & {$[0.07]$} & 10.20 & {$[0.02]$} & 8.09 & {$[0.10]$} & 5.69 & [0.09] \\
\hline MV $\left(l \cdot \min ^{-1}\right)$, passive & \multicolumn{2}{|c|}{3.16} & \multicolumn{2}{|c|}{3.91} & \multicolumn{2}{|c|}{4.44} & \multicolumn{2}{|c|}{4.87} \\
\hline I/E-ratio, passive & \multicolumn{2}{|c|}{$1 / 2.83$} & \multicolumn{2}{|c|}{$1 / 1.99$} & \multicolumn{2}{|c|}{$1 / 1.49$} & \multicolumn{2}{|c|}{$1 / 0.86$} \\
\hline Expiration time (s), Ventrain & 5.11 & {$[0.04]$} & 5.14 & {$[0.02]$} & 5.07 & {$[0.03]$} & 5.21 & {$[0.07]$} \\
\hline MV $\left(l \cdot \min ^{-1}\right)$, Ventrain & \multicolumn{2}{|c|}{5.96} & \multicolumn{2}{|c|}{5.84} & \multicolumn{2}{|c|}{5.72} & \multicolumn{2}{|c|}{5.07} \\
\hline I/E-ratio, Ventrain & \multicolumn{2}{|c|}{$1 / 1.03$} & \multicolumn{2}{|c|}{$1 / 1.00$} & \multicolumn{2}{|c|}{$1 / 0.93$} & \multicolumn{2}{|c|}{$1 / 0.79$} \\
\hline
\end{tabular}

Table 2A Achievable minute volumes through the $2 \mathrm{~mm} \mathrm{ID} \mathrm{TTC} \mathrm{at} \mathrm{an} \mathrm{oxygen} \mathrm{flow} \mathrm{of} 12 \mathrm{l} \cdot \mathrm{min}^{-1}$; measured data presented as mean (SD)

\begin{tabular}{|c|c|c|c|c|c|c|c|c|}
\hline COMPLIANCE $\left(M L \cdot M^{-1 A R^{-1}}\right)$ & \multirow{2}{*}{\multicolumn{2}{|c|}{$\begin{array}{r}100 \\
2\end{array}$}} & \multirow{2}{*}{\multicolumn{2}{|c|}{$\begin{array}{r}50 \\
2\end{array}$}} & \multirow{2}{*}{\multicolumn{2}{|c|}{$\begin{array}{r}30 \\
8\end{array}$}} & \multirow{2}{*}{\multicolumn{2}{|c|}{$\begin{array}{l}10 \\
32\end{array}$}} \\
\hline RESISTANCE $\left(M B A R \cdot L^{-1} \cdot S^{-1}\right)$ & & & & & & & & \\
\hline Insufflation time (s) & 3.91 & {$[0.08]$} & 4.15 & {$[0.02]$} & 4.32 & {$[0.05]$} & 5.38 & {$[0.03]$} \\
\hline Expiration time (s), passive & 14.03 & {$[0.07]$} & 10.20 & {$[0.02]$} & 8.09 & {$[0.10]$} & 5.69 & {$[0.09]$} \\
\hline MV $\left(l \cdot \min ^{-1}\right)$, passive & \multicolumn{2}{|c|}{3.34} & \multicolumn{2}{|c|}{4.18} & \multicolumn{2}{|c|}{4.84} & \multicolumn{2}{|c|}{5.42} \\
\hline I/E-ratio, passive & \multicolumn{2}{|c|}{$1 / 3.59$} & \multicolumn{2}{|c|}{$1 / 2.46$} & \multicolumn{2}{|c|}{$1 / 1.87$} & \multicolumn{2}{|c|}{$1 / 1.06$} \\
\hline Expiration time (s), Ventrain & 4.58 & {$[0.07]$} & 4.56 & {$[0.05]$} & 4.62 & {$[0.03]$} & 4.85 & {$[0.03]$} \\
\hline MV $\left(l \cdot \min ^{-1}\right)$, Ventrain & \multicolumn{2}{|c|}{7.07} & \multicolumn{2}{|c|}{6.89} & \multicolumn{2}{|c|}{6.71} & \multicolumn{2}{|c|}{5.87} \\
\hline I/E-ratio, Ventrain & \multicolumn{2}{|c|}{$1 / 1.17$} & \multicolumn{2}{|c|}{$1 / 1.10$} & \multicolumn{2}{|c|}{$1 / 1.07$} & \multicolumn{2}{|c|}{$1 / 0.90$} \\
\hline
\end{tabular}

Table 2B Achievable minute volumes through the $2 \mathrm{~mm}$ ID TTC at an oxygen flow of $15 \mathrm{l} \cdot \mathrm{min}_{-1}$; measured data presented as mean $(\mathrm{SD})$

The suction pressure was $-97 \mathrm{cmH}_{2} \mathrm{O}$ while continuously aspirating air through the TTC and reached a maximum of -217 $\mathrm{CmH}_{2} \mathrm{O}$ when the tip of the TTC was blocked (Table 1). At a flow rate of $151 \cdot \mathrm{min}^{-1}$, the Ventrain shortened the expiratory time in all simulated pulmonary settings. This effect was for all flows most pronounced at a compliance of 100 $\mathrm{ml} \cdot \mathrm{CmH}_{2} \mathrm{O}^{-1}$ (Table 2 and Supplementary Tables S1 and S2). At this compliance, the expiratory time for 1 litre of oxygen decreased from $14.03 \mathrm{~s}$ in the case of passive egress through the TTC to $4.58 \mathrm{~s}$ with expiratory assistance by the Ventrain at an oxygen flow of $15 \mathrm{l} \cdot \mathrm{min}^{-1}$, resulting in a calculated minute volume of $7.1 \mathrm{l} \cdot \mathrm{min}^{-1}$. A decrease in compliance, however, limited the efficacy of the Ventrain. At a compliance of $10 \mathrm{ml} \cdot \mathrm{cmH}_{2} \mathrm{O}^{-1}$, the (theoretically) achievable minute volume decreased to $5.9 l \cdot \mathrm{min}^{-1}$. 


\section{Discussion}

Passive outflow of gas during ventilation through a narrow-bore TTC is limited by the high internal resistance of the catheter [16]. One solution to facilitate the egress of gas is to apply suction during the expiratory phase [10]. The novel emergency ventilation ejector evaluated in this study (Ventrain) achieved a minute volume of up to $7.1 \mathrm{l} \cdot \mathrm{min}^{-1}$ through a $2 \mathrm{~mm}$ ID catheter, by generating expiratory suction applying the Bernoulli principle.

The Bernoulli principle states that for an inviscid fluid, an increase in flow velocity at a constriction leads to an increase in dynamic pressure (kinetic energy) and causes a corresponding decrease in static pressure (potential energy).

The Ventrain turns the high driving pressure (up to 2.3 bar), measured in the oxygen tubing, into high velocity of the oxygen stream. As can be estimated from the driving pressure and the diameter of the jet nozzle, the $0.7 \mathrm{~mm}$ ID jet nozzle of the Ventrain accelerates the oxygen at a flow rate of $15 \mathrm{l} \cdot \mathrm{min}^{-1}$ to a flow velocity close to the speed of sound. The subatmospheric pressure of up to $-97 \mathrm{cmH}_{2} \mathrm{O}$ caused by the Bernoulli effect facilitates the egress of gas through the narrow-bore catheter. The degree of expiratory assistance is flow-dependent, with a maximum suction capacity of $12.4 \mathrm{l} \cdot \mathrm{min}^{-1}$ at an oxygen flow of $15 \mathrm{l} \cdot \mathrm{min}^{-1}$.

The DAS guidelines recommend using a high-pressure device capable of delivering a high minute volume to re-oxygenate a patient in a CICV situation through a narrow-bore cricothyroidotomy [2]. Although the Ventrain is a high-pressure oxygen source device (as defined by its driving pressure), the insufflation pressure measured proximal to the TTC is significantly lower than the pressure usually used for conventional 'jet ventilation'. In contrast to conventional high-pressure source ventilation devices, the Ventrain is flow-regulated and the insufflated oxygen is only slightly compressed. This might decrease the risk of barotrauma as the volume of insufflated oxygen can easily be estimated (e.g. redirecting an oxygen flow of $15 \mathrm{l} \cdot \mathrm{min}^{-1}$ for 1 second results in insufflation of $250 \mathrm{ml}$ of oxygen).

To ensure a stable inspiratory flow, a pressure-compensated flow meter or flow regulator capable of handling backpressure is mandatory. Insufflation and also suction pressures, suction capacity, inspiration and expiration times, and resulting inspiration/expiration ratio depend highly on the flow resistance of the attached catheter. The Ventrain has been specified to be used in combination with a $75 \mathrm{~mm}$ long, $2 \mathrm{~mm}$ ID TTC allowing manual control of ventilation in healthy adults with an inspiration/expiration ratio of about 1 to 1 at oxygen flows of $12^{-15} \mathrm{l} \cdot \mathrm{min}^{-1}$.

Changes in oxygen flow, pulmonary compliance, and flow resistance of the catheter might change the inspiration/expiration ratio. Therefore, it needs to be emphasized that during use of the Ventrain, one should always watch the chest movements of the patient. Failure to do so could lead to hyperinflation or the development of negative intrathoracic pressure.

In the case of hyperinflation or negative intrathoracic pressure, one needs to adjust the duration of the inspiration or expiration, or one might allow (slow) equilibration of the intrathoracic pressure with the atmosphere by releasing the aperture of the exhaust pipe and the bypass of the Ventrain.

If the Ventrain is connected to an oxygen flow, low levels of subatmospheric pressure (maximally $-6.5 \mathrm{cmH}_{2} \mathrm{O}$ at $15\left(\cdot \mathrm{min}^{-1}\right)$ are generated with both openings released. This subatmospheric pressure can compensate for the flow resistance of the connecting tubing with the distal T-piece. Thus, 
with the exhaust pipe and the bypass open, the Ventrain will be not only switched off, but also functionally disconnected from the catheter.

The maximal subatmospheric pressure created by the Ventrain in this bench study was $-217 \mathrm{cmH}_{2} \mathrm{O}$. In a clinical setting, this pressure can only be reached if the upper airway is completely obstructed and if more gas is suctioned out of the patient than has been insufflated. Negative pressure pulmonary oedema, however, is a potential complication that might develop even after a short period of high subatmospheric intrapulmonary pressure. Therefore, ongoing in vivo trials are needed to determine the clinical effects of any subatmospheric pressure potentially generated by the Ventrain.

However, if used correctly, the Ventrain provides positive pressure ventilation with controlled expiration with a minute volume of up to $7.1 \mathrm{l} \cdot \mathrm{min}^{-1}$, an increase in minute volume of $112 \%$ at a compliance of $100 \mathrm{ml} \cdot \mathrm{CmH}_{2} \mathrm{O}^{-1}$ compared with the minute volume achievable through a narrow-bore catheter with passive expiration. This minute volume would not only be enough for re-oxygenation, but it would also prevent hypercarbia in most adults. The value of the Ventrain compared with ventilation with passive backflow is influenced by pulmonary compliance and upper airway resistance. The Ventrain is proved to be most efficient at a high compliance, whereas a decrease in pulmonary compliance limited the effect of expiratory assistance. However, at a compliance of a healthy adult patient $\left(50 \mathrm{ml} \cdot \mathrm{cmH}_{2} \mathrm{O}^{-1}\right)$, the minute volume at an oxygen flow of $15 \mathrm{l} \cdot \mathrm{min}^{-1}$ was still 6.9 $1 \cdot \mathrm{min}^{-1}$. EVA can be regarded as a hybrid technique for narrow-bore ventilation between intermittent positive pressure ventilation with passive expiration, which requires a widebore and sealed airway, and conventional 'jet ventilation' through a narrow-bore catheter, which requires an open upper airway. The Ventrain applies EVA efficiently in vitro. If ongoing studies confirm the safety and efficacy of this ventilation ejector in vivo, it may become a beneficial tool in modern airway management, for example, as a portable ventilator for transtracheal emergency ventilation.

\section{Acknowledgements}

We would like to thank Dirk van Asseldonk (CEO; Dolphys Medical BV, Eindhoven, The Netherlands) for providing the pre-release sample of the Ventrain and the CAD drawings, and Appie Derks (AVteam, MUMC) for taking the photographs of the Ventrain.

\section{Declaration of interest}

A.H. is a member of the medical advisory board of Ambu and has received free samples of airway equipment for teaching and clinical evaluation from several companies. She has no financial interest in any company. D.E. is the inventor of the Ventrain and receives royalty payments from Dolphys Medical, Eindhoven, The Netherlands. Also the Maastricht University Medical Centre receives royalty payments from Dolphys Medical.

Funding

This work was supported by European funding, OP-Zuid (31R104). 


\section{References}

1. Caplan RA, Benumof JL, Berry FA, et al. Practice guidelines for management of the difficult airway. An updated report by the American Society of Anesthesiologists Task Force on Management of the Difficult Airway. Anesthesiology 2003; 98: 1269-77

2. Henderson JJ, Popat MT, Latto IP, Pearce AC. Difficult Airway Society guidelines for management of the unanticipated difficult intubation. Anaesthesia 2004; 59: 675-94

3. Jaquet $Y$, Monnier P, Van Melle G, Ravussin P, Spahn DR, Chollet-Rivier M. Complications of different ventilation strategies in endoscopic laryngeal surgery: a 10-year review. Anesthesiology 2006; 104: 52-9

4. Craft TM, Chambers PH, Ward ME, Goat VA. Two cases of barotrauma associated with transtracheal jet ventilation. Br J Anaesth 1990; 64: 524-7

5. Cook TM, Bigwood B, Cranshaw J. A complication of transtracheal jet ventilation and use of the Aintree intubation catheter during airway resuscitation. Anaesthesia 2006; 61: 692-7

6. Cook TM, Woodall N, Frerk C. Major complications of airway management in the UK: results of the Fourth National Audit Project of the Royal College of Anaesthetists and the Difficult Airway Society. Part 1: Anaesthesia. Br J Anaesth 2011; 106: 617-31

7. Kiyama S, Koyama K, Takahashi J, Fukushima K. Tension pneumothorax resulting in cardiac arrest during emergency tracheostomy under transtracheal jet ventilation. J Anesth 1991; 5: 427-30

8. Schumacher P, Stotz G, Schneider M, Urwyler A. Laryngospasm during transtracheal high frequency jet ventilation. Anaesthesia 1992; 47: 855-6
9. Eger El, Hamilton WK. Positive-negative pressure ventilation with a modified Ayre's T-piece. Anesthesiology 1958; 19: $611-8$

10. Dunlap LB, Oregon E. A modified, simple device for the emergency administration of percutaneous transtracheal ventilation. JACEP 1978; 7: 42-6

11. Hamaekers A, Borg P, Götz T, Enk D. Using expiratory ventilation assistance (EVA) to achieve an adequate minute volume through a $2 \mathrm{~mm}$ transtracheal catheter in a simulated upper airway obstruction. Eur J Anaesthesiol 2009; 26 (Suppl. 45): 19AP 4-4

12. Hamaekers A, Götz T, Borg P, Enk D. Ventilation through a small-bore catheter: optimizing expiratory ventilation assistance. Br J Anaesth 2011; 106: 403-9

13. Hamaekers A, Theunissen M, Jansen J, Honig W, Enk D. Fast recovery from severe hypoxia through a $2 \mathrm{~mm}$ transtracheal catheter in pigs with a completely obstructed upper airway. Eur J Anaesthesiol 2010; 27 (Suppl. 47): 19AP 1-9

14. Enk D. Gasstromumkehrelement. Patent application (10 2007013 385.7). German Patent Office, March 16, 2007

15. Hamaekers A, Borg P, Enk D. A bench study of ventilation via two self-assembled jet devices and the Oxygen Flow Modulator in simulated upper airway obstruction. Anaesthesia 2009; 64: 1353-8

16. Dworkin R, Benumof JL, Benumof R, Karagianes TG. The effective tracheal diameter that causes air trapping during jet ventilation. J Cardiothorac Anesth 1990; 4: 731-6 
104 


\section{Chapter 8}

General discussion 
Maintaining adequate oxygen supply to the tissues and removal of carbon dioxide from the lungs is essential to sustain life. The inability to oxygenate via mask or supraglottic airway device in a patient in which endotracheal intubation attempts have failed, is one of the most severe emergencies in anaesthesia, intensive care medicine and emergency care. Immediate insertion of a percutaneous emergency airway can prevent hypoxic brain damage and death in a 'cannot intubate, cannot oxygenate' (CICO) situation [1, 2]. Inserting a narrow-bore catheter or cannula through the cricothyroid membrane is for the majority of anaesthetists the firstchoice [3], as this technique is widely available and suggested to be simple and quick [4]. However, the increased flow resistance of these catheters requires a ventilator with a high driving pressure [5] and a patent upper airway to assure the egress of gas. Obstruction of the upper airway caused by laryngospasm, oedema or anatomical distortion, and overvigorous oxygen insufflation can result in air trapping. Many cases of barotrauma and haemodynamic instability associated with deleterious outcome using this type of ventilation are reported in the literature [6-8]. Therefore, within the scientific community, there is a lot of controversy on how to ventilate safely and efficiently in an emergency situation $[9,10]$.

The aims of this thesis were to investigate potential drawbacks of the currently available emergency jet ventilation devices and to develop a new ventilation mode controlling and facilitating expiration through a narrow-bore catheter. 


\section{Aim 1: Are self-assembled emergency jet- ventilation devices safe?}

In elective surgical cases a conventional jet ventilator (e.g. a manual Sanders ejector or an automated high frequency jet ventilator) is used to achieve adequate ventilation through a narrow-bore cannula. These devices are often not immediately available in emergency situations. Therefore, various simple, self-assembled devices made of a threeway stopcock and oxygen tubing, have been proposed for emergency jet ventilation [11-13]. When connected to a high-pressure, flow-regulated oxygen source these devices do transmit sufficient pressure and flow to allow effective low frequency jet ventilation by intermittent occlusion of the side port of the three-way stopcock $[12,14]$. However, during emergency jet ventilation it is mandatory that flow from the oxygen source is stopped (as in the conventional jet ventilators) or adequately released through the side port of the emergency jet device during the expiration phase.

As shown in chapter 2, a three-way stopcock based, self-assembled device acts as a 'flow splitter' and, when connected to an oxygen flow, even with the side port completely open, never ensures total flow and pressure release. In a completely obstructed upper airway, the oxygen flow will inevitably create high airway pressure during the expiratory phase that can lead to barotrauma and hemodynamic instability. Thus, the use of a three-way stopcock device to control oxygen flow during emergency jet ventilation, as described in current textbooks and recent literature, has a potentially dangerous effect and should not be recommended. Moreover, when comparing different devices, only the commercially available Oxygen Flow Modulator ensured sufficient flow and pressure release.

\section{Aim 2: Which emergency jet-ventilation device can function as a bidirectional airway?}

Transtracheal jet ventilation has a low morbidity as long as the egress of gas is secured [4]. As conventional jet ventilators have a mechanical one-way valve incorporated, no gas will egress through the transtracheal catheter and a patent upper airway is mandatory to assure efficient and safe ventilation. When the upper airway is obstructed, jet ventilation results in air trapping [15] with subsequent lung damage by over-distension and haemodynamic instability [68]. In a clinical emergency it is usually unknown whether the airway of the patient is patent or opens at a higher airway pressure. Therefore, it is crucial that every device used in a CICO situation is not only able to provide effective flow release and pressure control, but also allows bidirectional airflow. Only under these circumstances, the injection of oxygen and the egress of gas can take place through the same airway catheter.

The self-assembled jet ventilation devices studied in Chapter 2 did not ensure total flow and pressure release during the expiratory phase. However, changing the connecting position of the transtracheal catheter on the three-way stopcock from the in-line port (as in chapter 2) to the side port (device $B$ in chapter 3 ) resulted in a slightly negative pressure at the catheter's tip (Chapter 3 ). This improves the safety of the emergency ventilation device because under these circumstances device $B$ allows bidirectional airflow. So even in a fully obstructed upper airway air can escape. This is in contrast to the conventional jet ventilators that fully block the egress of gas through the catheter and need to be disconnected from the catheter to allow any air to escape in an obstructed airway. The negative expiratory pressure created by device $B$ did however not improve the egress of gas through the narrow-bore catheter compared to passive 
outflow. All devices tested impeded the expiratory outflow and hence decreased the achievable minute volume.

\section{Aim 3: Feasibility of expiration through a narrow- bore cannula by suction.}

Passive outflow of gas through a narrow-bore transtracheal catheter is limited because of the high internal resistance of the catheter and the low driving force for the egress of gas. The time necessary for the egress of $1000 \mathrm{ml}$ of oxygen via a catheter with an internal diameter of $2 \mathrm{~mm}$ is 13.4 seconds. An increase of flow through a small-bore catheter during expiration can only be performed via three mechanisms: First, the driving force can be increased, for example by applying compression to the thorax and abdomen. Second, the resistance of the outflow tract can be diminished, by inserting an additional transtracheal catheter. Third, it has been suggested to augment the outflow of gas by applying external suction [16-18]. In pediatric ventilation this third option has shown to be very useful [19]. However, in emergency ventilation in adults none of the proposed techniques and devices found their way into clinical practice, because they were not effective or too complex to use.

To solve this problem, we developed an alternative ventilation mode and constructed a simple emergency ventilation device. This device was based on an ejector. In principle, an ejector is a multipurpose device able to create a subatmospheric pressure via the Bernoulli principle and to entrain air from a side port [20]. A small, industrial ejector was transformed into a simple, manual ventilator providing oxygen insufflation and expiratory ventilation assistance (EVA) induced by suction. This device was able to shorten the expiration time significantly and achieved a calculated expiratory minute volume up to $6.6 \mathrm{l} \cdot \mathrm{min}^{-1}$ through a $2 \mathrm{~mm}$ ID transtracheal catheter in a simulated obstructed airway.

\section{Aim 4: Technical features necessary to optimize the entrainment effect for Expiratory Ventilation Assistance (EVA).}

Bernoulli's principle implies that for an inviscid flow of a non-compressible (or, with restrictions, a compressible) fluid, an increase in velocity at a constriction in a tube leads to an increase in dynamic pressure (and thus kinetic energy) and a corresponding decrease in static pressure (and potential energy). This is in accordance with the first law of thermodynamics (conservation of energy) [21]. Our results illustrate that the amount of entrainment and consequently the degree of expiratory assistance depend on the velocity of the driving gas and the resistance of the outflow tract of the ejector. Although an ejector's resistance to flow is primarily defined by its inner geometry, the velocity of the driving gas jet passing through the ejector modulates the effective resistance while the ejector is active. If, at a given flow, the velocity of the driving gas is decreased (e.g. by turbulent mixing with entrained gas), an ejector will become less efficient. In most industrial ejectors and also in a previously described ventilation ejector [22] the outflow tract has been designed to create a maximum subatmospheric pressure. The results of our study show that an industrial ejector (SBP07) is indeed capable of generating a high negative pressure in a static situation, that is, if no gas is entrained. However, in a dynamic situation, when gas is continuously entrained through the transtracheal catheter, the generated pressure was considerably less negative. Compared with the industrial ejector, our ventilation ejector (prototype DE5) built up a less negative pressure in a static situation, but maintained a higher negative pressure in a dynamic situation, leading to an improved suction capacity and a higher entrainment ratio. Our ventilation ejector was designed to provide an optimized entrainment effect for EVA 
and achieved a minute volume of up to 8.3 litres through a $75 \mathrm{~mm}$ long, $2 \mathrm{~mm}$ ID transtracheal catheter. So, Expiratory Ventilation Assistance (EVA), when applied by an optimized ventilation ejector, can achieve a minute volume adequate for normoventilation of an adult patient through a 'straw'.

\section{Aim 5: Efficiency of EVA on restoring oxygenation and ventilation.}

In six monitored and anaesthetized pigs a narrow-bore transtracheal catheter was placed under controlled circumstances. Following baseline recordings the pigs were exposed to 2 minutes of apnoea and the endotracheal tube was occluded. The oxygen saturation decreased to a median of $45 \%$ [range 33-60\%]. EVA was applied via the transtracheal catheter using the DE5 prototype. Within 20 seconds after the initiation of EVA, hypoxemia was corrected $\left(\mathrm{SaO}_{2}\right.$ $>95 \%$ ) in all animals. In the second part of the study, the experiment was repeated with a partly obstructed or open endotracheal tube, simulating different levels of upper airway patency. Under conditions of a partly obstructed endotracheal tube, EVA restored oxygenation again within 20 seconds $\left(\mathrm{SaO}_{2}>95 \%\right)$. However, when the airway was left completely open, 2 animals still had an oxygen saturation below $90 \%$ after 15 minutes. The efficacy of EVA decreased as the endotracheal tube was less obstructed resulting in protracted re-oxygenation and severe hypercarbia when the airway is open. Our results demonstrate that the adapted ventilation mode (EVA) applied by our optimized ventilation ejector can achieve rapid re-oxygenation and efficient ventilation through a narrow-bore catheter in an obstructed airway.

\section{Aim 6: To evaluate the efficacy of Ventrain ${ }^{\circledR}: a$ commercially available emergency ventilator applying EVA}

The novel emergency ventilation ejector introduced and evaluated in chapter 7 (commercial name: Ventrain ${ }^{\circledR}$ ) turns a high driving pressure (up to 2.3 bar) at the jet nozzle into a high velocity oxygen stream and creates a subatmospheric pressure up to $-217 \mathrm{cmH}_{2} \mathrm{O}$ to facilitate the egress of gas. The driving pressure, inspiratory pressure and degree of expiratory assistance of the Ventrain ${ }^{\circledR}$ are flow-dependent. The maximum suction capacity was reached at an oxygen flow of $15 \mathrm{l} \cdot \mathrm{min}^{-1}$. Although the Ventrain ${ }^{\circledast}$ is a high-pressure ventilation device, the insufflation pressure proximal to the transtracheal catheter (maximum $138 \mathrm{cmH}_{2} \mathrm{O}$ ) is significantly lower than the pressure used for conventional 'jet ventilation'. In the bench study the Ventrain ${ }^{\circledast}$ achieved a minute volume of up to $7 \mathrm{l} \cdot \mathrm{min}^{-1}$ through a $2 \mathrm{~mm}$ ID transtracheal catheter and seems an efficient ventilation ejector.

Based on our studies we can conclude that all available self-assembled emergency jet ventilation devices, with the exception of the OFM, cannot be used safely in a CICO situation, as there is always a risk of upper airway obstruction. Expiratory Ventilation Assistance (EVA), however, enables normoventilation through a narrow-bore airway catheter, minimizes the risk of air trapping and achieves rapid reoxygenation in pigs with an obstructed airway. The concept of EVA is successfully implemented in a novel commercially available emergency ventilation device: Ventrain ${ }^{\circledast}$. 
Should EVA via Ventrain ${ }^{\circledR}$ be integrated in standard clinical recommendations for management of a 'cannot intubate, cannot oxygenate' situation?

Narrow-bore cannula insertion with jet ventilation is included in the guidelines of the Difficult Airway Society (DAS) and American Society of Anesthesiologists (ASA) as an option for achieving swift re-oxygenation in a CICO situation. However, the fourth UK National Audit Project (NAP4) reports a series of cases where narrow-bore cricothyroidotomies had a very low success rate (37\%), whereas surgical percutaneous access was successful in all cases [23]. These results stimulated the debate on the dilemma of whether or not to attempt insertion of a narrow-bore cannula. Several recent publications have questioned the role of narrow-bore cricothyroidotomy and advised placement of a large-bore cannula in an airway emergency [2, 24, 25].

The rate of successful re-oxygenation via a narrow-bore cricothyroidotomy reported in the literature varies between 37 and $66 \%[23,26]$. This low success rate might be inherent to the technique, but is also suggested to be a consequence of lack of training and inadequate equipment [23]. Various studies and surveys indicate that most anaesthetists are not prepared for performing an emergency percutaneous airway. Moreover, knowledge on the technique and availability of the necessary equipment to ventilate through a narrow-bore catheter is often inadequate [3, 27, 28]. Self-assembled ventilation devices are inefficient and as discussed in this thesis use in an emergency case can even result in serious complications. The application of EVA via the Ventrain ${ }^{\oplus}$ device will provide swift re-oxygenation as it achieves a minute volume of 7 litres through a narrow-bore cricothyroidotomy cannula and minimizes the risk of airtrapping.
Besides appropriate equipment, the skills of a trained professional able to make the decision to perform an emergency percutaneous airway and then performs this procedure successfully before the patient suffers irreversible brain damage or death is needed. Surgical cricothyroidotomy is a reliable technique with a high success rate, but is often performed too late to avoid a poor outcome [29]. The time needed to reach sufficient re-oxygenation is of critical importance. Thus, delayed decision-making in $\mathrm{CICO}$ is a common reason for bad outcome [23,30]. Reluctance to perform a cricothyroidotomy (ie, human factors reasons) is most likely the primary cause for delay [31]. Anaesthetists are naturally reluctant to perform an emergency percutaneous airway [32]. However, in general, they feel more comfortable inserting a narrow-bore cannula (needle cricothyroidotomy) when compared to a large-bore cannula and have low confidence in performing a surgical airway themselves [3].

With the introduction of EVA and Ventrain ${ }^{\circledR}$ we need to change the focus of the debate on small-bore versus largebore cricothyroidotomy. Both cricothyroidotomy techniques now allow efficient and safe ventilation, but there may be differences in the speed of insertion, the success rate and the incidence of complications of cannula placement. Furthermore, the level of experience needed, the familiarity of the operator with the technique and the time needed to teach and retain the skills may differ between small and large-bore cricothyroidotomy.

Unfortunately, there is not sufficient evidence so far to answer the above questions. Future research should compare small-bore versus large-bore cannula placement by anaesthetists and should focus on the ease of use of Ventrain $^{\oplus}$ in an emergency situation and the retention of skills of performing a surgical cricothyroidotomy and of applying 
EVA. As a CICO situation is a rare complication, it seems questionable whether a clinical study on this subject is feasible. Thus alternative studies including scenario simulation research need to be performed.

However, successful cricothyroidotomy and swift reoxygenation in an airway emergency perhaps relies more on the operator's general clinical experience, practice and skills than on the devices themselves [33]. Whatever emergency technique is chosen, it is essential that the equipment is readily available, the anaesthetic team is familiar with its use and is trained regularly. Coming back on the question at the beginning of this paragraph: should EVA via Ventrain ${ }^{\circledast}$ be an integral part of standard clinical recommendations for management of a 'cannot intubate, cannot oxygenate' situation? Should this technique be available on the OR and be trained by the anaesthetic team? The strength of current evidence does not justify recommending one cricothyroidotomy technique over the other. However, for emergency ventilation through a narrow-bore cricothyroidotomy catheter, EVA is the safest ventilation mode available. For anaesthetists, insertion of a narrow-bore airway catheter and subsequent use of EVA by Ventrain ${ }^{\circledR}$ is a sensible first choice to achieve swift re-oxygenation under $\mathrm{CICO}$ conditions.

\section{EVA as a new ventilation mode}

It needs to be emphasized that EVA is not just a "modified" type of jet ventilation. Flow-controlled EVA for ventilation through small-bore cannulas can be considered a hybrid technique in between intermittent positive pressure ventilation with passive expiration, which requires a wide-bore tube and sealed airway, and jet ventilation through a narrow-bore catheter, which requires high injection pressures and an open upper airway. Although at its introduction the indication for EVA was deliberately and cautiously limited to emergency ventilation, the ability of controlling the expiration and achieving a sufficient respiratory minute volume of 7 litres through a narrow-bore catheter in a blocked airway allows for a new array of clinical applications and offers a source for many interesting research questions.

Two application features of EVA can be distinguished:

1 The possibility of fully ventilating through a narrowbore catheter while blocking the rest of the airway. EVA can be used for ventilation through narrow-bore catheters. In this thesis the results in combination with a transtracheal catheter are reported. However, one can also apply EVA with other airway catheters. This might offer new treatment options for patients with an airway stenosis, could improve the surgical view during a procedure in the airway, and might lower the laryngeal morbidity associated with endotracheal intubation. One could even place narrow-bore cuffed catheters in the main bronchi to ventilate both lungs separately. This could mean an important advantage in thoracic surgery, but also in critically ill patients with an acquired respiratory disease, cystic fibrosis, infectious diseases or pathology of one lung.

Currently, Ventrain ${ }^{\circledR}$ is the only commercially available ventilation device able to apply EVA. It is manually operated, can only insufflate $100 \%$ non-humidified oxygen and has no pressure reading. Therefore, long-term use is still problematic and thus the abovementioned clinical applications are not well feasible yet. An electronic ventilator with EVA incorporated is mandatory to study these clinical and experimental applications.

There are, however, several clinical situations in which EVA via Ventrain ${ }^{\circledast}$ has additional value compared to 
existing ventilation modes. Its use might already be considered in clinical practice for ventilation through:

- a jet ventilation catheter in case of failure of jet ventilation due to airtrapping in an obstructed airway,

- a tube exchanger for reoxygenation while managing a difficult airway,

o the working channel of a flexible intubation scope in case of desaturation while performing endoscopy and intubation, and

- transtracheal cannulas in elective laryngeal surgery in patients with a large space occupying lesion with a high risk of jet ventilation failure (see Epilogue).

\section{Controlling expiration}

Using EVA it is possible to control the expiration. EVA can increase the expiratory flow, shortens the expiration time and can create negative end expiratory pressure if desired. Furthermore, the EVA ventilation mode produces distinct flow and pressure curves and has different ventilation properties compared to conventional ventilation modes. These features may have a beneficial effect on venous return, pulmonary circulation and cardiac output and may create different shear stress patterns. EVA could provide a novel strategy of lung-protective ventilation.

It is fascinating to hypothesize about the potential applications of the EVA principle and as Prof. William Rosenblatt, Yale University stated:

\section{"The limitation of EVA is probably your own imagination"}

\section{Conclusion}

Expiratory Ventilation Assistance (EVA) is introduced as a new ventilation mode for ventilation through narrow-bore catheters in an obstructed airway. The concept of EVA is successfully implemented in a novel commercially available emergency ventilation device: Ventrain ${ }^{\circledR}$. Ventrain ${ }^{\circledR}$ is a valuable tool for ventilation through a narrow-bore catheter in an airway emergency. The full potential of EVA within modern airway management, including elective routine use, has yet to be explored. 


\section{References}

1. Henderson JJ, Popat MT, Latto IP, Pearce AC. Difficult Airway Society guidelines for management of the unanticipated difficult intubation. Anaesthesia 2004; 59: 675-94.

2. Law JA, Broemling N, Cooper RM, Drolet P, Duggan LV, Griesdale DE et al. The difficult airway with recommendations for management-Part 1-Difficult tracheal intubation encountered in an inconscious/induced patient. Canadian Journal of Anaesthesia 2013; 60: 1089-1118

3. Wong DT, Lai K, Chung FF, Ho RY. Cannot intubate-cannot ventilate and difficult intubation strategies: results of a Canadian national survey. Anesthesia and Analgesia 2005; 100: $1439-46$

4. Patel RG. Percutaneous transtracheal jet ventilation: a safe, quick, and temporary way to provide oxygenation and ventilation when conventional methods are unsuccessful. Chest 1999; 116: 1689-94.

5. Flint NJ, Russell WC, Thompson JP. Comparison of different methods of ventilation via cannula cricothyroidotomy in a trachea-lung model. British Journal of Anaesthesia 2009; 103: 891-5

6. Cook TM, Bigwood B, Cranshaw J. A complication of transtracheal jet ventilation and use of the Aintree intubation catheter during airway resuscitation. Anaesthesia 2006; 61: 692-7

7. Hardy MJ, Huard C, Lundblad TC. Bilateral tension pneumothorax during jet ventilation: a case report. AANA $J$ 2000; 68: 241-4

8. Craft TM, Chambers PH, Ward ME, Goat VA. Two cases of barotrauma associated with transtracheal jet ventilation. British Journal of Anaesthesia 1990; 64: 524-7

9. Scrase I, Woollard M. Needle vs surgical cricothyroidotomy: a short cut to effective ventilation. Anaesthesia 2006; 61: $962-74$

10. Cook TM, Nolan JP, Cranshaw J, Magee P. Needle cricothyroidotomy. Anaesthesia 2007; 62: 289-90
11. Gal T. Airway management. In: Miller RD, ed. Miller's Anesthesia, $6^{\text {th }}$ edn. Philadelphia, PA: Elsevier, 2005: 1637-39.

12. Bould MD, Bearfield P. Techniques for emergency ventilation through a needle cricothyroidotomy. Anaesthesia 2008; 63: 535-539.

13. Mace SE. Needle cricothyrotomy. Emergency Medicine Clinics of North America 2008; 26: 1085-101.

14. Schaefer R, Hueter L, Preussler NP, Schreiber T, Schwarzkopf $\mathrm{K}$. Percutaneous transtracheal emergency ventilation with a self-made device in an animal model. Paediatric Anaesthesia 2007; 17: 972-6

15. Craven RM, Vanner RG. Ventilation of a model lung using various cricothyrotomy devices. Anaesthesia 2004; 59: 595-9.

16. Dunlap LB, Oregon E. A modified, simple device for the emergency administration of percutaneous transtracheal ventilation. J Am Coll Emerg Physicians 1978; 7: 42-6

17. Schapera A, Bainton CR, Kraemer R, Lee K. A pressurized injection/ suction system for ventilation in the presence of complete airway obstruction. Critical Care Medicine 1994; 22: 326-33

18. Garry B, Woo P, Perrault DF Jr, Shapshay SM, Wurm WH. Jet ventilation in upper airway obstruction: description and model lung testing of a new jetting device. Anesthesia Analgesia 1998; 87: 915-20

19. Keuskamp DH. Automatic ventilation in paediatric anaesthesia using a modified Ayre's T-piece with negative pressure during expiratory phase. Anaesthesia 1963; 18: 46-56

20. Fluid flow. In: Davis PD, ed. Basic Physics and Measurement in Anaesthesia, $5^{\text {th }}$ Edn. Philadelphia, PA: Elsevier, 2007; $19-20$

21. Bernoulli D. Hydrodynamica, sive De viribus et motibus fluidorum commentarii. Opus academicum ab auctore, dum Petropoli ageret, congestum. Strasbourg: Johann Reinold Dulsecker, 1738 
22. Meissner K, Iber T, Roesner JP, Mutz C, Wagner HE, Layher C, Bartels U, Gründling M, Usichenko TI, Wendt M, Lehmann C, Pavlovic D. Successful transtracheal lung ventilation using a manual respiration valve: an in vitro and in vivo study. Anesthesiology 2008; 109:251-9

23. Cook T, Woodall N, Frerk C. Major complications of airway management in the UK: results of the 4th National Audit Project of the Royal College of Anaesthetists and the Difficult Airway Society. Part 1: Anaesthesia. British Journal of Anaesthesia 2011; 106: 617-31.

24. Nolan JP, Soar J, Zideman DA, Biarent D, Bossaert LL, Deakin C, Koster RW, Wyllie J, Boettiger B. European resuscitation council guidelines for resuscitation 2010 (section1): executive summary. Resuscitation 2010; 81: 1219-76

25. Crewdson K, Lockey D. Needle, knife, or device - which choice in an airway crisis? Scandinavian Jounal of Trauma, Resuscitation and Emergency Medicine 2013: 21: 49-50

26. Hubble MW, Wilfong DA, Brown LH, Hertelendy A, Benner RW. A meta-analysis of pre-hospital airway control techniques part II: alternative airway devices and cricothyrotomy success rates. Pre-hospital Emergency Care 2010; 14: 515-30.
27. Davies P. A stab in the dark! Are you ready to perform needle cricothyroidotomy? Injury 1999; 30: 659-62.

28. Green L. Can't intubate, can't ventilate! A survey of knowledge and skills in a large teaching hospital. European Journal of Anaesthesiology 2009; 26: 480-3.

29. Peterson GN, Domino KB, Caplan RA, Posner KL, Lee LA, Cheney FW. Management of the difficult airway: a closed claims analysis. Anesthesiology 2005; 103: 33-9.

30. Spaite DW, Joseph M. Pre-hospital cricothyrotomy: an investigation of indications, technique, complications, and patient outcome. Annals of Emergency Medicine 1990; 19: 279-85.

31. Frerk C, Frampton C. Cricothyroidotomy; time for change. Anaesthesia 2006; 61: 921-3.

32. Greenland KB, Acott C, Segal R, Goulding G, Riley RH, Merry AF. Emergency surgical airway in life-threatening acute airway emernegncies - why are we so reluctant to do it? Anaesthesia and Intensive Care 2011; 39: 578-84

33. Crosby ET, Cooper RM, Douglas MJ, et al. The unanticipated difficult airway with recommendations for management. Canadian Journal of Anaesthesia 1998; 45: 757-76. 


\section{Epilogue}

\section{The use of expiratory ventilation assistance in clinical practice}





\section{Case Report}

Editor-Ventrain (Dolphys Medical, Eindhoven, The Netherlands) has been registered as an emergency ventilation device (Fig. 1) [1]. We report its use in an ENT patient.

A 60-yr-old man with an exophytic glottis tumour and significant inspiratory stridor presented for diagnostic laryngo-tracheo-bronchoscopy and possibly tracheostomy. Several options were considered for management of the airway.

First, high-frequency jet ventilation (HFJV) is the routine ventilation technique in our hospital for diagnostic laryngoscopies. Usually, a narrow-bore jet ventilation catheter is introduced via the nose into the trachea with the help of a Magill forceps, guided by routine direct laryngoscopy. The second option was routine (flexible) laryngoscopy and (awake) tracheal intubation with a wide-bore ( $\geq 4 \mathrm{~mm}$ ID) tube over a flexible bronchoscope, gum elastic bougie, or Aintree intubation catheter. However, both the options carry the risks of bleeding and swelling of the tumour, making an emergency

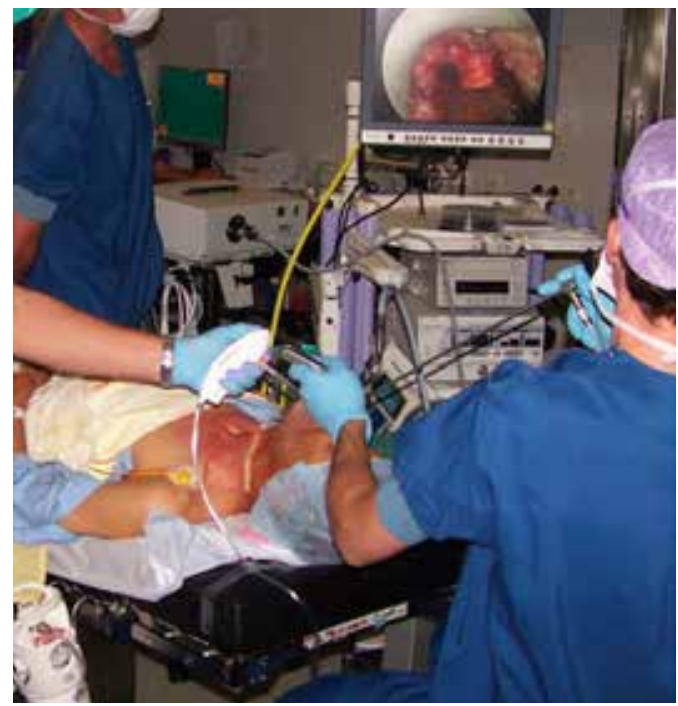

Figure 1 Ventrain being used for an elective laryngoscopy. 
tracheostomy more likely in a situation with pre-existing serious stridor. The third option would be an elective awake wide-bore tracheostomy, having a higher success rate than an emergency procedure, but this may be unnecessary and is not preferable from the oncological point of view.

Fourthly, introducing a narrow-bore cannula through the cricothyroid membrane into the trachea to apply HFJV is also a common procedure in our hospital. It creates a temporary, minimally invasive access to the airway below the level of the obstruction. However, any jet ventilator is a unidirectional device only providing inspiration, so expiration by the natural upper airway is mandatory. A large tumour might hinder expiration, leading to air trapping, with the risks of barotrauma and the inability to ventilate efficiently. In contrast, the Ventrain is capable of controlling both inspiration and expiration through a narrow-bore catheter and might thus reduce the risk of air trapping. We agreed on using this option as it is minimally invasive and safe compared with the other techniques and furthermore leaves all therapeutic options intact.

It was explained to the patient that a cannula would be introduced in the neck in order to ventilate the lungs throughout the procedure. The patient consented and was quiet and cooperative all the time. After local infiltration and injection of $3 \mathrm{ml} 4 \%$ lidocaine into the trachea, a $2 \mathrm{~mm} I D, 75 \mathrm{~mm}$ long emergency transtracheal airway catheter (ETAC; Cook Medical, Bloomington, IN, USA) was introduced via the cricothyroid membrane and its intratracheal position was confirmed by aspiration of air and by capnography. The Ventrain was then connected to the ETAC and to a 2 litres oxygen cylinder with a built-in pressure compensated flow regulator set to $15 \mathrm{l} \cdot \mathrm{min}^{-1}$. General anaesthesia was provided by our standard procedure: initially, propofol and remifentanil boluses and subsequently continuous pump-driven infusion combined with boluses of cisatracurium, gauged by train-of-four monitoring. Ventilation with the Ventrain ( 2 seconds each for inspiration and expiration, thus a frequency of $15 \mathrm{~min}^{-1}$ ) produced moderate, but clearly visible, thoracic excursions with the chest always returning to its original shape. Temporarily closing nose and mouth led to greater excursions, but not to air trapping. Laryngoscopy by the ENT surgeon revealed left-sided vocal paralysis besides the large glottic tumour, explaining the inspiratory stridor at least in part. Laryngoscopy and biopsies lasted 15 minutes. $\mathrm{SpO}_{2}$ was $100 \%$ throughout. After the surgical procedure, the syringe drivers were stopped, the neuromuscular blocking agent was reversed, and ven- 
tilation was reduced by lowering the driving oxygen flow to $5 \mathrm{l} \cdot \mathrm{min}^{-1}$, to raise the $\mathrm{PCO}_{2}$. Capnography was connected to the Ventrain and spontaneous ventilation started at an end-tidal $\mathrm{PCO}_{2}$ of $6.3 \mathrm{kPa}$. The patient woke up quietly. The Ventrain was disconnected and the ETAC was left in position and was only removed 6 hours later on the post-anaesthesia care unit, when it was clear there was no increase in inspiratory stridor by swelling or bleeding. The whole procedure was uneventful. The diagnostic information gathered led to the decision to start radiotherapy.

In conclusion, we report the successful and uneventful elective use of the Ventrain with 20 minutes of adequate ventilation and oxygenation in a patient with a partial obstruction of the laryngeal inlet.

\section{References}

1. Hamaekers AEW, Borg PAJ, Enk D. Ventrain: an ejector ventilator for emergency use. Br J Anaesth 2012; 108: 1017 



\section{Appendices}

Summary

Valorisation addendum

Curriculum vitae

Publications 



\section{Summary}

The inability to maintain oxygenation in a patient by non-invasive airway maneuvers is one of the most pressing emergencies in anaesthesia and emergency care. To prevent hypoxic brain damage and death, emergency percutaneous airway access must be performed immediately. In the prologue a case of a 'cannot intubate, cannot oxygenate' (CICO) situation is described. In this case a narrow-bore catheter was successfully inserted in the airway and oxygen could be insufflated into the lungs. However, a new problem arose as it was impossible to provide an adequate outflow of the gas, which resulted in air trapping and haemodynamic instability.

The various techniques, strategies and equipment available for emergency oxygenation are described in chapter 1. Unfortunately all available techniques have their limitations and the ideal rescue technique for a CICO situation seems not yet to exist. Although a narrow-bore cricothyroidotomy catheter is easy to insert and anaesthetists generally feel comfortable placing it, reoxygenation and ventilation through a narrow-bore catheter poses new challenges. In order to overcome the resistance of a narrow cannula, a high-pressure oxygen source is necessary for achieve adequate flow through the narrow cannula.

Because an automated or hand-triggered jet injector may not be immediately available, various self-assembled devices consisting of a three-way stopcock and oxygen tubing have been proposed for emergency jet ventilation through a narrow-bore airway catheter. Combined with a high oxygen flow, these devices are generally supposed to provide adequate pressure and flow for emergency reoxygenation. However, as shown in the bench study described in chapter 2 , a three-way stopcock based, self-assembled device acts as a 'flow splitter' and, when connected to an oxygen flow, even with the side port completely open, never ensures total flow and pressure release. In a completely obstructed upper airway, the oxygen flow will inevitably create high airway pressure during the expiratory phase that can lead to barotrauma and hemodynamic instability. Thus, the use of a three-way stopcock device to control oxygen flow during emergency jet ventilation, as described in current textbooks and recent literature, is potentially dangerous and should not be recommended.

When using an automated or hand-triggered jet injector it is mandatory to maintain a patent upper airway for the egress of gas. Obstruction of the outflow tract or insufficient expiratory time results in air trapping with subsequent barotrauma and haemodynamic instability as described in the prologue. In a CICO situation partial obstruction of the upper airway, resulting from oedema, laryngospasm or distorted anatomy occurs frequently and it is uncertain whether the upper airway will open at a higher airway pressure. Therefore, it is crucial that a device used in a $\mathrm{CICO}$ situation is not only 
able to provide effective flow release and pressure control, but also allows bidirectional airflow. The self-assembled jet ventilation devices studied in Chapter 2 did not ensure total flow and pressure release during the expiratory phase. However, changing the connecting position of the transtracheal catheter on the three-way stopcock from the in-line port (as in chapter 2 ) to the side port (device B in chapter 3 ) resulted in a slightly negative pressure at the catheter's tip. This improved the safety of the emergency ventilation device as it allowed bidirectional airflow. So even in a fully obstructed upper airway gas could escape.

Passive outflow of gas through a small-bore catheter is limited because of the high internal resistance of the catheter and the low driving force for the egress of gas. The time needed for passive backflow of $1000 \mathrm{ml}$ oxygen through a catheter with an internal diameter (ID) of $2 \mathrm{~mm}$ is $13.4 \mathrm{sec}$ onds. To facilitate the outflow external suction can be applied during the expiratory phase. In pediatric ventilation this has shown to be very useful. However, in emergency ventilation in adults none of the proposed techniques and devices found their way into clinical practice, because they were not effective or too complex to use. In chapter $4 \mathrm{a}$ small, modified industrial ejector is introduced for applying Expiratory Ventilation Assistance (EVA). An ejector is a multi-purpose device able to create subatmospheric pressure based on Bernoulli's principle. Comparable with a Venturi nozzle, the driving gas flowing through an ejector entrains gas (e.g. ambient air) through a side port. The modified ejector was able to shorten the expiration time significantly and achieved a calculated expiratory minute volume through a $2 \mathrm{~mm}$ ID transtracheal catheter in a simulated obstructed airway up to $6.6 \mathrm{l} \cdot \mathrm{min}^{-1}$.

An industrial ejector is designed to create a maximum negative pressure to pick up and hold parts during manufacturing processes in industrial assembly lines. It cannot be expected to work perfectly as a ventilator. In chapter 5 the technical features and abilities of the modified industrial ejector and an optimized ejector-based ventilation device (DE5) are described. The results illustrate that the amount of entrainment and consequently the degree of expiratory assistance depend on the velocity of the driving gas and the resistance of the outflow tract of the ejector. The optimized DE5 achieved a calculated minute volume up to $7.5 \mathrm{l} \cdot \mathrm{min}-1$ through a $2 \mathrm{~mm}$ ID transtracheal cannula in an artificial lung model with complete outflow obstruction

In severely hypoxic pigs with a completely obstructed airway EVA, applied by the DE5, restored oxygenation through a small-bore transtracheal catheter within 20 seconds and kept $\mathrm{PCO}_{2}$ stable (chapter 6). EVA was found to be less efficient in a setting simulating a completely open airway. As airway patency increased re-oxygenation was delayed and severe hypercapnia developed.

Based on the optimized prototype for EVA (DE5, chapter 5), a portable, flow-regulated, manually operated, and ergonomically shaped ventilation device was developed: Ventrain $^{\circledR}$ (Dolphys Medical BV, Eindhoven, The Netherlands). 
The results of the bench study as described in chapter 7 show that the degree of expiratory assistance is flow-dependent, with a maximum suction capacity of $12.4 \mathrm{l} \cdot \mathrm{min}^{-1}$ at an oxygen flow of $15 \mathrm{l} \cdot \mathrm{min}^{-1}$. At this flow rate Ventrain ${ }^{\circledast}$ can achieve through a $2 \mathrm{~mm}$ ID transtracheal catheter a minute volume of 7.1 litres. This minute volume would not only be enough for swift re-oxygenation, but it would also prevent hypercarbia in most adults. In a CICO situation use of EVA by Ventrain ${ }^{\circledR}$ would be the most efficient and safest technique currently available to reoxygenate the patient through a narrow-bore transtracheal catheter.
Expiratory Ventilation Assistance (EVA) is introduced as a new ventilation mode for ventilation through narrow-bore catheters in an obstructed airway. The full potential of EVA within modern airway management, including elective routine use, has yet to be explored. The general discussion (chapter 8) focuses on the possible role of EVA by Ventrain ${ }^{\circledR}$ in emergency ventilation and on potential future applications of EVA as a new ventilation mode for airway surgery, single lung ventilation and lung-protective ventilation strategies. 


\section{Valorisation addendum}

The focus of this thesis was on the management of a 'cannot intubate, cannot oxygenate' (CICO) scenario. This is a clinical situation wherein attempted tracheal intubation has failed and oxygenation cannot be maintained by non-invasive means. If not corrected rapidly hypoxia will inevitably lead to brain damage and death. The incidence of $\mathrm{CICO}$ in general anaesthetic practice is low. The 4th National Audit Project of the Royal College of Anaesthetists and Difficult Airway Society (NAP4) reported a calculated incidence of emergency percutaneous airway of 1 in 50,000 general anaesthetics. However, the incidence is strongly influenced by clinical setting and case-mix, and an incidence as high as $11 \%$ has been reported in the pre-hospital setting.

The clinical impact of the work described in this thesis is three-fold. Firstly, one of our studies revealed a potential hazard of currently recommended practice. Various simple, self-assembled devices made of a three-way stopcock and oxygen tubing have been proposed in standard anesthesia textbook for emergency jet ventilation. The assembling of these devices was also taught on several national and international airway and emergency courses (including ATLS). We tested the proposed devices and noticed that they carried an intrinsic risk as the they didn't control the oxygen flow to the patient. We concluded that the self-assembled devices based on a three-way stopcock, as described in the textbooks, should not be used in a $\mathrm{CICO}$ situation. The results of our study let to a change in the learning objectives of many airway course, are included in updated airway algorithms and are already referred to in some anesthesia textbooks.

The second part of this thesis focused on the introduction of a new ventilation mode called expiratory ventilation assistance (EVA). Flow-controlled EVA is used for ventilation through small-bore cannulas and can be considered a hybrid technique in between intermittent positive pressure ventilation with passive expiration, which requires a wide-bore tube and sealed airway, and jet ventilation through a narrow-bore catheter, which requires high injection pressures and an open upper airway. The ability of controlling the expiration and achieving a sufficient respiratory minute volume of 7 litres through a narrow-bore catheter in a blocked airway allows for a new array of clinical applications. The full potential of EVA within modern airway management, including elective routine use for airway surgery, single lung ventilation and lung-protective ventilation, has yet to be explored.

Thirdly, probably the most evident impact on current clinical practice of this thesis is the development of an emergency ventilation device using EVA. Based on the optimized prototype for EVA (DE5, chapter 5), a portable, flow-regulated, manually operated, and ergonomically shaped ventilation device was developed by Dolphys Medical. The Ven$\operatorname{train}^{\circledast}$ (Dolphys Medical BV, Eindhoven, The Netherlands) is available in Europe, Australia and the United States. Several 
case reports of adults and children that have been rescued by emergency oxygenation using the Ventrain ${ }^{\circledR}$ illustrate the importance of the work described in this thesis.

In addition to the risk reduction for the patient and of course the commercial benefits this thesis has an important impli- cation for all physicians responsible for securing the airway and maintaining oxygenation. For us it is a relief to know that when you get into serious difficulties insertion of only a $2 \mathrm{~mm}$ airway catheter will be sufficient to get control over the situation again. 


\section{Curriculum vitae}

Ankie Hamaekers was born in Geleen, The Netherlands on August 8th 1975. In 1993 she graduated at Stella Maris College in Meerssen and enrolled into the study of Medicine at Maastricht University. Before obtaining her master degree she did a research elective of 11 months at the research group of professor Marc Hanson at the University College London. In 2000 she finished medical school and graduated with honors. She worked for a period of almost one year as a physician at the department of cardiothoracic surgery before beginning her residence training in anaesthesia at the Maastricht University Hospital. After finishing her training in 2006 she became a staff member at the same department.

Her interest in airway management was evoked by a dramatic case of an emergency tracheostomy during her residency. Under the guidance of Pieter Borg she entered into the "world of airway management" and developed her clinical and teaching skills. She joined the project "Ventilation through a straw" initiated by Thomas Goetz and Dietmar Enk and together with Pieter Borg they conducted the research that led to this thesis.

In the last five years Ankie was course director, instructor and guest faculty for numerous national and international airway management courses and served on a few medical advisory and executive boards. Furthermore, she wrote several book chapters regarding different topics in airway management.

Although her research has focused on a specific technical part of airway management, she has always been interested in the non-technical aspects of anaesthesia. Whether it was teaching CRM to clinicians, talking about the second victim effect or discussing patient-centered care, these topics gave her energy and drive. Her future focus will, therefore, be more on the "soft" aspects of anaesthesia and empowering the heart in anaesthestic and medical care. 


\section{Publications}

Hamaekers AE, van der Beek T, Theunissen M, Enk D. Rescue ventilation through a small-bore transtracheal cannula in severe hypoxic pigs using expiratory ventilation assistance. Anesth Analg. 2015 Apr;120(4):890-4

Baker PA, Fernandez TM, Hamaekers AE, Thompson JM. Parker Flex-Tip or standard tracheal tube for percutaneous emergency airway access? Acta Anaesthesiol Scand. 2013 Feb;57(2):165-70

Borg PA, Hamaekers AE, Lacko M, Jansen J, Enk D. Ventrain $^{\circledR}$ for ventilation of the lungs. Br J Anaesth. 2012 Nov;109(5):833-4

Hamaekers AE, Borg PA, Enk D. Ventrain: an ejector ventilator for emergency use. Br J Anaesth. 2012 Jun;108(6):1017-21

Mendels EJ, Brunings JW, Hamaekers AE, Stokroos RJ, Kremer B, Baijens LW. Adverse laryngeal effects following short-term general anesthesia: a systematic review. Arch Otolaryngol Head Neck Surg. 2012 Mar;138(3):257-64

Hamaekers AE, Henderson JJ. Equipment and strategies for emergency tracheal access in the adult patient. Anaesthesia. 2011 Dec;66 Suppl 2:65-80

Wilbers NE, Hamaekers AE, Jansen J, Wijering SC, Thomas 0 , Wilbers-van Rens R, van Zundert AA. Prehospital airway management: A prospective case study. Acta Anaesthesiol Belg. 2011;62(1):23-31
Hamaekers AE, Borg PA, Götz T, Enk D. Ventilation through a small-bore catheter: optimizing expiratory ventilation assistance. Br J Anaesth. 2011 Mar;106(3):403-9

Hamaekers AE, Götz T, Borg PA, Enk D. Achieving an adequate minute volume through a $2 \mathrm{~mm}$ transtracheal catheter in simulated upper airway obstruction using a modified industrial ejector. Br J Anaesth. 2010 Mar;104(3):382-6

Hamaekers AE, Borg PA, Enk D. A bench study of ventilation via two self-assembled jet devices and the Oxygen Flow Modulator in simulated upper airway obstruction. Anaesthesia. 2009 Dec;64(12):1353-8

Enk D, Hamaekers AE, Borg PA. Pressure and flow(meter). Anesthesiology. 2009 May;110(5):1187

Hamaekers A, Borg P, Enk D. The importance of flow and pressure release in emergency jet ventilation devices. Paediatr Anaesth. 2009 May;19(5):452-7

Hamaekers A, Borg P, Enk D. Limitations of self-made jet devices. Paediatr Anaesth. 2008 Oct;18(10):984

Hamaekers AE, van Mook WN, Offermans JP, Marcus MA. Successful use of recombinant factor VIla for treatment of severe postpartum hemorrhage. Am J Crit Care. 2006 Jul;15(4):399-401 


\title{
Abstracts \& book chapters
}

\author{
Abstracts \\ Optimizing ventilation through a cuffed narrow bore catheter \\ (CNBC) using expiratory ventilation assistance (EVA): an animal \\ study \\ T van der Beek, A Hamaekers, D Enk - European Journal of \\ Anaesthesiology (EJA), 2013 19AP2-6 \\ Efficiency and safety of applying expiratory ventilation assis- \\ tance (EVA) through a jet ventilation catheter with a cuffed in \\ an open or sealed airway: an animal study \\ T. v/d Beek, A. Hamaekers, D. Enk - presented at DAS, Cardiff \\ 2012 \\ Adequate minute volume ventilation through a $100 \mathrm{~cm}$ long, \\ $3 \mathrm{~mm}$ inner diameter airway exchange catheter by expiratory \\ ventilation assistance (EVA) \\ EM Dias, A Hamaekers, PAJ Borg, D Enk - European Journal of \\ Anaesthesiology (EJA), 2012 19AP5-6 \\ The Ventrain: a Small Lumen Emergency Ventilation Device \\ AEW Hamaekers, PAJ Borg, D Enk - presented at DAS, Chelten- \\ ham, 2010 \\ Fast Recovery from Severe Hypoxia through a $2 \mathrm{~mm}$ Transtra- \\ cheal Catheter in Pigs with a Completely Obstructed Upper \\ Airway \\ A. Hamaekers, M. Theunissen, J. Jansen, W. Honig, D. Enk \\ - presented at NVA-dagen, Maastricht 2010 and ESA, Helsinki \\ 2010, Eur J Anaesthesiol, 2010 S 19AP1-9 \\ Optimizing Expiratory Ventilation Assistance (EVA) \\ A. Hamaekers, T. Götz, P. Borg, D. Enk - presented at DAS, \\ Perth, 2009 \\ Expiratory Ventilation Assistance (EVA) to Achieve an Adequate \\ Minute Volume through a "Straw" in Upper Airway Obstruction \\ A Hamaekers, T Götz, P Borg, D Enk - presented at SAM, Las \\ Vegas, 2009 \\ Awarded top 2 best oral presentation \\ Achievement of an Adequate Minute Volume through a $2 \mathrm{~mm}$ \\ Transtracheal Catheter by Expiratory Ventilation Assistance \\ (EVA) in a Simulated Upper Airway Obstruction \\ Ankie Hamaekers, Thomas Götz, Pieter Borg, Dietmar Enk - \\ presented at ESA, Milan, 2009 Eur J Anaesthesiol, 2009 S 19AP \\ Using a Modified Ejector Pump to Achieve Adequate Ventilation \\ through a $2 \mathrm{~mm}$ Transtracheal Catheter in a Simulated Upper \\ Airway Obstruction \\ A Hamaekers, T Götz, P Borg, D Enk - presented at NVA-dagen, \\ Maastricht 2009 \\ Pre-Hospitaal Luchtwegmanagement in Nederland \\ N. Wilbers, AEW. Hamaekers, J. Jansen, MAE. Marcus, AAJ. van \\ Zundert - presented at NVA-dagen, Maastricht, 2009 \\ A Clinical Evaluation of Performance of the Airway Scope in the \\ Caucasian Population \\ A Hamaekers, J Jansen - presented at DAS, Liverpool, 2008 \\ Using a Small Modified Ejector to Achieve Adequate Ventilation \\ through a $2 \mathrm{~mm}$ Transtracheal Catheter in a Simulated Upper \\ Airway Obstruction \\ A Hamaekers, T Götz, P Borg, D Enk - presented at DAS, Liver- \\ pool, 2008 \\ Awarded best oral presentation
}




\section{Book chapters}

Adequate Ventilation through a $2 \mathrm{Mm}$ Transtracheal Catheter in a Simulated Upper Airway Obstruction

A Hamaekers, T Götz, P Borg, D Enk - Presented at ASA, Orlando 2008, Anesthesiology, 2008

The efficacy of flow and pressure release in self-assembled emergency jet devices

A Hamaekers, P Borg, D Enk - Presented at SAM, Boston 2008, Journal of Clinical Anesthesia, 2009

Use of the Airway Scope in difficult-to-manage airways: case series of 16 patients

Ankie Hamaekers, Jochen Jansen; Society of Airway Management meeting, Boston, 2008

Airway scope videolaryngoscope: a novel technique in difficult airway management

V.M. Smit-Fun, A.E.W. Hamaekers, J. Klein Ovink, B.E. Timmerman; presented at NVA-dagen, Maastricht 2008

The Pentax-AWS videolaryngoscope - a clinical evaluation A Hamaekers, A van Zundert; presented at NVA-dagen, Maastricht 2008

\section{"Needle cricothyroidotomy."}

A. Hamaekers. In Master techniques in upper and lower airway management; edited by William Rosenblatt and Wanda Popescu, Wolters Kluwer 2015; ISBN-13: 978-1451193046

"Zo wordt een wakkere intubatie een fluitje van een cent". A. Hamaekers and S. Kessner. In probleemgeorienteerd denken voor gebruikers van lokaal anaesthestica; edited by Ivo Panhuizen, Tijdstroom 2015; ISBN 978-9058982643

"Tracheal intubation: rigid indirect laryngoscopy".

A. Hamaekers and P. Borg. In Core topics in Airway Manage-

University Press, 2011; ISBN 978-0-521-11188-1 
